\title{
Different approaches of combating bacterial canker in tomato: in pursuit of resistance
}




\section{Propositions}

1. Only one QTL is necessary for higher tolerance towards Clavibacter michiganensis subsp. michiganensis.

(this thesis)

2. There is no Clavibacter michiganensis subsp. michiganensis free tomato. (this thesis)

3. Cultured meat is not a sustainable solution to reduce land use.

4. The fourth industrial revolution will widen social inequalities.

5. Cakes resolve conflicts.

6. Science needs funny people.

Propositions belonging to the thesis entitled

“Different approaches of combating bacterial canker in tomato: in pursuit of resistance"

Mas Muniroh binti Mohd Nadzir

Wageningen, 14 December 2018 


\section{Different approaches of combating bacterial canker in tomato: \\ in pursuit of resistance}

Mas Muniroh binti Mohd Nadzir 


\section{Thesis committee}

\section{Promotor}

Prof. Dr R.G.F. Visser

Professor of Plant Breeding

Wageningen University \& Research

\section{Co-promotors}

Dr A.W. van Heusden

Scientist, Plant Breeding

Wageningen University \& Research

Dr J.M. van der Wolf

Scientist, Biointeractions and Plant Health

Wageningen University \& Research

\section{Other members}

Prof. Dr F.P.M. Govers, Wageningen University \& Research

Prof. Dr M. Koornneef, Wageningen University \& Research

Dr I. Rieu, Radboud University Nijmegen

Dr E. Heuvelink, Wageningen University \& Research

This research was conducted under the auspices of the Graduate School Experimental Plant Sciences. 


\section{Different approaches of combating bacterial canker in tomato: in pursuit of resistance}

Mas Muniroh binti Mohd Nadzir

\section{Thesis}

submitted in fulfilment of the requirements for the degree of doctor at Wageningen University

by the authority of the Rector Magnificus,

Prof. Dr A.P.J. Mol,

in the presence of the

Thesis Committee appointed by the Academic Board

to be defended in public

on Friday 14 December 2018

at 11 a.m. in the Aula. 
Mas Muniroh binti Mohd Nadzir

Different approaches of combating bacterial canker in tomato: in pursuit of resistance, 146 pages.

PhD thesis, Wageningen University, Wageningen, the Netherlands (2018)

With references, with summary in English

ISBN: 978-94-6343-510-9

DOI: $10.18174 / 459297$ 


\section{Contents}

$\begin{array}{lll}\text { Chapter } 1 & \text { General introduction } & \mathbf{7}\end{array}$

Chapter 2 Development of an in vitro protocol to screen Clavibacter 27

michiganensis subsp. michiganensis pathogenicity in different Solanum species

Chapter 3 Fine mapping of a Clavibacter michiganensis subsp. michiganensis ( $\mathrm{Cmm}$ ) tolerance gene originating from Solanum arcanum LA2157

Chapter 4 Exploiting the potential use of susceptibility genes against Clavibacter michiganensis subsp. michiganensis symptoms in tomato

Chapter 5 Alternative ways to reduce Clavibacter michiganensis subsp. michiganensis disease symptoms in tomato

Chapter 6 General discussion

References

Summary

Acknowledgements

About the author

Education statement 



\section{CHAPTER}

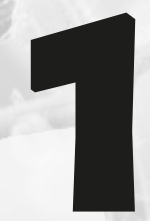

General introduction 


\section{The world of $\mathrm{Cmm}$ and tomato-possibilities to combat the pathogen}

\section{The unwanted guest-Clavibacter michiganensis subsp. michiganensis}

The Clavibacter michiganensis $(\mathrm{Cm})$ species belonging to the Clavibacter genus is a Gram-positive actinomycete. The Clavibacter genus was initially classified as Corynebacterium due to its morphological features (non-spore forming, irregular Gram-positive rods). Later on, it was discovered that there is no close relationship with Corynebacterium and the genus was classified to a different one (Eichenlaub et al. 2006). Currently, there are seven pathogenic Cm subspecies divided according to their host plant and two additional seed-associated and non-pathogenic subspecies. The pathogenic subspecies are Clavibacter michiganensis subsp. michiganensis which infects tomato (Solanum lycopersicum) (Strider 1969; Davis et al. 1984) and recently found to infect naranjilla (Solanum quitoense and Solanum pectinatum) (Bolanoscarriel et al. 2017), Clavibacter michiganensis subsp. sepedonicus which causes ring rot in potato (Solanum tuberosum) (Manzer and Genereux 1981), Clavibacter michiganensis subsp. insidiosus which causes wilting and stunting in alfalfa (Medicago sativa) (McCulloch 1925), Clavibacter michiganensis subsp. nebraskensis which promotes wilt and blight of maize (Zea mays) (Schuster et al. 1975), Clavibacter michiganensis subsp. tessellarius that results in leaf freckles and leaf spots in wheat (Triticum aestivum) (Carlson and Vidaver 1982), Clavibacter michiganensis subsp. phaseoli causing leaf yellowing in bean (Phaseolus vulgaris L.) (González and Trapiello 2014) and finally Clavibacter michiganensis subsp. capsici which causes bacterial canker in sweet pepper (Capsicum annum) and bell pepper (Capsicum frutescens) (Oh et al. 2016). The non-pathogenic subspecies are Clavibacter michiganensis subsp. californiensis and Clavibacter michiganensis subsp. chilensis which are associated with tomato and pepper (Yasuhara-Bell and Alvarez 2014). Recently, reclassification of some of the subspecies into species has been proposed by genomic data and a multi-locus phylogenetic analysis. The presently classified as Clavibacter michiganensis subsp. capsici, Clavibacter michiganensis subsp. nebraskensis, Clavibacter michiganensis subsp. insidiosus, Clavibacter michiganensis subsp. sepedonicus and Clavibacter michiganensis subsp. tessellarius should be reclassified as Clavibacter capsici sp. nov., comb. nov., Clavibacter nebraskensis comb. nov., Clavibacter insidiosus comb. nov., Clavibacter sepedonicus comb. nov., and Clavibacter tessellarius sp. nov., comb. nov., respectively, (Tambong 2017; Li et al. 2018).

The pathogen of our study is Clavibacter michiganensis subsp. michiganensis (Cmm). Clavibacter michiganensis subsp. michiganensis is a mesophilic bacterium with an optimum growth temperature between $25-28^{\circ} \mathrm{C}, \mathrm{Cmm}$ does not grow around $35^{\circ} \mathrm{C}$ and dies at a temperature of $50^{\circ} \mathrm{C}$ and higher. It grows fast and forms visible colonies three to seven days after plating on a selective agar medium. The optimum $\mathrm{pH}$ is 
around 7 to 8 , but $\mathrm{Cmm}$ still can grow as low as pH 5 (Strider 1969). The ability to grow at low $\mathrm{pH}$ is essential for $\mathrm{Cmm}$ because this allows it to grow in acidic xylem vessels (Eichenlaub et al. 2006).

\section{Mode of entry and disease symptoms}

Clavibacter michiganensis subsp. michiganensis is a pathogen which can lead to systemic or local infections. The pathogen can enter host plants through openings such as roots, shoots, stomata or hydathodes. The development of disease symptoms depends on the mode of entry, bacterial densities, environmental conditions, plant age at the time of infection, $\mathrm{Cmm}$ virulence and tomato genotypes (Sharabani et al. 2013b; Sen et al. 2013; Sharabani et al. 2014; Thapa et al. 2017).

Primary sources of infection are contaminated seeds, diseased seedlings, and infected debris (León et al. 2011; Lamichhane et al. 2011; Tancos et al. 2013). On the soil surface, $\mathrm{Cmm}$ can survive up to two years, but shorter periods when they are buried in the soil (Chang et al. 1992a; Gleason et al. 1993). The secondary spread from infected to uninfected plants occurs through agricultural practices such as pruning and watering. Secondary spread arises when $\mathrm{Cmm}$ enters non-infected plants through wounds or natural opening such as trichomes, stomas and hydathodes (Sharabani et al. 2013a; Frenkel et al. 2015; Sen et al. 2015; Chalupowicz et al. 2016) (Figure 1).

Systemic infection of $\mathrm{Cmm}$ results in stem canker and leaf wilting. Even though the pathogen is known as bacterial canker, the most apparent disease symptom is wilting. After entering the plant, $\mathrm{Cmm}$ has a biotrophic lifestyle (Eichenlaub and Gartemann 2011). It spreads in the plants through the vascular vessels resulting in unilateral wilting of leaves and leaflets, necrosis and cankers on stems, petioles and fruit lesions (Eichenlaub et al. 2006; de León et al. 2009). Localized infections in aerial parts of the plants resulting in marginal necrosis of leaflets (Werner et al. 2002), bird's-eye spots on fruits (Medina-Mora et al. 2001; Tancos et al. 2013) and white, small blister-like spots on leaves or stems (León et al. 2011; Chalupowicz et al. 2016). The spreading of $\mathrm{Cmm}$ from plant to plant is low if the bacterial density of the primary infection is low. Clavibacter michiganensis subsp. michiganensis contaminated seeds lead to infected seedlings, but the transmission rate is very variable (0.25 to 85\%) (Strider 1969).

However, even a transmission rate as low as $0.01 \%$ can initiate a severe outbreak under favourable conditions (Chang 1991). Infection by $\mathrm{Cmm}$ does not always lead to plants with wilting symptoms, but these infected plants without symptoms still can be the starting point for secondary infections. Secondary infections can result in serious infections from as few as ten bacteria (Chang et al. 1992a; Frenkel et al. 2015). 


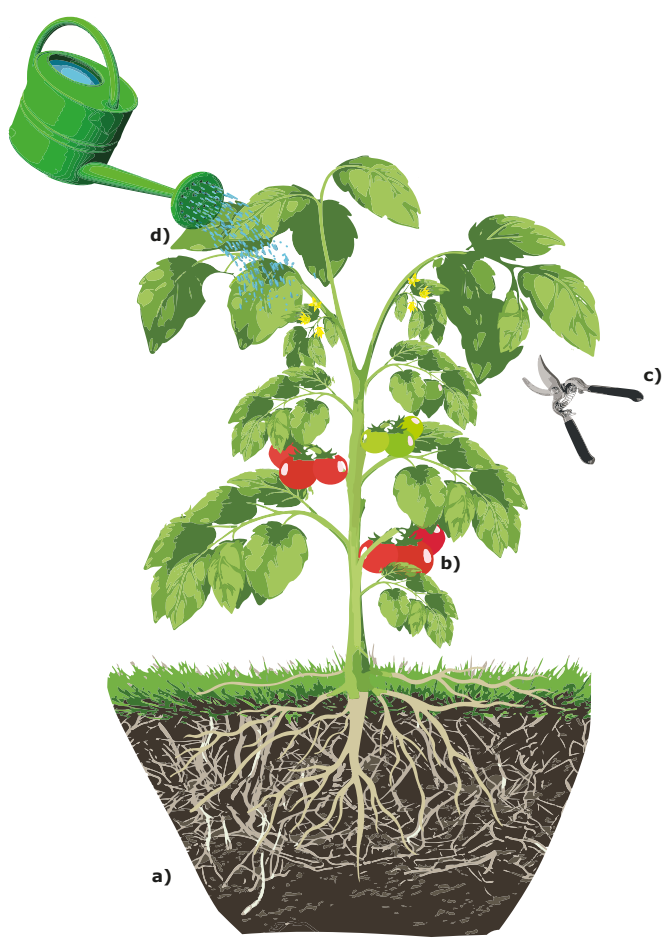

Figure 1 | The mode of entry of $\mathrm{Cmm}$. The primary inoculum can be contaminated seeds, seedlings or contaminated debris. a) $\mathrm{Cmm}$ can survive up to two years in remaining debris. It can enter through the roots of growing tomato plantlets. b) Latent infected plants may produce contaminated fruits and seeds. The infected seeds will subsequently be the vector and can be the reason for long distance dispersal. Cultural practices such as pruning (c) and watering (d) etc cause secondary spread.

\section{Quarantine status and worldwide distribution}

The severe consequences of $\mathrm{Cmm}$ infection and its easy spreading make it a quarantine organism listed under the EPPO A2. It can be present in Europe including the Mediterranean region, but $\mathrm{Cmm}$ is not commonly dispersed (Grund et al. 1990; Eichenlaub et al. 2006; Eichenlaub and Gartemann 2011; EPPO 2016). The pathogen is found in $16 \mathrm{EU}$ Member States. Except for Greece, the $\mathrm{Cmm}$ population in the other EU Member States has a restricted distribution and has low prevalence (EFSA 2014). Due to its quarantine status in Europe, companies need to sell $\mathrm{Cmm}$-free certified seeds and plant lots based on the Good Seed and Plant Practices (GSPP) (Munkvold 2009; GSPP Standard 2017). Clavibacter michiganensis subsp. michiganensis was first described and presumably originated from North America. The trade of contaminated seeds around the world is the main reason that the pathogen is now found in many continents (León et al. 2011) (Figure 2). 


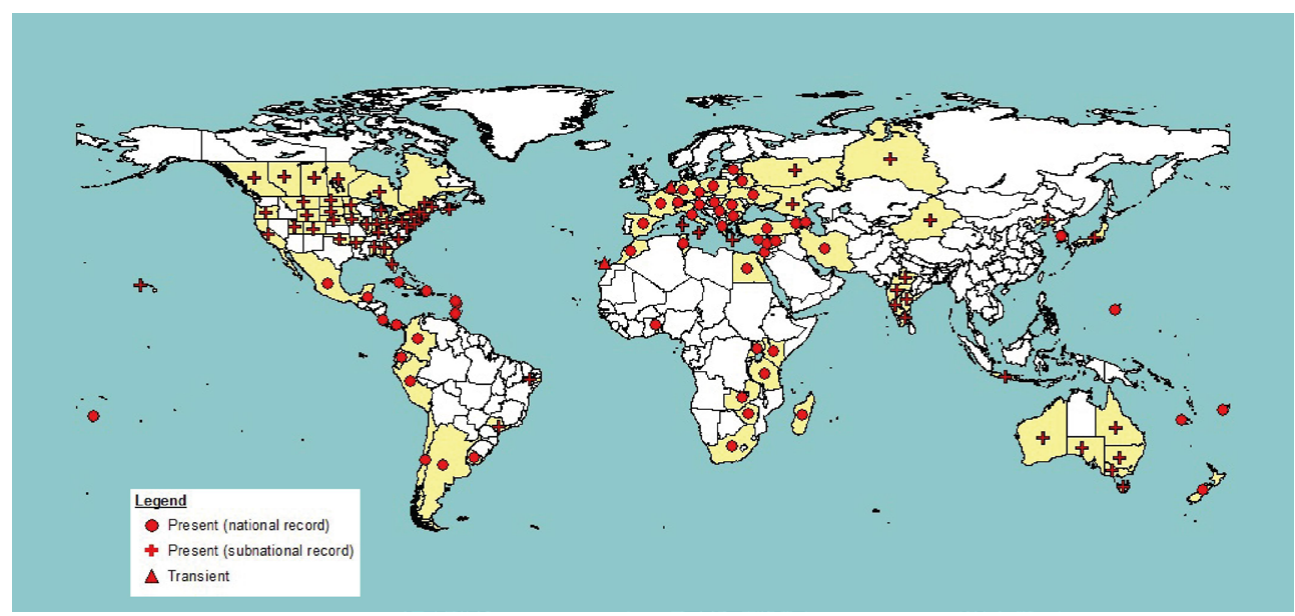

Figure 2 | Distribution of Cmm worldwide. Image extracted from EPPO (2017) PQR - EPPO database on quarantine pests http://www.eppo.int and used with permission.

\section{The interaction between the unwilling host (tomato) and the unwanted guest $(\mathrm{Cmm})$}

\section{Clavibacter michiganensis subsp. michiganensis virulence}

The first hypothesis why $\mathrm{Cmm}$ is virulent in tomato was based on the changes in the production of exopolysaccharides (EPS) (Rai and Strobel 1969). However, mutant $\mathrm{Cmm}$ strains with impaired EPS production were still virulent (Bermpohl et al. 1996). Molecular investigations (Eichenlaub et al. 1990; Meletzus and Eichenlaub 1991; Meletzus et al. 1993) showed that the virulent strain Cmm382 (also known as NCPPB382) has two circular plasmids, pCM1 (27 Kb) and pCM2 (70 Kb). Removing the plasmids resulted in the strain $\mathrm{Cmm100,}$ a plasmid-free endophytic strain (Meletzus et al. 1993). Both pCM1 and pCM2 carry virulence genes and strains with just a single plasmid resulted in less virulence and wilting. The pCM1 and pCM2 plasmids encode the pathogenicity genes celA or pat-1, respectively. celA encodes an endo$\beta-1,4$-glucanase, and pat-1 encodes a serine protease. Later on, it was discovered that a region in the $\mathrm{Cmm}$ chromosome together with the plasmids are responsible for disease development. The endophytic strain $\mathrm{Cmm} 100$ showed that the $\mathrm{Cmm}$ chromosome encodes genes involved in host recognition, infection, suppression and colonization of the host (Dreier et al. 1997; Jahr et al. 2000; Eichenlaub and Gartemann 2011). Both the chromosome and plasmid-encoded genes are essential for proliferation, evasion and virulence. 
Cmm382 contains the pathogenicity island (PAI), called the chp/tomA region. This region has the lowest GC content (65.5\%) in the genome. Clavibacter michiganensis subsp. michiganensis requires one of the virulence plasmids and the chp/tomA region to induce wilting (Chalupowicz et al. 2010). The GFP-tagged Cmm100 (lacking both virulence plasmids) and $\mathrm{Cmm} 27$ (lacking the chp/tomA region) remained at the vicinity of the inoculation point (Chalupowicz et al. 2012) and are unable to induce wilting. These studies show that $\mathrm{Cmm}$ needs at least one of these plasmids' virulence factors and the chp/tomA region to effectively suppress the basal defence, to colonize the host and to form cellular aggregates (Chalupowicz et al. 2012; Savidor et al. 2012; Chalupowicz et al. 2016).

The first group of virulence factors encodes serine proteases. Many gene families encode serine proteases in $\mathrm{Cmm} 382$ (Gartemann et al. 2008). The first group consists of ten different serine proteases and is named the Chp-family. Seven of these are clustered in the chp/tomA region and the other three are found on the $\mathrm{pCM} 2$ plasmid (pat-1, phpA and $p h p B$ ). In this family, chpC in the chp/tomA region is required for colonization (Stork et al. 2008). The second group of virulence factors encode chymotrypsin-related serine proteases and is named the Ppa-family (Gartemann et al. 2008). This group consists of eleven genes of which ten are located on the chromosome and one on the pCM1 plasmid (ppa)). Six of the ten chromosomal genes ( $p p a A$ to $p p a E$ ) are found in the PAI region and the four other genes ( $p p a F$ to $p p a l$ ) are located in two different chromosomal loci. The third gene family with three members encodes subtilase proteases. All of the members are located on the chromosome with $s b t A$ in the chp region of the PAI, while $s b t B$ and $s b t C$ are located on other parts of the chromosome. The PAl-encoded pectate lyases (PelA1 and PelA2) which are enzymes catalyzing the cleavage of pectin, are an important component of plant primary cell walls (Savidor et al. 2012). Genes on the plasmids are working together with genes on the chromosome. Without the $\operatorname{chp/tomA~region~there~is~a~}$ significantly reduced expression of celA and pat- 1 and also the expression of serine proteases in the chp/tomA region ( $c h p C$ and ppaA), decreased in the absence of the virulence plasmids (Chalupowicz et al. 2010). Other virulence sources were found in a recent transcriptomic analysis. Two transcription factors (Vatr1 and Vatr2) were involved in pathogenicity of $\mathrm{Cmm}$ (Savidor et al. 2014).

It is interesting to note that a different mode of infection (systemic or local) uses different virulence factors to induce disease symptoms (Chalupowicz et al. 2016). Virulence plasmids, which are essential to induce wilting, are not required for blister formation which appears after local infection. Differential gene expression studies showed that genes encoding serine proteases (chpC and $s b t A)$, cell wall-degrading enzymes ( $p g a A$ and end $X M$ ) a transcriptional regulator (vatr2), a putative perforin (perF) and a putative sortase (srtA) are expressed early (8-16 hpi) during blister 
formation. On the other hand, during wilting development, these genes are expressed at a later period (24-72 hpi) or are lowly expressed (Chalupowicz et al. 2016).

The molecular work of $\mathrm{Cmm}$ has been focusing on $\mathrm{Cmm}$ strain382 and mutants derived from it. We cannot rule out the possibility that different $\mathrm{Cmm}$ strains use different virulence factors. For example, Clavibacter michiganensis subsp. michiganensis strains from California do express full virulence in the absence of the pCM2 plasmid for virulence (Thapa et al. 2017). So far, many studies have been done to understand $\mathrm{Cmm}$ pathogenicity, but knowledge is still limited for $\mathrm{Cmm}$ and its tomato interaction. In general, more studies have been done to understand the $\mathrm{Cmm}$ virulence than for understanding the defence mechanism in the plant.

\section{$\mathrm{Cmm}$ - tomato interaction model}

A good understanding of the $\mathrm{Cmm}$ virulence is of utmost importance to understand the interaction with tomato. There are two levels of defence in the plant immune system (Jones and Dangl 2006). The first level of defence (basal defence), are transmembrane pattern recognition receptors (PRRs) which respond to microbialor pathogen-associated molecular patterns (MAMPS or PAMPs) resulting in PAMPtriggered immunity (PTI) that can stop further colonization. The responses to the first level of defence do not differentiate between pathogenic and endophytic microbes. Induction of pathogenesis-related (PR) proteins can occur to both (Savidor et al. 2012). The second level of defence happens inside the cell. Recognition of an effector (virulence factor) is either direct through NB-LRR (nucleotide-binding and leucinerich-repeat) or indirect resulting in effector-triggered immunity (ETI). Recognition using the NB-LRR protein products is encoded by resistance $(R)$ genes. Gramnegative type III secretion system (T3SS) secrete effectors to surpass both levels of defence (Desveaux et al. 2006; Jones and Dangl 2006). Clavibacter michiganensis subsp. michiganensis possesses a type II secretion system (T2SS), and so far, no Cmm effectors targeting specific $R$-genes are known. As for that, we hypothesize in the $\mathrm{Cmm}$-tomato interaction, that $\mathrm{Cmm}$ only must surpass the first layer of defence.

Clavibacter michiganensis subsp. michiganensis senses the plant environment upon infection and transmits a signal for activation of a virulence pathway. Induction of the virulence pathway leads to transcriptional activation of vatr 1 and vatr2 and secretion of several hydrolytic enzymes, including serine proteases of the Ppa, Sbt (Gartemann et al. 2008), and Pat-1 families (Burger et al. 2005), the XysA (Borneman and Akin 1990), CelA (Jahr et al. 2000), and NagA glycosyl hydrolases (Henrissat and Callebaut 1995), and other cell wall-degrading enzymes (Figure 3). The host perceives the invading bacterium, mounts a basal defence response and induces lipoxygenase-1 (LOX1) which may contribute to jasmonic acid production and 
antimicrobial activity (Gardner 1991). Further pathogenesis-related (PR) proteins which possess antimicrobial activity, contact toxicity, and are involved in defence signalling (van Loon et al. 2006), EDS1 (enhanced disease susceptibility 1) which is vital for nonhost resistance and $R$ gene-mediated response, and other defencerelated proteins are released. Consequently, $\mathrm{Cmm}$ has to overcome the host defence barrier, hydrolyzes and degrades the host tissue, and upregulates tomato ACCoxidase to promote ethylene biosynthesis. The host ethylene production is not the cause of its susceptibility, but a major signal that regulates disease progression. There was a significant delay with wilt symptoms when the ethylene insensitive Never ripe (Nr) tomato mutant and tomato mutant with impairment of ethylene production, the $A C D$ (bacterial ACC deaminase) mutant, were challenged with $\mathrm{Cmm}$ (Balaji et al. 2008). During infection, tomato ethylene-synthesizing enzyme ACC-oxidase (ACO) was induced by wild type $\mathrm{Cmm} 382$ but not by the $\mathrm{Cmm} 100$ strain without plasmids thus showing $\mathrm{Cmm}$-triggered tomato synthesis of ethylene as an important factor in disease symptom development (Savidor et al. 2012). The role of ACO in ethylene production in the host plant is important since it induces wilting, but it does not defend against the presence of $\mathrm{Cmm}$. Cmm382 actively induces ACO in the host, without the plasmids $(\mathrm{Cmm} 100)$ the induction is no longer obtained. The lack of wilt symptoms in $\mathrm{Cmm} 100$ infected plants might be due to the lack of ethylene synthesis. Strikingly, there is no difference between the regulation of the basal defence responses when challenged with $\mathrm{Cmm} 382$ or $\mathrm{Cmm} 100$ (Savidor et al. 2012). 


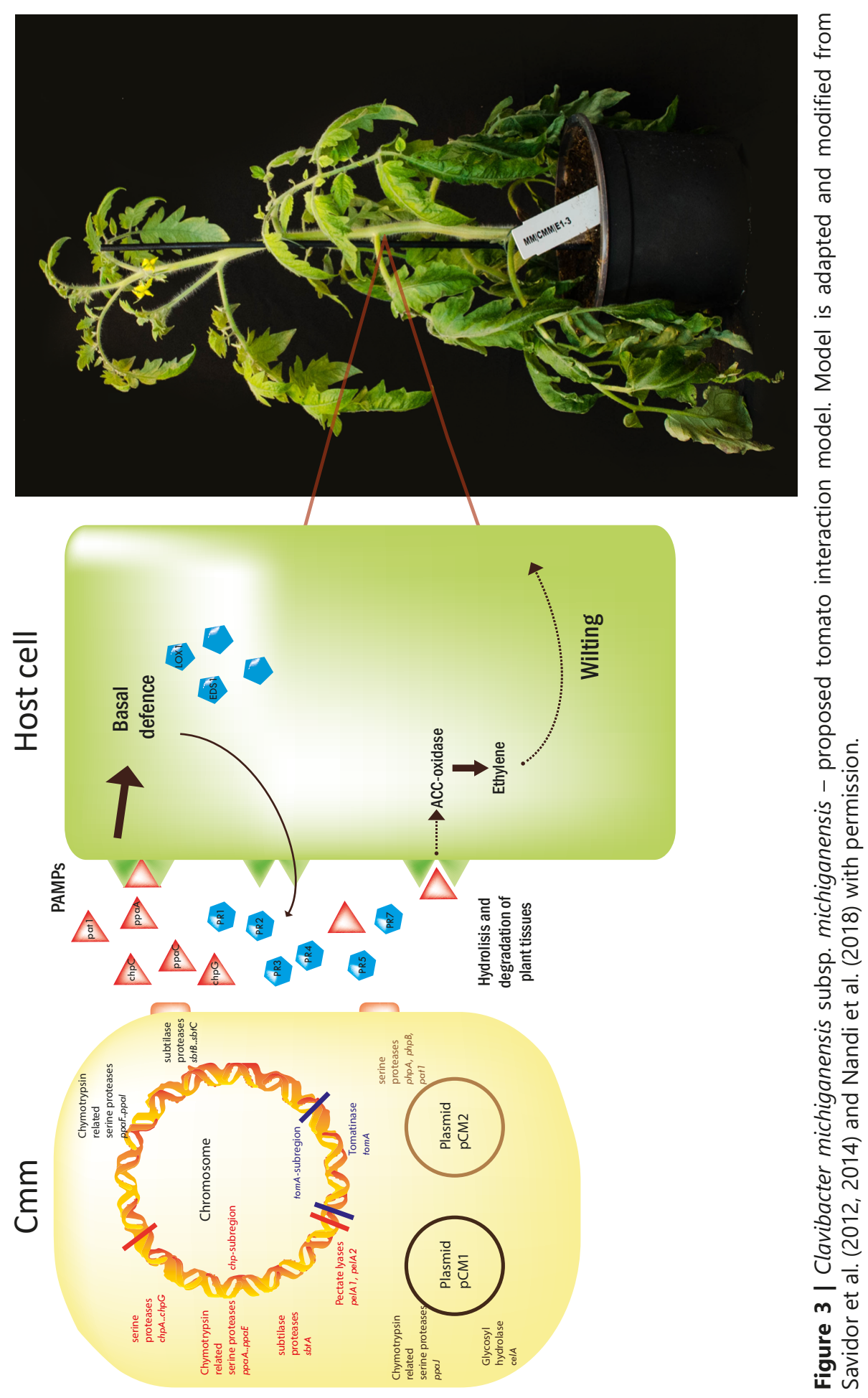




\section{Source of tomato tolerance to $\mathrm{Cmm}$}

Savidor et al. (2012) showed which virulence factors are secreted by $\mathrm{Cmm}$ and how the gene products cause wilting after systemic infection. However, the study does not address the potential genes secreted by the host as defence mechanism. There are no $R$-genes against $\mathrm{Cmm}$ known to date and all cultivated tomatoes are susceptible (Balaji et al. 2008; Stüwe and Tiedemann 2013). Resistant sources have not been found in wild relatives or cultivated tomatoes, only tolerant sources. The resistance mechanism is the host's ability to inhibit pathogen multiplication, while the tolerance mechanism is the ability of the host to reduce the effect of infection despite the level of pathogen multiplication (Pagan and Garcia-Arenal 2018). Sen et al. (2013) have (re)screened sources of $\mathrm{Cmm}$ tolerance in wild relatives of tomato. These include S. pimpinellifolium GI.1554, S. parviflorum LA735 and S. parviflorum LA2072. Other tolerant genotypes are S. arcanum LA2157, S. arcanum PI127829, S. arcanum LA385, S. habrochaites LA407 and S. lycopersicum cv. IRAT L3. The tolerance mechanism(s) from these wild species is unknown. Other studies looking at quantitative trait loci (QTL) between the wild species and cultivated tomatoes showed that the tolerance is complex, additive and may involve multiple genes (van Heusden et al. 1999; Kabelka et al. 2002).

Differential gene expression of several wild tomato genotypes and cultivated tomato was studied (Lara-Ávila et al. 2011). The study included the susceptible cultivated tomato $S$. lycopersicum cv. Moneymaker and other wild relatives such as $S$. arcanum LA2157 (previously known as S. peruvianum LA2157), S. arcanum LA2172 (previously known as S. peruvianum LA2172), and S. habrochaites LA2128. The genes with contrasting regulations in the cultivated tomato compared to the wild relatives include genes involved in the ubiquitin-mediated protein degradation pathway and secretory peroxidase. The group of Lara-Ávila recently silenced (virus-induced gene silencing) the SUMOE2 conjugating enzyme (SCEI) which was upregulated in S. arcanum LA2172 after infection with $\mathrm{Cmm}$. It encodes an enzyme involved in protein modification through sumoylation, which is a post-translational modification that covalently conjugates the small ubiquitin-like modifier (SUMO) protein to lysines on target proteins. This gene may play a part in the tolerance against $\mathrm{Cmm}$, as silenced S. arcanum LA2172 plants are more susceptible to the pathogen (EsparzaAraiza et al. 2015). This finding highlights a potential gene that could play a role in the tolerance against $\mathrm{Cmm}$. However, S. arcanum LA2172 was susceptible in our hands to Cmm (Sandbrink et al. 1995). It can be suggested from all findings that there are no real major genes in cultivated or wild species known to give high levels of tolerance against $\mathrm{Cmm}$. Thus, what alternatives can be used to reduce symptom development by $\mathrm{Cmm}$ ? 


\section{How to combat the unwanted guest?}

\section{Cmm prevention}

Up to now, managing bacterial canker is based on prevention and control. This includes the use of $\mathrm{Cmm}$-free seed, healthy seedlings, cultivation practices including hygiene, crop rotation, and chemical treatments (Gleason et al. 1993; Hausbeck et al. 2000). Once $\mathrm{Cmm}$ establishes in greenhouse or field, it is difficult to stop the disease even with the use of bactericides (Hausbeck et al. 2000). Other types of prevention by using biocontrol means have been studied but still a long way lies ahead for a successful application in the field (Yogev et al. 2009; Amkraz et al. 2010; Barda et al. 2015). Successful suppressing the disease at the production site is a challenge for growers and producing $\mathrm{Cmm}$-free seeds is a challenge for the breeders. Genetic aspects of tomato resistance/tolerance, cultural practices and biological control should be considered to manage and reduce $\mathrm{Cmm}$ as much as possible (Figure 4).

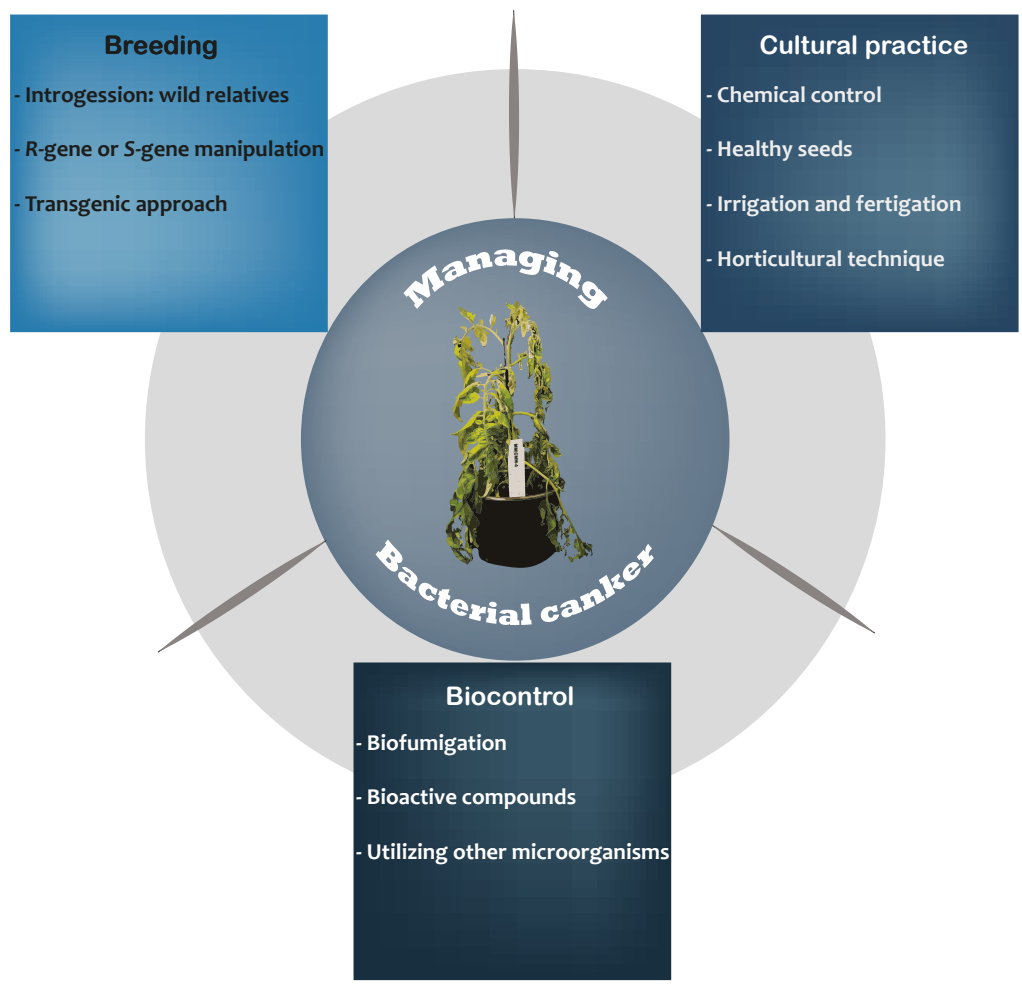

Figure 4 | General scheme of combating $\mathrm{Cmm}$. 


\section{Resistance/ tolerance breeding}

Developing resistant crops is a major objective for plant breeders. Breeders may use conventional breeding techniques or genetic modification as a breeding strategy. The choice of the strategy depends on the sustainability and acceptance of the consumers. With the help of molecular markers, conventional breeding strategy can be expedited. Introgressing a region from exotic genetic libraries into the background of cultivated crops, enhances the resistance of elite lines (Zamir 2001). As mentioned above, several sources of $\mathrm{Cmm}$ tolerance have been found in wild relatives of tomato (Sen et al. 2013). Screening tomato wild relatives for enhancing $\mathrm{Cmm}$ resistance/ tolerance has been going on since the 1930's (Cardon 1934) and incorporating the wild relatives in tomato breeding has been tried (Elenkov 1965). Tolerance was found in lines after crossing with S. pimpinellifolium (Elenkov 1965; Thyr 1968; Jong and Honma 1976; Thyr 1976; Sen et al. 2013), S. habrochaites (Hassan et al. 1968; Vulkova and Sotirova 1993; Sotirova et al. 1994; Francis et al. 2001; Kabelka et al. 2002), and S. arcanum (Lindhout and Purimahua 1987; Vulkova and Sotirova 1993; Sandbrink et al. 1995; van Heusden et al. 1999). Inheritance of tolerance in some of the wild relatives is complex and may be controlled by several genes as seen in the F2 population between the cultivated tomato and S. arcanum LA2157 (van Heusden et al. 1999; Sen et al. 2015). From the screening of wild relatives, the tolerant individuals still contain a considerable amount of bacteria although lacking symptoms (Sen et al. 2013). Despite that, there is a commercial value for the breeders if cultivated tomato containing the tolerance from the wild species can be developed. The background for the absence of wilt symptoms in the wild relatives might be morphological (Francis et al. 2001; Kabelka et al. 2002), or due to the production of metabolites involved in tolerance (Shinde et al. 2017) or based on the immune system (Jones and Dangl 2006). The pitfalls of introgression breeding can be $\mathrm{F} 1$ hybrid sterility, infertility of the progenies, reduced recombination between the chromosomes of the two species, and undesired genes being tightly linked to the trait of interest (linkage drag) (Zamir 2001; Wolters et al. 2015). This is not desirable for breeders, but it can be overcome by doing embryo rescue in the early stage of crossing and backcrossing, and later selecting the lines with small introgression size containing the favourable trait. Our effort of getting nearly isogenic lines with the smallest possible introgression size from the tolerance wild relative S. arcanum LA2157 is further discussed in Chapter 3.

The most common approach of using introgression breeding is to breed for resistance by using $R$-genes. The downside of using this approach is that $R$-genes target specific effectors. Modulation of the effector changes the recognition of an $R$-gene and breaks the resistance (Jones and Dangl 2006). To overcome this problem, stacking several $R$-genes (also called gene pyramiding) can be done. The justification behind this approach is that the pathogen needs to surpass multiple $R$-genes at the 
same time, so it needs to modulate several avirulence (Avr) genes to be able to infect the cultivar carrying the stacked $R$-genes. Gene pyramiding in resistance breeding has been applied in rice (Huang et al. 1997; Hittalmani et al. 2000), bean (Haley et al. 1993; Miklas et al. 1993), wheat (Liu et al. 1999; Zheng et al. 2017) and other crops. So far, no $R$-gene has been found against $\mathrm{Cmm}$ in tomato.

Manipulating susceptibility $(S)$ genes can be an alternative approach for acquiring resistance resp. tolerance. S-genes are innate genes in the crop that are used by the pathogen to expedite the infection and support compatibility (van Schie and Takken 2014). The genes facilitate host recognition and penetration, encode negative regulators of immune signalling, and allow post-penetration to sustain compatibility. Thus, loss-of-function of the genes could lead to broad-spectrum resistance. The best example of a S-gene is the MLO (mildew resistance locus o) (Acevedo-garcia et al. 2014). Inactivation of the MLO gene through loss-of-function or silencing leads to resistance towards powdery mildew (PM) (Pavan et al. 2009). Resistance is due to the inability of fungi to penetrate host cells (Higgs and Peterson 2005). The benefit of using $S$-genes is its broad-spectrum resistance. Silencing or knocking-out an $S$-gene can confer resistance to multiple pathogens (Sun et al. 2016a). However, the downside of manipulating $S$-genes are the possible, pleiotropic effects. $S$-genes not merely exist to facilitate infection processes and disease by the pathogen. Silencing the genes could lead to pleiotropic effects as they have evolutionary conserved functions in plant processes (van Schie and Takken 2014). The magnitude of adverse pleiotropic effects depends on the environmental conditions and plant species (Pavan et al. 2009; Sun et al. 2016b). Thus, using S-gene in breeding is desirable, if silencing or knocking-out the gene does not lead to a pleiotropic effect. The use of $S$-genes is further discussed in Chapter 4.

Apart from $R$-gene and $S$-gene approaches, modification of other genes might enhance tolerance. Transgenic tomato plants made to combat $\mathrm{Cmm}$ have been studied recently. Tomato plants transformed with the bacteriophage CMP1 endolysin gene (lys) exhibited reduced to no disease symptoms in transgenic plants (Wittmann et al. 2015). The gene encodes a peptidase which is highly specific for the hydrolysis of Clavibacter michiganensis species' murein type B2y (Schleifer and Kandler 1972). Overexpression of snakin-2 (SN2) and extensin-like protein (ELP) genes in tomato plants increased tolerance towards Cmm (Balaji and Smart 2012). SN2 protein is an antimicrobial peptide which plays a role in the innate defence against invading pathogen (López-Solanilla et al. 2003). The ELP protein is transcriptionally upregulated after Cmm infection (Balaji et al. 2008). Transgenic lines with high levels of SN2 or ELP mRNA show a significant delay in the development of wilt symptoms and a reduction in the canker lesion size. Also, the modification of the PAMPs recognition receptors lead to tolerance. Transfer of the Arabidopsis FLAGELLIN-SENSING 2 (FLS2), 
BRI1-ASSOCIATED RECEPTOR KINASE1 (BAK1) and EF-TU RECEPTOR (EFR) into tomato, reduced the $\mathrm{Cmm}$ infection up to $83 \%$ (Torre et al. 2016). Although genetic modification in crops is still debatable in many countries, its application might be allowed in a later stage.

\section{Cultural practice}

Good cultural practice is important for growers. Knowing the pathogen disease cycles, and the suitable environment to reduce $\mathrm{Cmm}$ development will reduce yield loss. Cmm-free seeds are the initial step to combat the disease. However, growing healthy seedlings can only be done when no $\mathrm{Cmm}$ is in the soil due to infected plants from the last season(s). Once a plant is infected with $\mathrm{Cmm}$, it can easily spread the bacteria to neighbouring plants through wounds or natural openings of the other plants. In general the dispersion of the pathogen can be reduced with manipulating the fertigation or irrigation system (Sharabani et al. 2013a; Frenkel et al. 2015), using uncontaminated appliances (Kawaguchi et al. 2010) and changing the temperature settings in the greenhouse (Chang et al. 1992b; Sharabani et al. 2014). Asymptomatic plants in combination with diagnostic tests can be used to show that $\mathrm{Cmm}$ is present in a field (Yasuhara-Bell et al. 2015; Yasuhara-Bell and Alvarez 2015). Finally rotating tomatoes with other solanaceous crops every 2-3 year (Gleason et al. 1991) in combination with other horticulture techniques will reduce the spread of $\mathrm{Cmm}$.

In greenhouses and nurseries, the epiphytic $\mathrm{Cmm}$-infected plants can spread through guttation and splashing droplets due to overhead irrigation and spraying of chemicals (Strider 1967; Sharabani et al. 2013a). The secondary spread in Israel spreads from diseased plants to healthy plants due to the overhead irrigation system. To avoid this, a sub-irrigation system where water was added into pots for irrigation. This was done twice a day for 15 min followed by draining, this method was used to avoid spread of bacteria by water droplets on the foliage. Sub-irrigation reduces $\mathrm{Cmm}$ dispersion, but does not completely prevent $\mathrm{Cmm}$ spread (Frenkel et al. 2015). Sub-irrigated plants might be infected through the procedure of spraying pesticides. Growers may avoid pathogen dispersal by avoiding contact with plants during periods when they bear guttation droplets and changing the irrigation system. This practice provides an eco-friendly and easy means for decreasing the spread of the disease.

Using contaminated appliances hasten the bacterial spread like it was shown in a recent outbreak in Japan. Since watering was done by tubes under the plastic mulch the spreading of $\mathrm{Cmm}$ was not caused by the irrigation system. The spread in greenhouses in Japan was due to farmers removing buds and leaves by hands and pruning with non-sterilized scissors (Kawaguchi et al. 2010). Consequently, disease spreading can be reduced with strict greenhouse hygiene (Jarvis 1992). 
In addition, temperature plays a big role in disease development. In some cases, plants become more susceptible towards fungal diseases at lower temperatures (Balass et al. 1993; Ge et al. 1998), while they become more resistant under other circumstances (Kaul and Shaner 1989; Roderick et al. 2000). In the case of Cmm, the optimal temperature for disease development is between $23-28^{\circ} \mathrm{C}$ (Forster and Echandi 1973; Gartemann et al. 2003). Disease development and the incubation period lasts longer when the pathogen infects at colder temperatures (Chang et al. 1992b). Recent studies showed that temperatures predominant in the first $48 \mathrm{~h}$ after inoculation affect the $\mathrm{Cmm}$ density, expression of the virulence genes, and affects the disease development season-long. The time observed for half of the plants to wilt or to die after inoculation $\left(\mathrm{T}_{50}\right)$ in Israel was two month in spring $\left(21-24^{\circ} \mathrm{C}\right)$ and autumn $\left(18-23^{\circ} \mathrm{C}\right)$, and three to four months in the winter $\left(15-18^{\circ} \mathrm{C}\right)$ and summer $\left(28-31^{\circ} \mathrm{C}\right)$ (Sharabani et al. 2014). The aggressiveness of the pathogen in different seasons may differ from one country to another. Nevertheless, good knowledge about which temperature affects the disease development the most, is useful to control the disease.

Growers commonly eradicate infected $\mathrm{Cmm}$ plants in the fields and greenhouses to prevent the spreading of the disease. Eradication is usually done on symptomatic plants as the disease development is more obvious. Nonetheless, also asymptomatic plants in the field or greenhouse can result in severe disease spreading. The use of the $\mathrm{Cmm}$ ImmunoStrip ${ }^{\circledR}$ (Agdia Inc., Elkhart, IN) assay can facilitate detecting the presence of $\mathrm{Cmm}$ on asymptomatic plants, even before symptoms develop. The downside of this test is that it cannot discriminate between pathogenic and nonpathogenic $\mathrm{Cmm}$, or other bacteria such as Ochrobactrum and Microbacterium spp., which can also be present in tomato plants and seeds (Yasuhara-Bell and Alvarez 2015). The advancement of technology might prevent that problem. A Loopmediated Amplification (LAMP) assay was recently developed that can differentiate between pathogenic, non-pathogenic $\mathrm{Cmm}$, and other bacteria compared to the ImmunoStrip ${ }^{\circledR}$ (Yasuhara-Bell et al. 2013; Yasuhara-Bell et al. 2015; Yasuhara-Bell and Alvarez 2015). Hence, disease outbreaks can be combatted faster since it is possible in an early stage to identify the presence of low densities of $\mathrm{Cmm}$ in the plants or seeds.

Application of other horticultural techniques should be considered to ascertain the reduction of the infection in planta against $\mathrm{Cmm}$. Grafting is an agricultural practice that has been used for centuries. It fuses the root system (rootstock) from one plant to shoot (scion) of another. The application of this technique is wide, and one of it is managing disease resistance. Grafting has been used widely as a substitute of methyl bromide ( $\mathrm{MeBr}$ ) to manage soilborne pathogens like Ralstonia solanacearum (Peregrine and Ahmad 1982; Grimault and Prior 1994; Lin et al. 2008), Verticillium 
dahliae (Paplomatas et al. 2002; Liu et al. 2009) and root-knot nematodes (Augustin et al. 2002; Cortada et al. 2008). In addition, grafted vegetables can also show a disease reduction due to foliar pathogens Cucurbita ficifoli (Gu et al. 2008) and Leveillula taurica (Albert et al. 2017); and viruses (Miguel 2004; Huitrón et al. 2011). The application of grafting and the use of known rootstocks to manage $\mathrm{Cmm}$ has never been done. In Chapter 5, we will discuss the potential use of grafting to manage bacterial canker in tomato.

\section{Biocontrol measures}

Combating $\mathrm{Cmm}$ with chemicals is not an efficient way to control the disease. Chemical treatments only reduce the pathogen population on the surface of the plants or on the infected seeds (Hausbeck et al. 2000). Furthermore, repeated use of the same type of pesticides might increase the proportion of resistant $\mathrm{Cmm}$ strains. This is not true with the use of biocontrol means as $\mathrm{Cmm}$ requires a more complex mode of action to break the resistance/tolerance mechanisms. Even though the use of biocontrol agents to manage the disease has not been applied so far in the field, the possibility of using them in the future is likely. Biocontrol means that have been studied to control $\mathrm{Cmm}$ is the application of soil amendments (Zanón and Jordá 2008), antibacterial properties of bioactive compounds (Daferera et al. 2003; Kotan et al. 2014; Nguyen et al. 2017; Pham et al. 2017) and the use of other microorganisms (Boudyach et al. 2001; Lanteigne et al. 2012; Barda et al. 2015; Mora et al. 2015).

In recent years, there has been a demand on the use of organic matter in cultivated soil to improve soil quality especially in organic farming. Soil amendments such as biochar, composts, coffee grounds etc. can have different effects on soilborne plant pathogens (Lazzeri et al. 2003). Biofumigation, which is the use of active plant compounds into the soil by decomposing soil amendments to manage soilborne pathogens, can manage plant diseases as good as conventional pesticides (Bello et al. 2000; Stapleton 2000). The application of soil amendments for integrated pest management systems against $\mathrm{Cmm}$ has been studied in Spain. Its utilization is to make use of the farmer's cultural practice of keeping their crop residues on the soil surface. Amended soil containing fresh tomato debris artificially infected with $\mathrm{Cmm}$ was treated with two different temperatures $\left(25^{\circ} \mathrm{C}\right.$ and $\left.45{ }^{\circ} \mathrm{C}\right)$ to determine the effect of soil amendments with thermal treatment. $\mathrm{Cmm}$ was eradicated after four weeks treatment at $45^{\circ} \mathrm{C}$, but still present at $25^{\circ} \mathrm{C}$ (Zanón and Jordá 2008). These findings suggest adequate heat treatments on plant debris could be a different and effective soil disinfection technique, and the possibility of soil amendments and heat treatments for biofumigation in the field. 
Plant extracts exhibit broad-spectrum inhibition and potent activity against many phytopathogens (Pham et al. 2017). Bioactive compounds in the plants can be potentially utilized for developing plant-derived chemicals that are sustainable for the environment (Copping and Duke 2007; Yoon et al. 2011). Clavibacter michiganensis subsp. michiganensis is sensitive to oregano, thyme and dictammus essential oils as could be seen by the inhibition of the pathogen's growth in vitro. The three essential oils were characterised by the presence of $p$-cymene, $\gamma$-terpinene, thymol and carvacrol. The main compound in oregano oil is thymol, while it is carvacrol in thyme and dictamnus oils (Daferera et al. 2003). Additionally, coating the tomato seeds with carvacrol from Origanum onites increased the germination rate of tomato seeds, decreased the disease severity and improved the seedlings growth (Kotan et al. 2014). The antagonistic or synergistic effect may be due to the major component of particular plant compound, although it is possible that minor percentage of several compounds in combination with other mixtures may affect the pathogen's growth or virulence. Aside using the active components of plant extracts to control $\mathrm{Cmm}$, utlitizing other microorganisms are also able to control the pathogen.

Different types of responses may occur in tomato plants in the presence of $\mathrm{Cmm}$ and other microorganisms. During systemic infection, $\mathrm{Cmm}$ releases virulence factors and colonizes the xylem vessels. Wilting is due to the induction of ACO in ethylene in the presence of $\mathrm{Cmm}$. Cmm382 (containing both virulence plasmids) actively induced ACO in the host, but not $\mathrm{Cmm} 100$ (without virulence plasmids) (Savidor et al. 2012). Furthermore, degradation of cell walls in xylem vessels is hypothesized to occur due to the production of CelA and other extracellular enzymes from Cmm (Jahr et al. 2000; Gartemann et al. 2003). It is possible that when other microorganisms are present in the host, they might compete with $\mathrm{Cmm}$ and lead to antagonistic interactions (Utkhede and Koch 2004; Amkraz et al. 2010; Jung et al. 2014), the competition for nutrients (Boudyach et al. 2001), might change the hydraulictic conductivity of the xylem vessel (Romero et al. 2014) or trigger an induced resistance response (Barda et al. 2015). Several microorganisms have been tested and shown to inhibit Cmm: Pseudomonas spp. (Boudyach et al. 2001; Ślusarski 2009; Amkraz et al. 2010; Lanteigne et al. 2012; Novinscak et al. 2016), Bacillus spp. (Kasselaki et al. 2011; Jung et al. 2014; Mora et al. 2015), Pseudozyma aphidis (Barda et al. 2015), Aureobasidium pullulans and Pantoea agglomerans (El et al. 2017). Considering these studies, it is tempting to speculate that a microbial consortium containing more than one microorganism could enhance the resistance of the host plant. Further work on utilizing microbial consortia against $\mathbf{C m m}$ is discussed in Chapter $\mathbf{5}$. 


\section{Aim of this thesis}

The focus of this thesis is the application of several approaches to fight $\mathrm{Cmm}$ to get symptomless tomato plants with minimal bacterial density. From the overview of $\mathrm{Cmm}$ virulence and lifestyle, we can speculate that it is a challenge to combat and manage the pathogen. Relying on tolerant lines is not enough, other aspects of prevention should be applied to avoid $\mathrm{Cmm}$ dispersion which can lead to diseased plants. We have developed several means to control the pathogen. We developed an efficient system for the disease assay, which in turn speed up our fine mapping process. We made use of the host gene to work against the uninvited guest. Furthermore, we look at a horticultural practice and use of biological agents that could control the pathogen.

Chapter 2 describes a newly developed disease screening protocol which is efficient and cost effective. The quarantine status of the pathogen and lack of space hurdled the disease screening of large populations. The disease assay was based on the inoculation of in vitro seedlings, in which we could discriminate between highly tolerant, middle tolerant and susceptible genotypes. In combination with the use of PathoScreen ${ }^{\mathrm{TM}}$ imaging system, we could detect the presence of the GFP-tagged $\mathrm{Cmm}$ in whole plantlets. This new disease assay can be applied to many wild tomato relatives, where many of them produced similar symptom scores as with the more laborious greenhouse symptom assay. The use of this protocol speeds up the disease screening process of large populations using minimal space.

Following up from the previous chapter, Chapter 3 describes the fine mapping of the QTL on chromosome 7 using the in vitro disease screening. Fine mapping was done using the KASP (KBiosciences, UK) assay. The disease assay was performed on a selection of nearly isogenic lines using the newly developed disease assay. We could delimit the QTL region to $211 \mathrm{~Kb}$ and we have individuals with only a small introgession of S. arcanum LA2157 that are highly tolerant to $\mathrm{Cmm}$.

Chapter 4 describes the application of susceptibility $(S)$ genes against $\mathrm{Cmm}$. Since no known resistance $(R)$ genes have been found against $\mathrm{Cmm}$, utilizing the $S$-genes could be an alternative approach to fight the pathogen. From the VIGS assay, we found a candidate gene (WAT1) that confers higher tolerance than the control plants. This finding could be a starting point of utilizing $S$-genes in tolerance breeding against $\mathrm{Cmm}$.

Chapter 5 describes the alternative approaches to combat $\mathrm{Cmm}$ : grafting and utilizing biocontrol agents. A grafting method using the rootstock of a highly tolerant genotype (S. arcanum LA2157) to the scion of a susceptible (genotype) and vice versa was done to see any difference with the wilting severity. Biocontrol agent 
using Pseudomonas spp. consortia was applied to enhance the tolerance mechanism in different tomato genotypes. The wilt symptom was compared in the treated plants (with biocontrol agent) to the non-treated (without biocontrol agents) plants.

Finally, Chapter 6 summarizes the main results obtained in this thesis, gives concluding remarks and future perspectives to combat $\mathrm{Cmm}$. 



\title{
CHAPTER
}

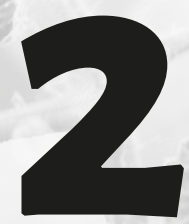

Development of an in vitro protocol to screen Clavibacter michiganensis subsp. michiganensis pathogenicity in different Solanum species

\author{
M.M. Mohd Nadzir, F.M. Vieira Lelis, B. Thapa, A. Ali, \\ R.G.F. Visser, A.W. van Heusden, J.M. van der Wolf
}


Clavibacter michiganensis subsp. michiganensis $(\mathrm{Cmm})$ is a quarantine organism in Europe and in many other countries. It is one of the most severe bacterial pathogens affecting tomato. Screening tomato plants for their tolerance level to $\mathrm{Cmm}$ requires a large amount of space under quarantine conditions and is therefore costly. This project developed a new inoculation protocol on in vitro tomato plants to facilitate a more economic and higher throughput disease screening. A new method using the PathoScreen ${ }^{\mathrm{TM}}$ system was tested to localize Green Fluorescent Protein-tagged $\mathrm{Cmm}$ in planta and to quantify the pathogen based on the percentage of corrected GFP (cGFP\%). The system was sensitive in detecting the GFP-tagged $\mathrm{Cmm}$ in the shoots, but a high autofluorescence in the roots masked detection and thus sensitivity of the assay. The best inoculation procedure was found by doing direct inoculation method on the fourth leaf stage plants. The in vitro protocol was tested on several wild relatives of tomato, which were previously screened in a greenhouse assay. The correlation between wilt symptoms in vitro and wilt symptoms in the greenhouse was overall moderate $(r=0.6462)$. The protocol worked well in differentiating the two parents that we used in our mapping studies. This study shows that the in vitro protocol can be efficiently used for resistance/tolerance breeding in many tomato genotypes.

$\checkmark$ Keywords: Clavibacter, Cmm, Tomato, Disease screening, in vitro, PathoScreen 


\section{Introduction}

Clavibacter michiganensis subsp. michiganensis $(\mathrm{Cmm})$ is a Gram-positive bacterium which causes wilting and canker in tomato (Solanum lycopersicum) (Davis et al. 1984). It can decrease tomato production worldwide and leads to major economic losses. The severe consequences of an infection with $\mathrm{Cmm}$ and its easy spreading make it listed under the EPPO A2, which defines as a quarantine pest present in the European and Mediterranean region but not commonly dispersed, and is regularly administrated (EPPO 2016). Clavibacter michiganensis subsp. michiganensis can enter the host plant via roots, natural openings and wounds (Chang 1991). Contaminated seeds and infected plant debris in the soil are the main sources of infection (Strider 1969; de León et al. 2009). The symptoms of the bacterial infection depend on several factors: infection pathways, level of resistance of the host, plant age at infection, bacterium density and the physiology of the tomato plant (Gleason et al. 1993; Sharabani et al. 2013b). The common symptom caused by $\mathrm{Cmm}$ in infected plants is wilting, other symptoms can be stem canker, firing of the foliage, discoloration of the vascular bundles, adventitious root formation on stems, bacterial sludge from infected parts and bird's eye spots on fruits (Strider 1969). Measures have been used to control $\mathrm{Cmm}$ so far are production of pathogen-free seed and good agriculture practices. The use of biocontrol agents might be an alternative approach to manage the pathogen in the future, but the application in the field has not been used so far (Barda et al. 2015). Another effective way to combat Cmm outbreaks will be the development of resistant/tolerant cultivars. No commercial tomato varieties are known that prevent $\mathrm{Cmm}$ symptoms even though related wild crossable relatives have been identified without symptoms after infection with $\mathrm{Cmm}$. Examples are S. pimpinellifolium (Thyr 1976; Sen et al. 2013), S. habrochaites (Vulkova and Sotirova 1993; Francis et al. 2001), S. lycopersicum (Elenkov 1965) and S. arcanum (Lindhout and Purimahua 1987; Vulkova and Sotirova 1993). To broaden the genetic variation of cultivated varieties parts of the genome of wild tomatoes can be introgressed (Haggard et al. 2015). From our previous studies, the best source of tolerance is $S$. arcanum LA2157 (van Heusden et al. 1999).

To pinpoint the chromosomal region and to identify underlying genes that are responsible for the tolerance it is necessary to test the interaction between the pathogen and the host in bigger populations. However, the strict laws on quarantine organisms in Europe make this very expensive and this hinders the progress of the work. After the plants have been infected they must be grown in small and expensive greenhouse compartments in a special quarantine section. Our group has tested different tomato genotypes in the greenhouse with different inoculation methods to find the best protocol for greenhouse screening (van den Bulk et al. 1991). However, 
currently greenhouse screening is costly for big populations. We wanted to develop a new screening method in vitro to make high throughput screenings possible.

In vitro methods for determining the level of resistance have been developed in several crops (Svabova et al. 2005). This has been done on plant parts (Borras et al. 2001), on callus cultures (Mangal and Sharma 2002) or on protoplasts (Nyange et al. 1997). For tomato, an in vitro inoculation with $\mathrm{Cmm}$ on tomato has been done on cells (Kraemer et al. 1988), callus (Sotirova et al. 1999) and seedlings (Lelis et al. 2014). Those studies showed an interaction between the pathogen and plant, and the development of the disease symptoms without the presence of other microorganisms. Disease symptoms, such as wilting, could be clearly seen six days post inoculation (dpi). Other symptoms (yellowing of lower leaves, followed by black spots, decay of the petiole, canker) that were seen in the greenhouse assay were also observed in the in vitro inoculated plants (Lelis et al. 2014).

In our study, we tested different tomato genotypes with different inoculation methods for optimising an in vitro protocol. The PathoScreen ${ }^{\mathrm{TM}}$ assay was used to detect the localization of the Green Fluorescent Protein-tagged pathogen in planta and to quantify the bacteria (Lelis et al. 2014). Our protocol showed that in vitro plants can be efficiently used in high throughput disease screenings.

\section{Materials and methods}

\section{Growth of in vitro plants}

The susceptible Solanum lycopersicum cv. Moneymaker and the highly tolerant S. arcanum LA2157 were used for developing an in vitro protocol. The seeds were sterilized in $70 \%$ ethanol for $2 \mathrm{~min}, 1 \% \mathrm{NaOCl}$ (Sigma-Aldrich, St. Louis, MO) for 20 min and washed with sterile water for $5 \mathrm{~min}$. Seeds were sown on a germination medium (GEM) (2.2 g MS salts/L, $10 \mathrm{~g}$ sucrose/L, $8 \mathrm{~g}$ Daishin agar/L; pH 5.8) and incubated for 3 days at $4{ }^{\circ} \mathrm{C}$ and then for approximately 2 weeks in a growth chamber (Technisch Buro I.K.S. B.V, Leerdam, The Netherlands) at $25^{\circ} \mathrm{C}$ with a relative humidity of $40-70 \%$, and a $16 \mathrm{~h} / 8 \mathrm{~h}$ day/ night photoperiod. Cotyledonary explants obtained from seedlings were transferred to rooting medium (MS30B5) (4.3 g MS salts/L, 112 mg Vitamin B5/L, $30 \mathrm{~g}$ sucrose/L and $8 \mathrm{~g}$ agar/L; pH 5.8) (Lelis et al. 2014).

\section{Inoculation of in vitro plants}

The GFP-tagged, virulent $\mathrm{Cmm}$ strain IPO3525, kanamycin and rifampicin resistant, was used for inoculation (Lelis et al. 2014). Two different plant stages were tested (the second and fourth leaf stage) and two types of inoculation methods (direct 
and indirect inoculation). Direct inoculation was done by cutting the first leaf using scissors that were dipped into $10^{7} \mathrm{cfu} \mathrm{ml}^{-1}$ bacterial suspension and the indirect inoculation was done by drop inoculating $100 \mu \mathrm{l}$ of $10^{7} \mathrm{cfu} \mathrm{ml}^{-1}$ bacterial suspension at the interspace between stem base and agar medium. Three replicates were used for each treatment with untreated plants as controls. The inoculated in vitro plants were collected at several time points $(3,7,1421,28$ and 35 days post inoculation - dpi). Wilting symptoms were recorded based on the following scale: $0=$ no symptoms; 1 $=0$ to $25 \%$ leaf wilting; $2=26$ to $50 \%$ leaf wilting; $3=51$ to $75 \%$ leaf wilting; $4=76$ to $100 \%$ leaf wilting; 5 = dead plants (Figure 1 ).

The in vitro inoculation method was also tested on twelve wild relatives of tomato (each with ten plantlets): S. habrochaites LA407, S. cheesmanii LA0166, S. parviflorum LA735, S. pimpinellifolium GI1554, S. habrochaites LYC4, S. arcanum LA2157, S. pennellii LA716, S. neorickii LA1045, S. arcanum PI127829, S. chilense IVT56140, S. cheesmanii LA1409, and S. arcanum LA385.

These genotypes were previously tested in a greenhouse assay (Sen et al. 2013). The wild relatives were inoculated using the direct inoculation method the fourth leaf stage. Wilting symptoms were recorded every week up to the $35 \mathrm{dpi}$. The symptom scoring was based on the scale above.

\section{Localization in planta and quantification of bacteria of in vitro growing plants}

The population densities of the bacteria between the different variables in planta were measured by collecting samples of the treated and untreated plants on 0,3 , $7,14,21,28$ and $35 \mathrm{dpi}$. The roots and the shoots (stems and leaves) were removed from the medium and sterilized with $70 \%$ ethanol. The surface of the plants were blotted dry and placed onto petri dishes $(120 \mathrm{~mm} \times 120 \mathrm{~mm}$ ) and images were captured using the imaging system PathoScreen ${ }^{\mathrm{TM}}$ (PhenoVation B.V: https://www. phenovation.com/) under several parameters: absolute and relative area of $\mathrm{Cmm}$ GFP and plants, GFP corrected and red, green, and blue intensities (RGB values).

The plant parts were then placed in extraction bags (Bioreba, Reinach, Switzerland), macerated with hammer, homogenized in Ringer buffer ( $2 \mathrm{ml} \mathrm{g}^{-1}$ of tissue) and analysed by dilution plating. Dilution plating was done by diluting six 10 -fold serial dilution of the $10 \mu \mathrm{l}$ macerated suspension onto $60 \mathrm{~mm} \times 15 \mathrm{~mm}$ petri dishes containing TBY medium (10 g tryptone/L, $5 \mathrm{~g}$ yeast extract/L, $5 \mathrm{~g} \mathrm{NaCl} / \mathrm{L}, \mathrm{pH} 7.5$ and $15 \mathrm{~g}$ agar/L) with final concentration of kanamycin $\left(50 \mu \mathrm{g} \mathrm{ml}^{-1}\right)$ and rifampicin $\left(25 \mathrm{~g} \mathrm{ml}^{-1}\right)$. Plates were incubated at $28^{\circ} \mathrm{C}$ for 4 days. The number of GFP- positive bacterial colonies was determined using epifluorescence stereomicroscopy. 


\section{PathoScreen $^{\mathrm{TM}}$ and statistical analyses}

The localization of GFP-tagged bacteria in the shoots was determined using the PathoScreen ${ }^{\text {TM }}$ Seed Data Analysis Software (version 2.4.1). Images of the plants were captured, the region without the presence of chlorophyll was masked, the Cmm-GFP signal in the images of the inoculated plants were normalized against the images of untreated plants, and the percentage of the corrected GFP (cGFP \%) signal was determined by the number of pixels detected in a normalized image. The correlation between the in vitro symptom scoring and cGFP\% was calculated. To determine the difference between the disease index with the age of plants at the time of inoculation (two versus four leaf stage) and inoculation methods (direct versus indirect), the variables were analysed by doing a two-way ANOVA analysis using the SPSS 23.0 statistical software package (SPSS Inc., Chicago, IL,). The difference between the bacterial titre and the two variables were also determined with the same analysis. Data of the cfu number were transformed to log10 after adding a value 1. Effects were significant at $P=0.05$. Symptom scoring data of each wild tomato genotype was averaged to determine the correlation of the wilting symptom of the in vitro infected plants and the greenhouse infected plants.

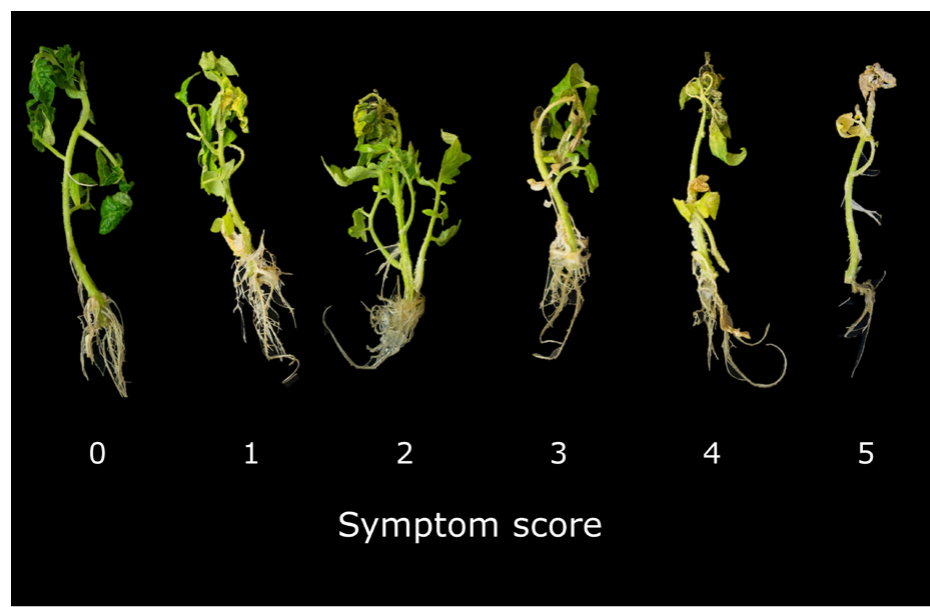

Figure 1 | Symptom score scale in vitro. $0=$ no symptoms; $1=0$ to $25 \%$ leaf wilting; $2=26$ to $50 \%$ leaf wilting; $3=51$ to $75 \%$ leaf wilting; $4=76$ to $100 \%$ leaf wilting; $5=$ dead. 


\section{Results}

\section{In vitro inoculation on S. lycopersicum cv. Moneymaker and S. arcanum LA2157}

For optimising the in vitro assay, an indirect and a direct inoculation were compared. Additionally, two different plant ages were tested, the inoculation was done on the plants in the second leaf stage and the fourth leaf stage.

The first symptoms on the susceptible genotype cv. Moneymaker became visible fourteen days past inoculation (dpi). The symptoms were: (1) yellowing of the lower leaves followed by unilateral wilting, (2) black spots on the leaves, (3) necrosis of the midribs and veins, (4) development of adventitious roots and (5) stem canker. S. arcanum LA2157 did not show any disease symptoms at fourteen dpi. Later, at 21 dpi, mild wilting symptoms were observed on S. arcanum LA2157 but without stem canker development.

On cv. Moneymaker a more clear leaf wilting and also stem cankers were observed after the direct inoculation (cutting first leaves with $\mathrm{Cmm}$-infected scissors) (Figure $2 c$, e) compared to the indirect inoculation (Figure $2 \mathrm{~g}$, i). Indirect inoculation on the second leaf stage of cv. Moneymaker resulted in a wilting score of 1 (Figure 2g), which cannot be explained as the density in the plant is as high as the concentration of directly inoculated cv. Moneymaker with wilting score 5 (Table 1) (Figure 2c). We can conclude that indirect inoculation is not an optimal method to detect wilting symptoms especially when inoculated at the second leaf stage plants. The wilting symptoms on 35 dpi were less severe in S. arcanum LA2157 (Table 1) (Figure 2d, $f, h, j)$. Ultimately the direct inoculation method on the second leaf stage resulted in stunted S. arcanum LA2157 (Figure 2d) plants and dead cv. Moneymaker plants (Figure 2c). These results confirm that S. arcanum LA2157 is more tolerant than cv. Moneymaker. The untreated plants of both genotypes did not show any symptoms (Figure 2a, b).

Based on a two-way ANOVA analysis, the symptom score was significantly different between the two inoculation methods but was not dependent on plant age $(P=0.05)$. 


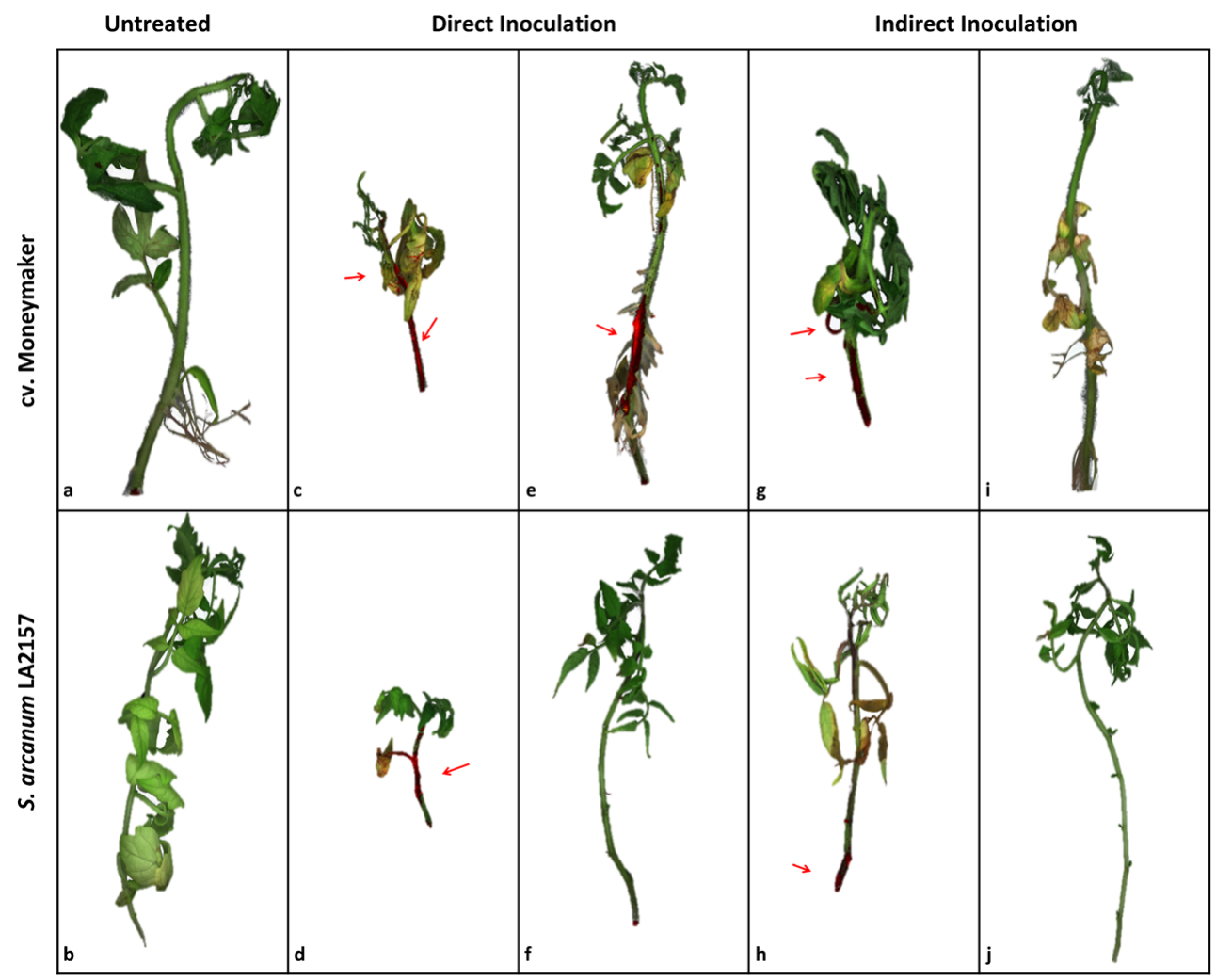

Figure 2 | In vitro plants after 35 dpi. Untreated plants $(a, b)$. Plants inoculated during the second leaf stage ( $c, d, g$ and $h$ ) and fourth leaf stage (e, $f, i$ and j). Plants inoculated with direct inoculation (c, d, e and $\mathrm{f}$ ) and indirect inoculation ( $\mathrm{g}, \mathrm{i}, \mathrm{h}$ and $\mathrm{j}$ ). Red arrows indicate strong signal of GFP-tagged Cmm. Images were taken with the PathoScreen ${ }^{\mathrm{TM}}$ system under the RGB and GFP lights. Analysis of the images and the number of pixels containing GFP were done using the PathoScreen ${ }^{\mathrm{TM}}$ analysis software.

\section{In vitro inoculation of tomato wild relatives}

For comparing the in vitro and greenhouse screenings (Sen et al. 2013) twelve wild species of tomato and cv. Moneymaker were used. A direct inoculation was done because the wilting symptoms are more obvious and more uniform, and this method is more similar to the greenhouse testing procedure. In vitro symptom scoring was done on 7, 14, 21 and 28 days after inoculation. At seven dpi, all plants were still symptomless, wilting started at $14 \mathrm{dpi}$. A significant difference between genotypes was observed on 14, 21 and $28 \mathrm{dpi}(\mathrm{P}<0.001$ at all-time points). At fourteen dpi, some cv. Moneymaker and S. neorickii LA1045 plants developed stem canker. S. cheesmanii LA1409 and S. cheesmanii LA0166 showed more severe wilting than Cv. Moneymaker at 14 and $21 \mathrm{dpi}$ (Figure S1). An overall correlation of 0.6462 was found between the wilting scores in the greenhouse and the in vitro conditions 
(Figure S2). The somewhat moderate correlation was due to two genotypes with very contrasting scores under the two conditions: S. habrochaites LYC4 and S. pennellii LA716. Under the greenhouse conditions S. habrochaites LYC4 and S. pennellii LA716 are susceptible (score 5), but in vitro tolerant (score 1 and 2; respectively).

Infected wild relatives were examined with PathoScreen ${ }^{\mathrm{TM}}$ and dilution plating to determine the in planta colonization and bacterial titre. A strong GFP signal was detected in the plants with severe wilting symptoms. No GFP signal was detected on symptomless and control plants. The bacterial titre based on dilution plating (14, 21 and $28 \mathrm{dpi}$ ) showed a highly significant difference between genotypes ( $<<0.001$; Figure S1). Surprisingly, S. arcanum LA385, S. arcanum PI127829, S. habrochaites LYC4 and S. arcanum LA2157 have low wilting scores and yet still contained high bacterial titres (Figure S3).

\section{Population dynamics of $\mathrm{Cmm}$ in the in vitro inoculated plants}

The population dynamics of $\mathrm{Cmm}$ was examined in the roots and shoots (stems and leaves). The bacterial titre in the plant tissue was related to the timing of the inoculation and which inoculation method was used. The direct inoculation resulted in the beginning in higher concentrations $\mathrm{Cmm}$ in shoots and roots of the plants compared to the indirect inoculation. Thirty five days after direct inoculation on the second leaf stage, there was hardly any difference in the bacterial titre of $\mathrm{cv}$. Moneymaker and S. arcanum LA2157 in the shoots and roots. However, there was a higher bacterial titre in cV. Moneymaker than in S. arcanum LA2157 on the fourth leaf stage inoculation (Table 1). A similar trend was observed after the indirect inoculation. Here, a higher concentration $\mathrm{Cmm}$ was detected in the second leaf stage inoculation compared to the fourth leaf stage inoculation in both genotypes. In the fourth leaf stage inoculation at $35 \mathrm{dpi}$, there was a higher $\mathrm{Cmm}$ concentration in the shoot of $\mathrm{cv}$. Moneymaker than in S. arcanum LA2157 (Table 1). The indirect inoculation resulted in a higher variation of the bacterial titre throughout the experiment.

Based on the two-way ANOVA analysis, the bacterial titre log $(c f u / g+1)$ was significantly different between the two inoculation methods and the plant age $(P=$ 0.05). 


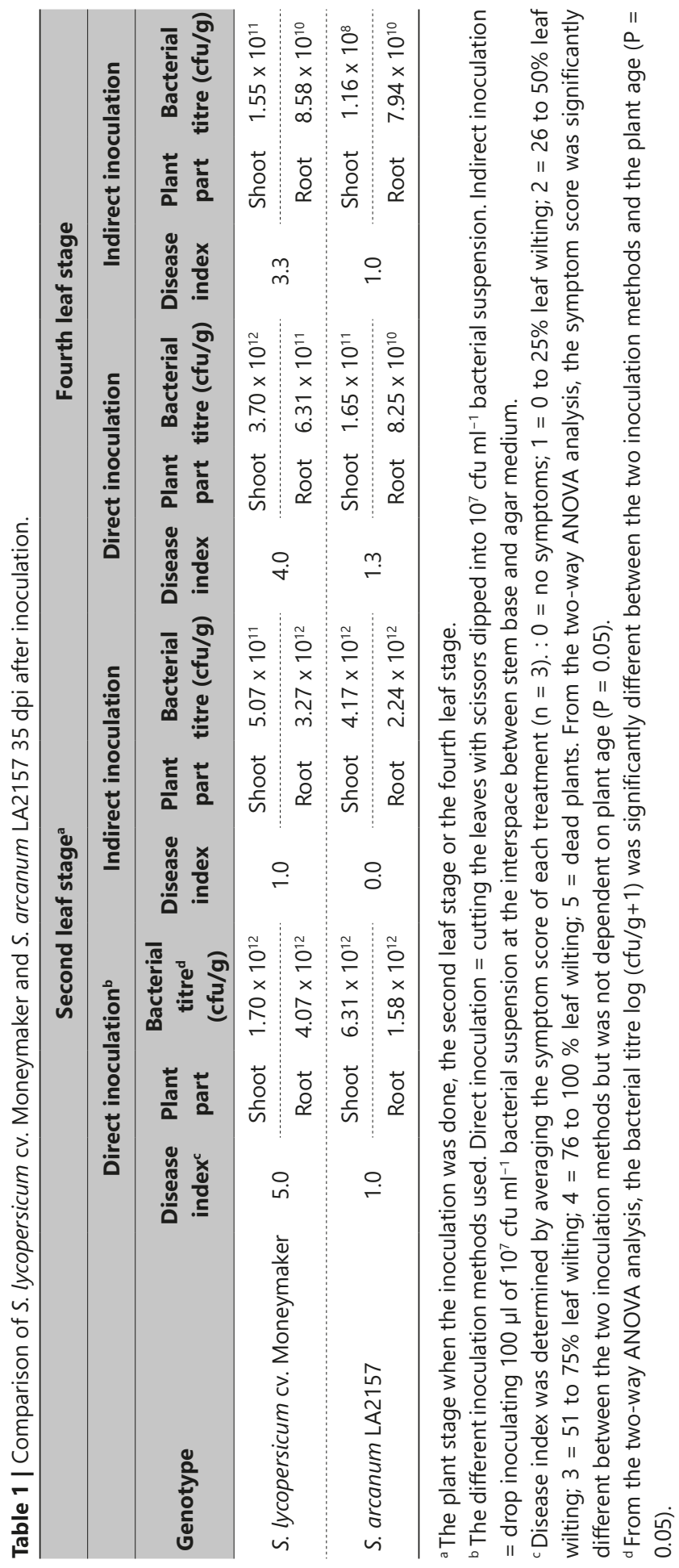




\section{In planta colonization}

The PathoScreen ${ }^{\mathrm{TM}}$ analysis showed the colonization of the GFP-tagged $\mathrm{Cmm}$ in planta (Figure 2). Bacterial signals were detected in planta as early as $21 \mathrm{dpi}$ with direct inoculation on second leaf stage in both genotypes. The $\mathrm{Cmm}$ titre did not correlate with wilting and in planta colonization. The corrected GFP normalized against untreated plants (cGFP \%) had a low correlation ( $r=0.225)$ with log $(c f u+1 / g)$. The wilting symptom was more severe in the cv. Moneymaker than in S. arcanum LA2157, but their bacterial titres were almost equal (second leaf stage inoculation) (Figure 2 and Table 1), and surprisingly the GFP signal was hardly detected in $S$. arcanum LA2157 (Figure 2d, h) compared to cv. Moneymaker (Figure 2c, g).

At $35 \mathrm{dpi}$, a strong GFP signal was detected in different parts of cv. Moneymaker such as the stem, petiole, midvein and lateral vein (Fig $2 c$, e and g), but the translocation was less in S. arcanum LA2157 and the pathogen was detected only in the stem (Figure $2 \mathrm{~d}, \mathrm{~h}$ ). No GFP signal could be detected in the fourth leaf stage inoculation of the indirect inoculated cv. Moneymaker and S. arcanum LA2157 (Figure 2i, j), and direct inoculated S. arcanum LA2157 (Figure 2f).

PathoScreen ${ }^{\mathrm{TM}}$ could not be used to detect the presence of $\mathrm{Cmm}$ in the roots as it could not efficiently differentiate between the autofluorescence presence in the roots and the Cmm-GFP signal.

\section{Discussion}

We developed an in vitro protocol to evaluate disease symptoms of $\mathrm{Cmm}$ in tomato. Two types of variables were tested: inoculation method and plant age. Both direct and indirect inoculation methods resulted in the presence of bacteria and wilting in the plants and the bacterial titre was relatively similar. The indirect inoculation method resulted in less visible wilt symptoms and very variable bacterial titres. Other studies already indicated that a root inoculation method is undesirable due to the disparity with wilt symptoms (Forster and Echandi 1973). The plant age also affects wilting, the best plant age to do in vitro inoculation was the fourth leaf stage. An inoculation at this stage, makes it easy to differentiate severity of wilting. The age of the plants plays an important role in disease development (Sharabani et al. 2013b). Younger plants are more susceptible to $\mathrm{Cmm}$ compared to older plants. Inoculation done on older plants (more than 16 leaf stage) do not result in wilt symptoms and inoculation on young plants may result in early plant death (Sharabani et al. 2013b). In previous studies done in our group, inoculation done on the fourth leaf stage could more distinctly differentiate between the tolerant genotype Irat L3 and the susceptible genotype cv. Moneymaker than inoculation done on the second leaf 
stage (van den Bulk et al. 1991). The result is similar to the results obtained in our in vitro screening. Thus, in our system, the best inoculation procedure is a direct inoculation on the fourth leaf stage of the plant. This inoculation procedure resulted in less variation in wilting severity within a genotype, but in clear differences between susceptible and resistant/tolerant genotypes.

In agreement with earlier studies with cv. Moneymaker (Lelis et al. 2014) the disease symptoms developed faster also in the in vitro growing wild relatives. Some variation of severity of wilting was found between individual plants of a genotype. The variation could be due to the fact that some genotypes are heterogeneous. Since many of the wild genotypes are self-incompatible, genetic differences can exist within a genotype (Grandillo et al. 2011). The tolerant genotypes from the in vitro screening contained considerable amounts of bacterial titre even with low symptom scores (Figure S3). It is similar with what has been observed by Sen et al. (2013). What causes the wild relatives to be tolerant is still unknown. It could be that that tomato wild relatives are nonhost to Cmm (Niks and Marcel 2009) or the metabolic compounds in some wild relatives could inhibit the virulence of $\mathrm{Cmm}$ (Shinde et al. 2017). When these tolerant and symptomless plants are grown in the field or greenhouse they could be the source of disease dispersion on the production site, which causes many susceptible plants to severely wilt and wither (Kawaguchi et al. 2010).

The correlation between the symptoms of the in vitro screening with the greenhouse experiment was 0.6462 (Figure S2). This moderate score was due to two genotypes, which have high conflicting results between greenhouse scores and in vitro scores (S. habrochaites LYC4 and S. pennellii LA716). Those genotypes are susceptible in the greenhouse (Sen et al. 2013) but were tolerant in our in vitro experiment. We hypothesize that the differences in environmental conditions during in vitro plant growth and in the glasshouse affected symptom development in these two genotypes more than in the other genotypes. This might be due to differences in the tolerance mechanisms of the wild relatives. Or that specific conditions during the in vitro screening might also change the metabolic pathways responsible for tolerance to $\mathrm{Cmm}$. Different metabolites may be synthesized after in vitro inoculation compared to greenhouse infection (Schauer et al. 2005). Or that differences in environmental conditions make it more difficult to score the disease severity. For instance, humidity is high (100\%) in the in vitro containers and moderately high (60\%) in the greenhouse. Under $100 \%$ humidity the S. pennellii in vitro plants were small and the growth was stunted. On the small leaves it is difficult to score wilting severity reliably. S. habrochaites originates from humid environments (Grandillo et al. 2011). The less high humidity in the greenhouse might result in stress and a relative high susceptibility (Sen et al. 2013). In general, the in vitro inoculations work well on most wild relatives. The difference between the two parental lines of our mapping 
population (Moneymaker and S. arcanum LA2157) was very clear. This makes the in vitro method very suitable for recombinant screenings and fine mapping in progeny of these two plants. We used the PathoScreen ${ }^{\mathrm{TM}}$ system to detect and quantify the GFP-tagged $\mathrm{Cmm}$ in planta. This system captures high quality images and quantifies GFP-tagged pathogen based on the pixel number. The PathoScreen ${ }^{\mathrm{TM}}$ system is more sensitive and convenient than the epifluorescence stereomicroscope (ESM). The PathoScreen $^{\mathrm{TM}}$ system detected the pathogen in planta as fast as $21 \mathrm{dpi}$ without the alternative approach of enriching the samples. Using ESM or CLSM, an incubation of plant tissue for 24 to $48 \mathrm{~h}$ under selective conditions for growth of the pathogen was required to visualize the bacteria (Lelis et al. 2014). Another advantage is that the pathogen is visualized in the complete in vitro plant instead of a visualization in different small parts (Tancos et al. 2013; Lelis et al. 2014). A disadvantage is that with PathoScreen $^{\mathrm{TM}}$ the GFP-tagged pathogen cannot be visualized in the roots. This is due to the high autofluorescence in the roots. To visualize the GFP-tagged in planta, the PathoScreen ${ }^{\mathrm{TM}}$ like ESM and CLSM require a high bacterial titre of at least $10^{12}$ $\mathrm{cfu} / \mathrm{ml}$ of GFP-tagged $\mathrm{Cmm}$. However, the PathoScreen ${ }^{\mathrm{TM}}$ system is so far the most sensitive and convenient method to detect a bacterial GFP signal. The sensitivity and convenience make the system suitable for detecting GFP-tagged phytopathogens.

In vitro inoculation is a new approach to screen large populations for resistance/ tolerance levels. This technique has earlier been used to screen for resistance and to develop new breeding lines (Evans 1986). Tomato callus was screened with $\mathrm{Cmm}$ to identify tolerant regenerants (van den Bulk et al. 1991; Zagorska et al. 2004). But a disease screening using callus is not efficient to screen existing tomato genotypes. It is more time effective to use plantlets from seeds for in vitro inoculation (Flores et al. 2012).

In conclusion, our in vitro inoculation method allows mass screening of many tomato genotypes in an efficient way against a quarantine organism like $\mathrm{Cmm}$. Less space, time and costs are needed for the disease screening. Our work showed that the wilting with the in vitro inoculation was similar to the wilt symptoms in a greenhouse assay with only a few exceptions of specific wild relatives. Hence, the protocol could be successfully used to replace greenhouse screenings. This in vitro inoculation and screening method will be used to fine map a QTL region originating from S. arcanum LA2157 known to harbour a tolerance factor against $\mathrm{Cmm}$. 


\section{Acknowledgements}

We would like to thanks Patricia van der Zouwen and Theo van der Lee from Wageningen University and Research, Biointeractions and Plant Health for their help, and Nunhems, vegetable seeds of BASF, the Netherlands; Universiti Putra Malaysia and Ministry of Higher Education Malaysia, Malaysia for financial support.

\section{Supplementary material}

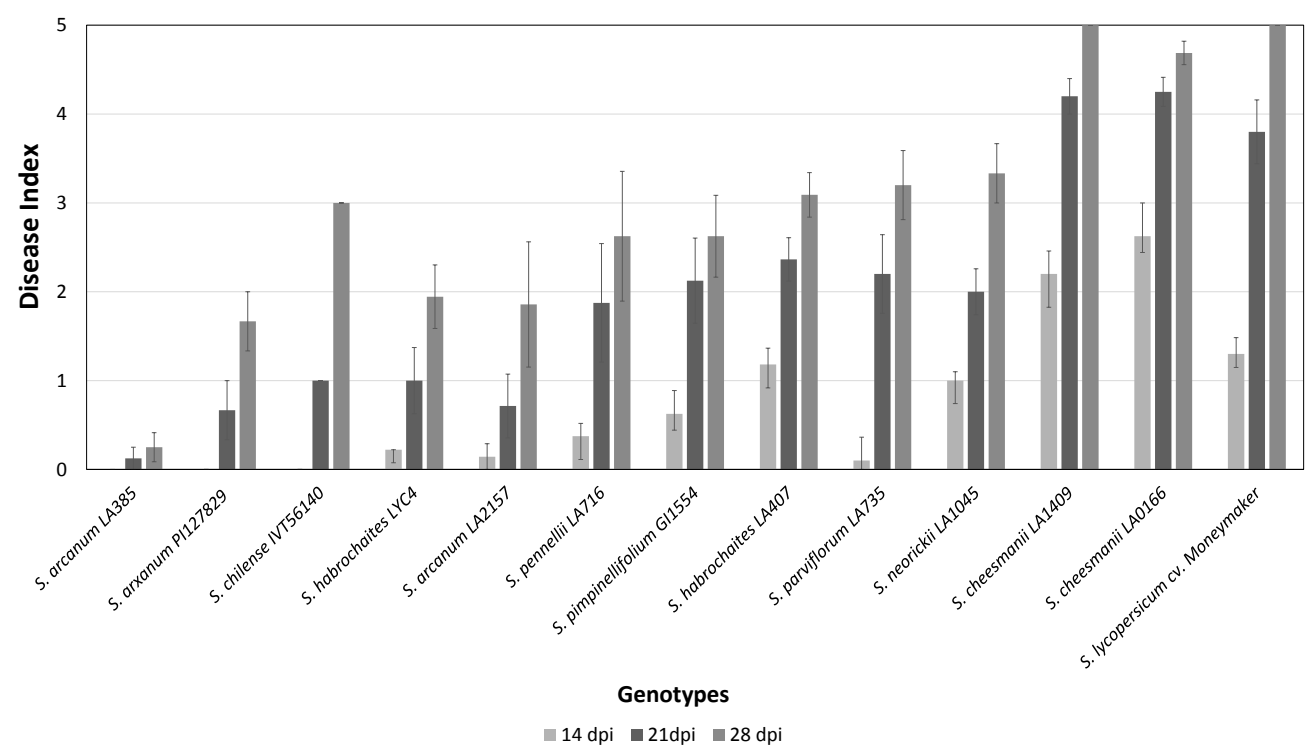

Figure S1 | Disease index of in vitro wild tomato genotypes at 14, 21, and $28 \mathrm{dpi}$. The bars represent the average symptom score of each genotype, vertical lines represent the standard error of the mean $(n=10)$. 


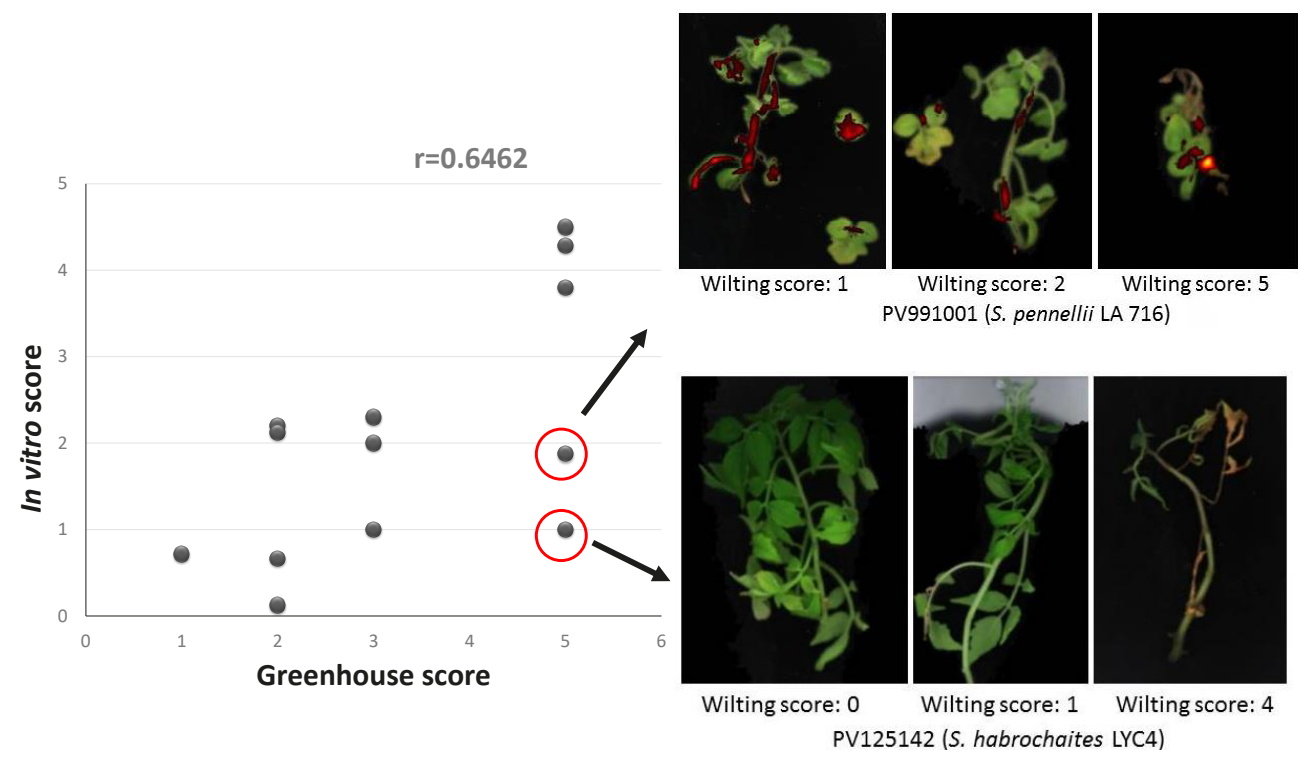

Figure S2 | Relationship between the wilting symptom scores in vitro and the greenhouse (Sen et al. 2013). Red circles indicate the genotypes with high conflicting scores between greenhouse and in vitro (S. habrochaites LYC4 and S. pennellii LA716). Three plants out of ten plants of these genotypes are shown to indicate the variation of disease symptom within each genotype.

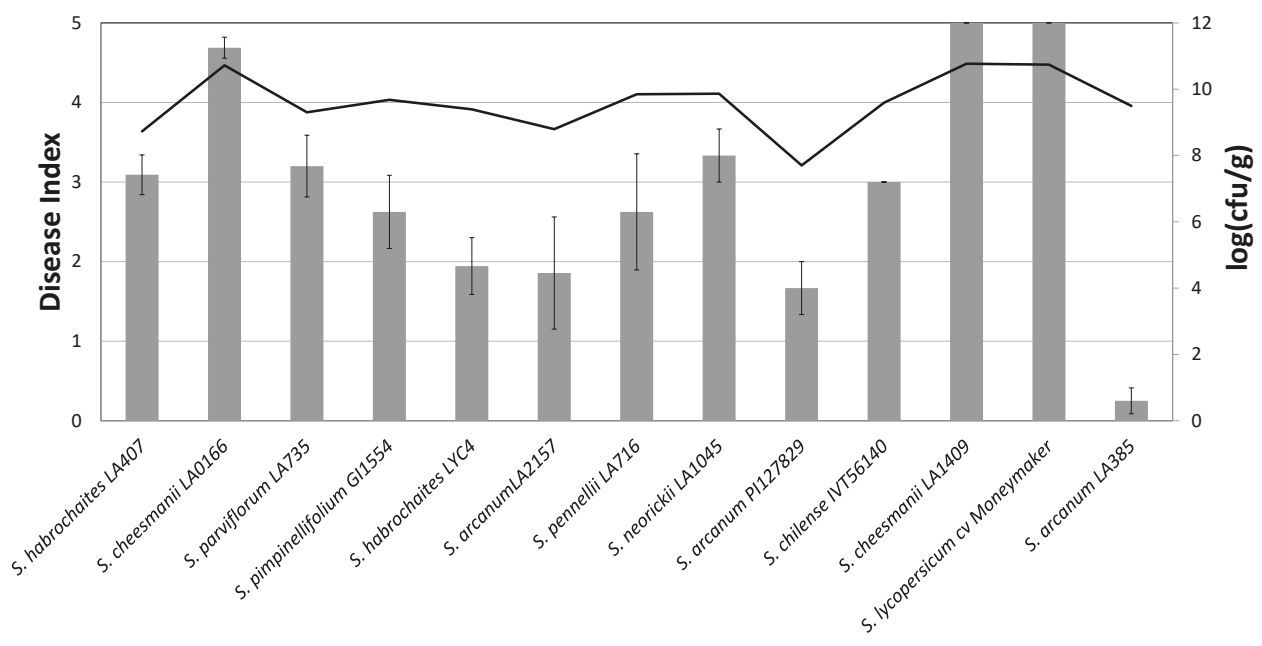

Genotype

Disease Index - log(cfu/g)

Figure S3 | Disease index and bacterial density of in vitro wild tomato genotypes at $28 \mathrm{dpi}$. The bars represent the average symptom score of each genotype, vertical lines represent the standard error of the mean $(n=10)$. Bacterial titre is represented by the black line. 



\section{CHAPTER}

Fine mapping of a Clavibacter michiganensis subsp. michiganensis $(\mathrm{Cmm})$ tolerance gene originating from Solanum arcanum LA2157

M.M. Mohd Nadzir, B. Thapa, S. Subedi, F. Millenaar, Y. Sen, R.G.F. Visser, J.M. van der Wolf, A.W. van Heusden 
Clavibacter michiganensis subsp. michiganensis $(\mathrm{Cmm})$ is a quarantine bacterium in Europe and many other countries. Outbreaks cause severe losses in tomato production. Resistance/tolerance breeding is one of the approaches to reduce the effects of $\mathrm{Cmm}$. To understand the resistance mechanism and to identify candidate genes, we fine mapped on chromosome 7 the most important genetic factor(s) involved. This fine mapping was optimised by using a disease screening on in vitro plants. The marker analyses were done with Single Nucleotide Polymorphisms (SNPs) and the KASP platform. An in-house prediction tool, the HaploSmasher, was used to predict the gene variants in the fine mapped region of the highly tolerant wild source Solanum arcanum LA2157. The region has been fine mapped to $211 \mathrm{~Kb}$ which resulted in 15 annotated genes. The results are the first step to understand a tolerance mechanism against $\mathrm{Cmm}$.

Keywords: Clavibacter, Cmm, Tomato, Disease screening, in vitro, QTL, Fine mapping, KASP 


\section{Introduction}

Infection with the Gram-positive pathogenic bacteria, Clavibacter michiganensis subsp. michiganensis $(\mathrm{Cmm})$, causes wilting and canker in tomato (Solanum lycopersicum) (Strider 1969; Davis et al. 1984; Gartemann et al. 2003). Cmm is considered one of the most important bacterial diseases of tomato. The substantial economic losses caused by the pathogen and the difficulty to control the disease made $\mathrm{Cmm}$ a quarantine organism under the European Union Plant Health Legislation (CABI and EPPO 1999; Gartemann et al. 2003; Eichenlaub and Gartemann 2011).

Contaminated seeds can be the starting point of major $\mathrm{Cmm}$ outbreaks, but in general the production loss in a field or greenhouse is caused by secondary spread of Cmm (León et al. 2011; Lamichhane et al. 2011; Tancos et al. 2013) due to agricultural practices such as the use of contaminated equipment and the spontaneous spread from diseased plants to healthy plants (Sharabani et al. 2013a; Frenkel et al. 2015; Sen et al. 2015; Chalupowicz et al. 2016). Once the pathogen has infected the plant, severe leaf wilting and stem canker can occur. Ultimately the plants with wilting and canker symptoms will die. The severity of the infection is dependent on environmental conditions, the virulence of the strain and the plant genotype (Jahr et al. 1999; Sharabani et al. 2014; Sen et al. 2015). Seed companies and plant multipliers are obliged to sell $\mathrm{Cmm}$-free certified seeds and plantlets based on the Good Seed and Plant Practices (GSPP) (Munkvold 2009; GSPP Standard 2017). For seed companies, resistant/tolerant cultivars should have no seed transmission of $\mathrm{Cmm}$ and preferably no $\mathrm{Cmm}$ in the plant. For growers, the presence of $\mathrm{Cmm}$ should not lead to lower yields or loss of quality of the tomatoes. So far, there are no tomato cultivars in the market that are resistant or medium resistant to $\mathrm{Cmm}$ (Thyr 1971; van Steekelenburg 1985; Sen et al. 2013), but several wild relatives of tomato are resistant towards $\mathrm{Cmm}$ and show no symptoms (Sen et al. 2013). We investigated how we can transfer the tolerance from the wild species into modern cultivars and which mechanisms and sort of genes play a role in the tolerance.

Screening for $\mathrm{Cmm}$ resistance/ tolerance in wild tomato accessions has been going on since the 1930's (Cardon 1934). In tomato breeding, introgression breeding in general started in the sixties of the $20^{\text {th }}$ century (Elenkov 1965). Differences in tolerance were found between individual plants in offspring populations of several crosses between wild tomato species and cultivated tomato. Examples of these wild species are: S. pimpinellifolium (Elenkov 1965; Thyr 1968; Jong and Honma 1976; Thyr 1976; Sen et al. 2013), S. habrochaites (Hassan et al. 1968; Vulkova and Sotirova 1993; Sotirova et al. 1994; Francis et al. 2001; Kabelka et al. 2002), and S. arcanum (Lindhout and Purimahua 1987; Vulkova and Sotirova 1993; Sandbrink et al. 1995; van Heusden et al. 1999). Resistance due to a substantially lower bacterial titre has not yet been 
found in the wild relatives. Infected, highly tolerant plants still contain a considerable amount of bacteria (Sen et al. 2013). Nonetheless, these accessions are still valuable as none of them wilt severely after infection and no visible reduction in yield is found. The highest tolerance we identified was in Solanum arcanum LA2157 (Sandbrink et al. 1995; van Heusden et al. 1999). Three major Quantitative Trait Loci (QTL) were identified on chromosomes 5, 7 and 9 in the van Heusden study. In an F2 mapping population the QTLs were additive and more than one QTL was needed to have a similar resistance level as the resistant source (van Heusden et al. 1999). The most prominent QTL is located on chromosome 7 and in this study we focused on further fine mapping the gene(s) underlying this QTL. Our fine mapping was successful and reduced the QTL region to $211 \mathrm{~Kb}$. Since the tolerance mechanism is still unknown it is difficult to identify the most likely candidate gene based on their gene sequence only.

\section{Materials and methods}

\section{Plant materials and in vitro propagation}

We used a progeny population of selfed heterozygous Nearly Isogenic Lines (NILs) for fine mapping. The material development is shown in Figure 1.The original $F_{2}$ population was a cross between Solanum lycopersicum cv. Solentos and S. arcanum LA2157 (van Heusden et al. 1999). Progenies containing the introgressed region located in the QTL regions were backcrossed to S. lycopersicum cv. Moneymaker to obtain $\mathrm{F}_{2} \mathrm{BC}_{3} \mathrm{NIL}$ lines. A whole background screening was done to identify those NILs with a minimum level of the resistant donor on other chromosomes (Sen 2014). Nearly Isogenic Lines containing different QTLs can be crossed, selfed and screened with markers to find NILs with more than one QTL (combiNILS). Three hundred and seventy seeds of the selfings were sterilized in $70 \%$ ethanol for $2 \mathrm{~min}, 1 \% \mathrm{NaOCl}$ (Sigma) for $20 \mathrm{~min}$ and washed with sterile water for $5 \mathrm{~min}$. Seeds were sown on a GEM medium (2.2 g MS salts/L, $10 \mathrm{~g}$ sucrose/L, $8 \mathrm{~g}$ Daishin agar/L; $\mathrm{pH}$ 5.8) and incubated for 3 days at $4{ }^{\circ} \mathrm{C}$ and then for approximately 2 weeks in a growth chamber (Technisch Buro I.K.S. B.V, Leerdam, The Netherlands) at $25{ }^{\circ} \mathrm{C}$, with a relative humidity of 40-70\%, and a $16 \mathrm{~h} / 8 \mathrm{~h}$ day/ night photoperiod. Cotyledonary explants were transferred to MS30B5 medium (4.3 g MS salts/L, $112 \mathrm{mg}$ vitamin B5/L, $30 \mathrm{~g}$ sucrose/L and $8 \mathrm{~g}$ agar/ $\mathrm{L} ; \mathrm{pH}$ 5.8). Three weeks after transplanting, cuttings were made from the stem of each genotype grown in the MS30B5 medium. Leaf samples were collected and send to VHLGenetics ${ }^{\circledR}$ (Wageningen, The Netherlands) for DNA extraction and genotyping. 


\section{Marker development}

KASP assays (KBiosciences, UK) were used for genotyping. The nomenclature of the Single Nucleotide Polymorphism (SNP) is based on their physical position on the tomato map (Sol 2.40). Polymorphic markers were designed from the QTL regions of chromosome 7 and 9 (Sen 2014). Other sources of KASP markers were based on results of the SolCAP array (http://solcap.msu.edu/) and the Wageningen UR 150 Tomato Genome Resequencing project (Aflitos et al. 2014). For confirmation of SNPs, some regions were resequenced. The PCR reaction was set up in a final volume of $20 \mu \mathrm{l}(2 \mu \mathrm{l}$ of PCR buffer (10x), $1 \mu \mathrm{l} 5 \mathrm{mM}$ deoxynucleoside tri-phosphates (dNTPs), $0.1 \mu \mathrm{l}$ of DreamTaq DNA Polymerase (Thermo Scientific, USA) $(5 \mathrm{U} / \mathrm{ul}), 0.25 \mu \mathrm{l}$ of forward primer $(10 \mu \mathrm{M}), 0.25 \mu$ l of reverse primer $(10 \mu \mathrm{M})$ and $1 \mu \mathrm{l}$ of DNA $(10 \mu \mathrm{M})$. Touchdown PCR with 25 cycles $94{ }^{\circ} \mathrm{C}, 30 \mathrm{~s} ; 60(-0.4){ }^{\circ} \mathrm{C}, 30 \mathrm{~s} ; 72{ }^{\circ} \mathrm{C}, 30 \mathrm{~s}$ and 10 cycles $94{ }^{\circ} \mathrm{C}, 30 \mathrm{~s} ; 55^{\circ} \mathrm{C}, 30 \mathrm{~s} ; 72{ }^{\circ} \mathrm{C}, 30 \mathrm{~s}$. Single band PCR products were send for sequencing (GATC BIOTECH, Germany). Single Nucleotide Polymorphism between the parents were choosen to set up KASP assays (Table S1).

\section{Inoculation on the in vitro plants}

Three hundred and seventy plantlets of the fine mapping population were screened for the QTL regions on chromosome 7 and 9. After this screening a limited number of plants were in vitro screened for $\mathrm{Cmm}$ tolerance. Two cuttings per accession were used for the disease assay and the virulent bacterial strain Cmm IPO3356 (Culture Collection of Plant Research International) was used for inoculation. Inoculation was done in plants with four to five leaves, in this stage the petiole of the lower leaf was cut with scissors which had been dipped into $10^{8} \mathrm{cfu} \mathrm{ml}^{-1}$ bacterial suspension. Plants were scored on 7, 14, 21 and 28 days post inoculation (dpi) by looking at wilting symptoms and the presence of cankers on the stem. Wilting symptoms were scored based on the following scale: $0=$ no symptoms; $1=$ to $25 \%$ leaf wilting; 2 $=26$ to $50 \%$ leaf wilting; $3=51$ to $75 \%$ leaf wilting; $4=76$ to $100 \%$ leaf wilting; 5 $=$ dead plants. The wilting score combined with the severity of the cankers led to three categories. Plants scored up to 2 were categorised as highly tolerant, plants with wilting score 3 (without stem canker) were categorised as medium tolerant and finally plants scored 3 (with stem canker), 4 and 5 (with/without stem canker) were categorised as susceptible. 


\section{Genes in the fine mapped region}

Candidate genes in the fine mapped region were mined from the available annotated genes ITAG 3.2 using the Jbrowse browser. Differences in protein sequences between the two parental lines were determined using the in-house HaploSmasher software developed by Plant Breeding, Wageningen University \& Research, Wageningen, the Netherlands (http://xapps.plantbreeding.nl:5001). HaploSmasher is a prediction tool which predicts the effects of genetic variants of the annotated genes in tomato. Differences in allelic variations between S. arcanum LA2157 and Heinz were determined based on filtering the impact prediction starting from high impact (variants cause disruptive change in the protein), moderate impact (variants cause a non-disruptive change in the protein) to low impact (variants unlikely change protein behaviour) (http://snpeff.sourceforge.net/SnpEff_manual.html).

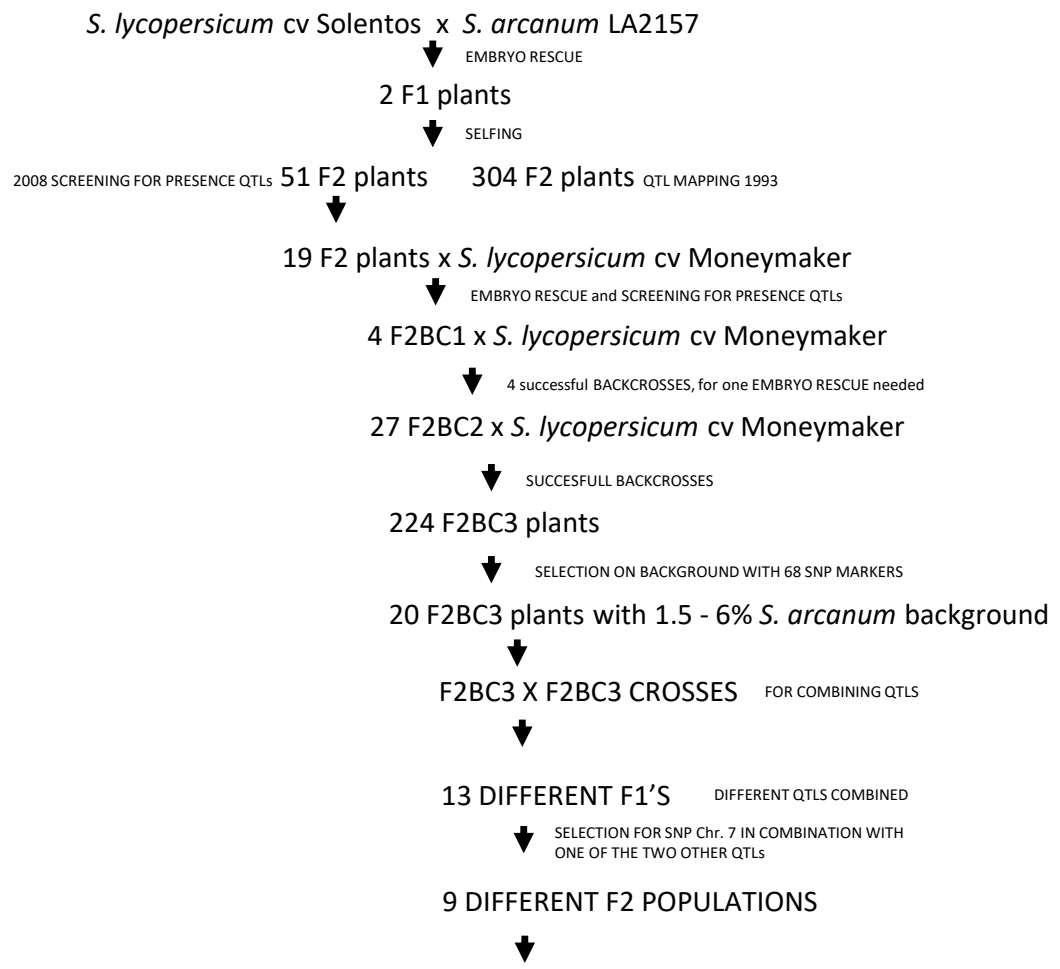

Screening with markers and in vitro disease screening

FOUR RECOMBINANTS

Remaining Fragment Size $211 \mathrm{~Kb}$

Figure 1 | Material development. 


\section{Results}

\section{Marker development and mapping}

We focused the QTL on chromosome 7 since it is the QTL with the biggest effect. The additional effect of the presence of the whole QTL region on chromosome 9 was also determined. To do this, crosses had to be made between nearly isogenic lines (NILs) containing the QTL region on chromosome 7 and lines with the QTL region on chromosome 9. In our laboratory S. lycopersicum cv. Moneymaker and S. arcanum LA2157 were resequenced (MM) or de novo sequenced (LA2157) (Aflitos et al. 2014). Twelve KASP assays were designed between the positions of the known markers TG418 and TG61 on chromosome 7 (genetic distance $30 \mathrm{cM}$; physical region $3.5 \mathrm{Mb}$ ) and eight assays between TG254 and TG223 on chromosome 9 (genetic distance 30 cM; physical region $0.5 \mathrm{Mb}$ ). Eight out of twelve markers on chromosome 7 and seven out of eight markers on chromosome 9 were indeed polymorphic in the KASP-assay. In total $370 \mathrm{~F} 1$ seedlings were genotyped, after screening 127 plants were selected for the in vitro screening. Two selection criteria were used: (1) the presence of a recombination between markers SOL07-538753 and SOL07-35387838 (2) chromosome 9 was homozygous S. arcanum LA2157 or homozygous cv. Moneymaker between marker SOL09-4822 and SOL09-2840894. The 127 plants were divided into three categories based on their phenotypes (highly tolerant, medium tolerant, and susceptible). More markers were added and some of the F1 plants were genotyped again. In this way, the size of the QTL region on chromosome 7 was delimited to the region between SOL071053473 and SOL07-1762987. Plants with no S. arcanum LA2157 genome in the QTL region of chromosome 7 but homozygous LA2157 for the QTL region on chromosome 9 were all scored as susceptible (Figure 2a). Plants heterozygous or homozygous LA2157 for both regions were scored as highly tolerant (Figure 2b). Four recombinants in the region of interest on chromosome 7 were found (Figure 2c). The susceptible recombinants PV131855-32 and PV131850-58 delimited the QTL to the region between position $1223013 \mathrm{bp}$ and $1762987 \mathrm{bp}$. Another susceptible recombinant (PV13185729) delimited the QTL to the region between position $1053473 \mathrm{bp}$ and $1557551 \mathrm{bp}$. The highly tolerant, double recombinant PV131857-36 points to the region between $1345699 \mathrm{bp}$ and $1677474 \mathrm{bp}$. All together this results in a QTL which encompasses the region from $1345699 \mathrm{bp}$ to $1557551 \mathrm{bp}$, meaning a reduction to $211 \mathrm{~Kb}$.

Figure 3a shows that most plants homozygous or heterozygous for the QTL on chromosome 7 but without additional QTLs are highly tolerant (16 out of 18). Plants having both QTLs are always highly tolerant or medium tolerant (Figure $3 \mathrm{~b}$ ) and finally plants with only the QTL on chromosome 9 were evaluated as susceptible (Figure 3c). This clearly shows that the QTL on chromosome 7 is more important and that the introduction of only this QTL most of the times result in tolerant plants. 


\section{Annotated genes in the fine mapped region}

Annotated genes (ITAG 3.2) have been mined in between marker SOL07-1345699 and SOL07-1557551 using JBrowse software. This resulted in 15 annotated genes. The annotated genes were based on the sequence of Heinz 1706 and the cr. Moneymaker is known to be very similar. Allelic changes and possible mutations of the candidate gene in S. arcanum LA2157 were further determined using an inhouse variant annotation tool, the HaploSmasher software. Three annotated genes were predicted to have high impact variants which resulted in truncated or nonfunctional proteins in S. arcanum LA2157 (Solyc07g006620, Solyc07g006630, and Solyc07g006680) (Table 1). Nine genes were in the moderate impact category. These genes of S. arcanum LA2157 are predicted to have different amino acid changes that might change protein effectiveness but not disrupt the proteins or their function. Another three genes were in the low impact category. These genes have a synonymous mutation or splice variant that most probably will not change the protein behaviour (Table 1). The genes in this region could be the starting point for further studies such as functional analysis or differential gene expression.

$\mathbf{a}$

\begin{tabular}{|c|c|c|c|c|c|c|c|c|c|c|c|c|c|c|c|c|c|c|c|c|c|}
\hline & \multicolumn{13}{|c|}{ Position on Chromosome 7} & \multicolumn{8}{|c|}{ Position on Chromosome 9} \\
\hline & \begin{tabular}{l}
$\stackrel{m}{f}$ \\
\multirow{N}{N}{} \\
$\stackrel{-}{O}$
\end{tabular} & 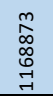 & 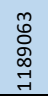 & 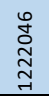 & 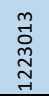 & 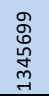 & $\begin{array}{l}\vec{n} \\
\hat{n} \\
\hat{n} \\
\end{array}$ & 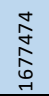 & 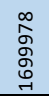 & 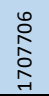 & 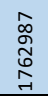 & $\begin{array}{l}\stackrel{n}{0} \\
\stackrel{\infty}{\infty} \\
\stackrel{-}{-}\end{array}$ & $\begin{array}{l}\text { ने } \\
\text { హे } \\
\text { ने }\end{array}$ & $\begin{array}{l}\widetilde{N} \\
\infty \\
\infty \\
\sigma\end{array}$ & $\begin{array}{l}\hat{\infty} \\
\infty \\
0 \\
\infty\end{array}$ & $\begin{array}{l}\overrightarrow{0} \\
\infty \\
\stackrel{్}{ } \\
0\end{array}$ & $\begin{array}{l}\text { مે } \\
\stackrel{0}{\circ} \\
\stackrel{n}{N}\end{array}$ & 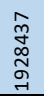 & 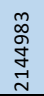 & 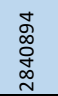 & 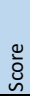 \\
\hline PV131859-09 & $\mathrm{MM}$ & MM & MM & $\mathrm{MM}$ & $\mathrm{MM}$ & $\mathrm{MM}$ & $\mathrm{MM}$ & $\mathrm{MM}$ & $\mathrm{MM}$ & $\mathrm{MM}$ & $\mathrm{MM}$ & $\mathrm{MM}$ & MM & AA & AA & AA & AA & AA & $\mathrm{AA}$ & AA & $\mathrm{s}$ \\
\hline PV131859-20 & MM & MM & MM & MM & MM & MM & MM & MM & MM & MM & MM & MM & MM & AA & AA & AA & AA & AA & AA & AA & $\mathrm{s}$ \\
\hline PV131854-17 & MM & MM & MM & MM & MM & MM & MM & MM & MM & MM & MM & MM & MM & AA & AA & AA & AA & AA & AA & MM & $\mathrm{s}$ \\
\hline PV131854-02 & MM & MM & MM & MM & MM & MM & MM & MM & MM & MM & MM & MM & MM & AA & AA & AA & AA & AA & AA & MM & $\mathrm{s}$ \\
\hline PV131855-27 & MM & MM & MM & MM & MM & MM & MM & MM & MM & MM & MM & MM & MM & AA & AA & AA & AA & AA & AA & MM & $\mathrm{s}$ \\
\hline PV131855-24 & MM & MM & MM & MM & MM & $\mathrm{MM}$ & $\mathrm{MM}$ & $\mathrm{MM}$ & $\mathrm{MM}$ & $\mathrm{MM}$ & $\mathrm{MM}$ & $\mathrm{MM}$ & $\mathrm{MM}$ & AA & AA & $A A$ & $A A$ & $\mathrm{H}$ & $\mathrm{H}$ & MM & $\mathrm{S}$ \\
\hline
\end{tabular}

b

\begin{tabular}{|lllllllllllllllllllll|}
\hline PV131852-06 & MM & H & H & H & H & H & H & H & H & H & MM MM MM & AA & AA & AA & AA & AA & AA & AA & HT \\
PV131852-13 & MM & H & H & H & H & H & H & H & H & H & MM MM MM & AA & AA & AA & AA & H & H & H & HT \\
PV131852-14 & MM & H & H & H & H & H & H & H & H & H & MM MM MM & AA & AA & AA & AA & AA & AA & AA & HT \\
PV131852-15 & MM & H & H & H & H & H & H & H & H & H & MM MM MM & AA & AA & AA & AA & AA & AA & AA & HT \\
PV131852-16 & MM & H & H & H & H & H & H & H & H & H & MM MM MM & AA & AA & AA & AA & AA & AA & AA & HT \\
PV131852-18 & MM & H & H & H & H & H & H & H & H & H & MM MM MM & AA & AA & AA & AA & AA & AA & AA & HT \\
PV131852-19 & MM & H & H & H & H & H & H & H & H & H & MM MM MM & AA & AA & AA & AA & H & H & H & HT \\
\hline
\end{tabular}

c

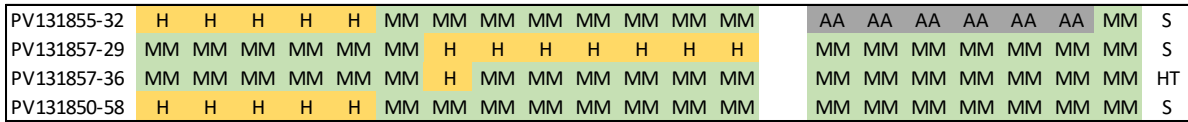

Figure 2 | Marker scores of 13 markers on chromosome 7 and seven markers on chromosome 9. MM stands for S. lycopersicum cv. Moneymaker, AA for S. arcanum LA2157 and H is heterozygous. The disease scores are: S (susceptible), MR (medium tolerant) and HT (highly tolerant). The disease score has been done on two cuttings of the same genotype. 

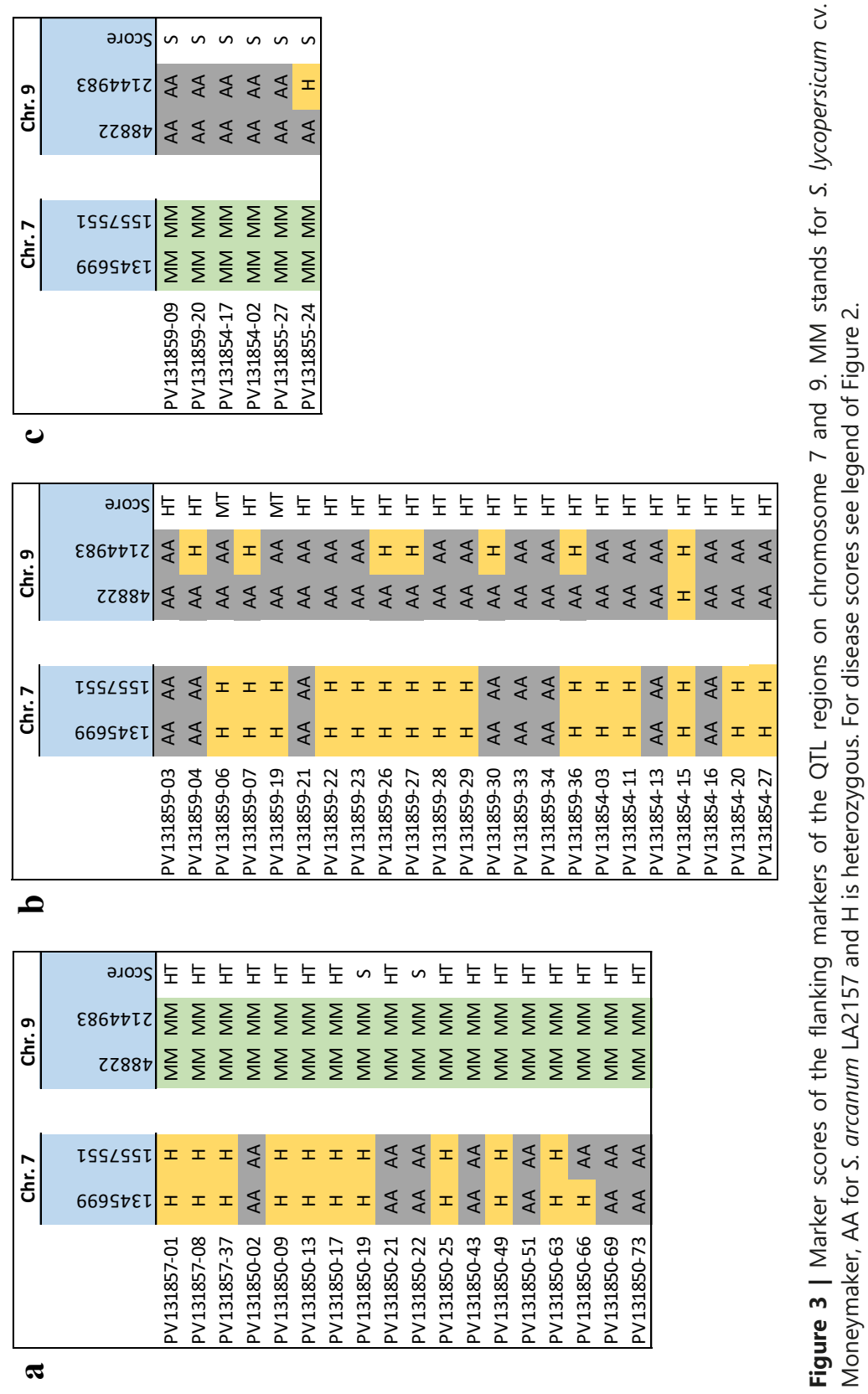
Table 1 | Annotated genes in the region of SOL07-1345699...SOL07-1557551.

\begin{tabular}{|c|c|c|c|}
\hline SGN ITAG 3.2 & Position & Description $^{a}$ & Ontology term \\
\hline Solyc07g006550 & 1370920..1371769 & Ribonuclease S-6 & \\
\hline Solyc07g006560 & $1375314 . .1372873$ & $\begin{array}{l}\text { Hypersensitive response } \\
\text { assisting protein }\end{array}$ & $\begin{array}{l}\text { GO:0033897 - ribonuclease T2 } \\
\text { activity }\end{array}$ \\
\hline Solyc07g006570 & $1383245 . .1385020$ & Ribonuclease & $\begin{array}{l}\text { GO:0033897 - ribonuclease T2 } \\
\text { activity }\end{array}$ \\
\hline Solyc07g006580 & $1387336 . .1406636$ & Diacylglycerol kinase & $\begin{array}{l}\text { GO:0004143 - diacylglycerol } \\
\text { kinase activity }\end{array}$ \\
\hline Solyc07g006590 & 1425532..1425798 & $\begin{array}{l}\text { Kinase superfamily with } \\
\text { octicosapeptide/Phox/ } \\
\text { Bem1p domain-containing } \\
\text { protein }\end{array}$ & \\
\hline Solyc07g006600 & 1448390..1448947 & Glutamine dumper 3 & \\
\hline Solyc07g006610 & $1469104 . .1474046$ & $\begin{array}{l}\text { Tyrosine kinase family } \\
\text { protein }\end{array}$ & $\begin{array}{l}\text { GO:0005515 - protein binding } \\
\text { GO:0004674 - protein serine/ } \\
\text { threonine kinase activity }\end{array}$ \\
\hline Solyc07g006620 & $1480278 . .1487817$ & Receptor-like kinase & $\begin{array}{l}\text { GO:0006468 - protein } \\
\text { phosphorylation }\end{array}$ \\
\hline Solyc07g006630 & 1496758..1494884 & CONSTANS-like protein & $\begin{array}{l}\text { GO:0003700 - sequence-specific } \\
\text { DNA binding transcription factor } \\
\text { activity }\end{array}$ \\
\hline Solyc07g006640 & 1506409..1518012 & $\begin{array}{l}\text { ADP-ribosylation factor } \\
\text { family protein }\end{array}$ & $\begin{array}{l}\text { GO:0005525 - GTP binding } \\
\text { GO:0005622 - intracellular }\end{array}$ \\
\hline Solyc07g006650 & $1523093 . .1516230$ & Xylose isomerase & $\begin{array}{l}\text { GO:0005975 - carbohydrate } \\
\text { metabolic process } \\
\text { GO:0009045 - xylose isomerase } \\
\text { activity }\end{array}$ \\
\hline Solyc07g006660 & $1526859 . .1525198$ & $\begin{array}{l}\text { Glyoxal oxidase-related } \\
\text { protein }\end{array}$ & \\
\hline Solyc07g006670 & $1528452 . .1529837$ & $\begin{array}{l}\text { HXXXD-type acyl- } \\
\text { transferase family protein }\end{array}$ & $\begin{array}{l}\text { GO:0016740 - transferase } \\
\text { activity }\end{array}$ \\
\hline Solyc07g006680 & $1533723 . .1535081$ & $\begin{array}{l}\text { HXXXD-type acyl- } \\
\text { transferase family protein }\end{array}$ & $\begin{array}{l}\text { GO:0016740 - transferase } \\
\text { activity }\end{array}$ \\
\hline Solyc07g006690 & $1558351 . .1547717$ & $\begin{array}{l}\text { alpha/beta-Hydrolases } \\
\text { superfamily protein }\end{array}$ & \\
\hline
\end{tabular}

a Annotated genes from the Sol Genomics Network. Genes retrieved from the Wageningen UR 150 Tomato Genome Resequencing Project (https://solgenomics.net/organism/Solanum_lycopersicum/tomato_150).

${ }^{\mathrm{b}}$ Impact prediction of the annotated genes of S. arcanum LA2157 compared to Heinz using the in-house software, the HaploSmasher. Three impact categories: High, variant has high impact in the gene products causing truncated or loss-of-function protein; Moderate, variant is non-disruptive causing effectiveness of the protein; and Low, variant is harmless and do not change behaviour of the protein. (http://snpeff. sourceforge.net/SnpEff_manual.html).

' Type of allelic variation of the annotated gene $\mathrm{f}$ S. arcanum LA2157 compared to Heinz.

${ }^{\mathrm{d}}$ Type of mutation of the annotated gene in S. arcanum LA2157. 


\begin{tabular}{|c|c|c|c|c|c|}
\hline $\begin{array}{l}\text { Functional } \\
\text { category }\end{array}$ & Gene orthologue & $\begin{array}{l}\text { Impact } \\
\text { prediction }^{\mathrm{b}}\end{array}$ & $\begin{array}{l}\text { Genetic } \\
\text { variation }\end{array}$ & $\begin{array}{l}\text { Type of } \\
\text { mutations }\end{array}$ & References \\
\hline Nucleic acid-related & RNS6_PYRPY & Low & SNPs & $\begin{array}{l}\text { Synonymous } \\
\text { mutation }\end{array}$ & (Kondo et al. 2002) \\
\hline Defence & Q9SWC6_CAPAN & Moderate & SNPS & $\begin{array}{l}\text { Missense } \\
\text { mutation }\end{array}$ & $\begin{array}{l}\text { (Tripathi et al. 2010; } \\
\text { Tripathi et al. 2017) }\end{array}$ \\
\hline Nucleic acid-related & Q41722_ZINVI & Moderate & SNPs & $\begin{array}{l}\text { Missense } \\
\text { mutation }\end{array}$ & \\
\hline Signalling & K4CBC9_SOLLC & Moderate & SNPS & $\begin{array}{l}\text { Missense } \\
\text { mutation }\end{array}$ & $\begin{array}{l}\text { (Snedden and } \\
\text { Blumwald 2000) }\end{array}$ \\
\hline Stress & AT3G24715.3 & Low & SNP & $\begin{array}{l}\text { Synonymous } \\
\text { mutation }\end{array}$ & (Shahzad et al. 2016) \\
\hline Nucleic acid-related & AT5G57685.1 & Moderate & SNPS & $\begin{array}{l}\text { Missense } \\
\text { mutation }\end{array}$ & (Pratelli et al. 2010) \\
\hline Signalling & G7JD53_MEDTR & Moderate & SNPS & $\begin{array}{l}\text { Missense } \\
\text { mutation }\end{array}$ & $\begin{array}{l}\text { (Lemmon and } \\
\text { Schlessinger 2011) }\end{array}$ \\
\hline Signalling & $\begin{array}{l}\text { G7JD52_MEDTR, } \\
\text { AT5G57670 }\end{array}$ & High & Deletion & $\begin{array}{l}\text { Frameshift } \\
\text { mutation }\end{array}$ & $\begin{array}{l}\text { (Tunc-Ozdemir and } \\
\text { Jones 2017) }\end{array}$ \\
\hline Transcription & $\begin{array}{l}\text { B2MW87_SOLLC, } \\
\text { AT5G57660 }\end{array}$ & High & Deletion & $\begin{array}{l}\text { In frame } \\
\text { mutation }\end{array}$ & $\begin{array}{l}\text { (Riechmann et al. } \\
\text { 2000) }\end{array}$ \\
\hline Nucleic acid-related & B9IM33_POPTR & Low & SNPs & $\begin{array}{l}\text { Synonymous } \\
\text { mutation }\end{array}$ & (Memon 2004) \\
\hline $\begin{array}{l}\text { Carbohydrate } \\
\text { metabolism }\end{array}$ & AOAOVOIEZ8_SOLCH & Moderate & SNP & $\begin{array}{l}\text { Missense } \\
\text { mutation }\end{array}$ & (Jaquinod et al. 2007) \\
\hline Cell wall-related & AT3G57620.1 & Moderate & SNPS & $\begin{array}{l}\text { Missense } \\
\text { mutation }\end{array}$ & (Kim et al. 2006) \\
\hline \multirow[t]{2}{*}{ Stress } & AT3G26040.1 & Moderate & SNPS & $\begin{array}{l}\text { Missense } \\
\text { mutation }\end{array}$ & (Černý et al. 2013) \\
\hline & AT3G26040.1 & High & Insertion & $\begin{array}{l}\text { Frameshift } \\
\text { mutation }\end{array}$ & \\
\hline Nucleic acid-related & AT4G25770.1 & Moderate & SNPS & $\begin{array}{l}\text { Missense } \\
\text { mutation }\end{array}$ & $\begin{array}{l}\text { (Dal Bosco et al. } \\
2004 \text { ) }\end{array}$ \\
\hline
\end{tabular}




\section{Discussion}

The fine mapping of the two most valuable QTLs was started by Sen (2014) by using more markers in the original $F_{2}$ population (van Heusden et al. 1999). Even though more markers help in saturating the linkage map and reducing the QTL region, the region was still large (Sen 2014). To speed up the fine mapping process we used recombinants based on crosses between combi-NILs (both the known QTL region on Chr. 7 and on Chr. 9 heterozygously present). In this way, the QTL regions are present but there is no donor background on the other chromosomes. A previous study had shown that resistance is additive and the combination of more than one QTL results in a better resistance (van Heusden et al. 1999).

We decided to fine map only the QTL on chromosome 7 since it confers the highest resistance level. Fine mapping the QTL region on chromosome 9 was difficult because there was no recombination detected in this QTL region. This was unexpected since this region on the chromosome was expected to have higher levels of recombination. This could be due to the different chromosome structures of the two parents (Yang et al. 2014c) or an inversion of S. arcanum LA2157 in certain region(s) of this chromosome (Wolters et al. 2015).

Although we could not test as many plants as we wanted due to technical reasons, the results are clear. The final QTL region on chromosome 7 was only $211 \mathrm{~Kb}$ in size and this region was essential to obtain tolerance. Figure 3 shows that the additional effect of the QTL on chromosome 9 is not big. Only two plants were scored susceptible although they were LA2157 in the QTL region on chromosome 7. We are not sure what the reason for this is; maybe an experimental mistake or a special phenotype of these plants. Exceptions were not found when both QTL7 and QTL9 were present (all plants were highly tolerant with two plants being medium tolerant). Our results show that in a relatively easy way the QTL region can even be more delimited. This can be done by extensive genotyping or even sequencing the QTL region of the four recombinants. Depending on the sites of recombination this will delimit the size of the QTL region even more. Phenotyping the offspring which contain the introgression between marker SOL07-1345699 and SOL07-1557551 should confirm the results. Overall, we have shown that in a single nearly isogenic line with only $1.5-6 \%$ of the wild relative tolerance to $\mathrm{Cmm}$ depends on a relatively small region on chromosome 7 .

A big challenge that we were facing in the fine mapping was the limited space we have available in our quarantine greenhouse. We could only work in a small quarantine compartment that could barely fit 100 plants. In such a setting, crosscontamination from one plant to another can occur when plants are too close together. Even though we have highly tolerant plants, $\mathrm{Cmm}$ can infect the plants 
systemically (vascular infection) and externally (local infection). The virulence factors used for $\mathrm{Cmm}$ for each type of infections are different (Chalupowicz et al. 2016). Plus, the severity of wilt symptoms depends on many aspects. Previously, the F2 plants that were tested for identifying the QTL was done in a large compartment, and we did vascular infection for the disease test (van Heusden et al. 1999). We do not know whether our NILs are also highly tolerant towards the local infection, so to overcome this problem, we developed a disease screening assay using an in vitro approach (Chapter 2). This protocol functions very well to distinguish our two parental lines; the in vitro screening showed distinct differences in wilt symptoms between cv. Moneymaker and S. arcanum LA2157. The scores of the in vitro scoring and the greenhouse scoring were comparable for cv. Moneymaker and S. arcanum LA2157 using the optimised protocol we developed (Chapter 2). The method might need some minor adaptations for different parental combinations and might also give variable results depending on differences between the different resistance mechanisms.

With the in vitro screening, up to 1000 screenings can easily be done in one experiment and the screenings become more reliable due the fact that more cuttings can be made of a single genotype. To our knowledge, this is the first time that such a method has been used to screen for $\mathrm{Cmm}$ symptoms in a fine mapping study.

The defence mechanisms in tomato plants against $\mathrm{Cmm}$ are still unknown, our original QTL analysis and studies done in other populations show that the resistance mechanism look complex (Emmatty and John 1973; Kuriyama and Kuniyasu 1974; van Heusden et al. 1999). It is still unclear what genes are involved in giving resistance. Wilting is not caused by xylem plugging by bacterial cells as Cmm100, cured of the virulent plasmids, still colonized the plants but did not cause wilting symptoms (Meletzus et al. 1993; Savidor et al. 2012). Also in our case the number of the bacterial titre did not correlate with wilting symptoms as tolerant accessions still contain considerable amounts of bacterial titre (Sen et al. 2013). Thus it is highly possible that the tolerance in S. arcanum LA2157 might be due to changes in the immune system against $\mathrm{Cmm}$, its morphology or metabolites (Shinde et al. 2017).

Studies on differential gene expression can be done to look at the up- or downregulation of genes in the small fine mapped region. Similar studies have been done but no genes were identified that could be connected directly to resistance in S. arcanum LA2157 (Balaji et al. 2008; Lara-Ávila et al. 2011; Savidor et al. 2012). The advancement of technologies like RNA-seq in combination with very well defined nearly isogenic lines might help to overcome this problem. Further 
breeding will make it possible to remove all, not tolerant related LA2157 genome in the nearly isogenic lines. In our lines there is still $1.5-6 \%$ LA2157 present. A functional analysis of genes in the very small fine mapped region can be done to see if silencing, knock-outs or overexpression of the identified genes improve the resistance in susceptible cultivars. We have made a big step in the development of plant material most suited to do further studies. We showed that only a very small region on chromosome 7 of $S$. arcanum LA2157 induces resistance and that the possibilities to clone (the) tolerance factors are promising. Further development and multiplication of material will make it possible to study the effects of this region under greenhouse conditions. This might also give indications how general applicable and durable the resistance is. 


\section{Acknowledgements}

We would like to thank Nunhems, vegetable seeds of BASF, the Netherlands for financial support and their molecular marker analysis and Universiti Putra Malaysia and Ministry of Higher Education Malaysia, Malaysia for financial support. 


\section{Supplementary material}

Table S1 | All KASPar markers used. Markers are named based on the physical position of SNP between Heinz and Solanum arcanum LA2157.

\begin{tabular}{|c|c|c|c|}
\hline Marker & Position (bp) & Chr. & Marker used for \\
\hline SOL07-538753 & 538753 & 7 & $\begin{array}{l}\text { Screening for } \\
\text { recombinants }\end{array}$ \\
\hline SOL07-681821 & 681821 & 7 & $\begin{array}{l}\text { Screening for } \\
\text { recombinants }\end{array}$ \\
\hline SOL07-1345699 & 1345699 & 7 & $\begin{array}{l}\text { Screening for } \\
\text { recombinants }\end{array}$ \\
\hline SOL07-1557551 & 1557551 & 7 & $\begin{array}{l}\text { Screening for } \\
\text { recombinants }\end{array}$ \\
\hline SOL07-3459000 & 3459000 & 7 & $\begin{array}{l}\text { Screening for } \\
\text { recombinants }\end{array}$ \\
\hline SOL07-7464234 & 7464234 & 7 & $\begin{array}{l}\text { Screening for } \\
\text { recombinants }\end{array}$ \\
\hline SOL07-22385907 & 22385907 & 7 & $\begin{array}{l}\text { Screening for } \\
\text { recombinants }\end{array}$ \\
\hline SOL07-35387838 & 35387838 & 7 & $\begin{array}{l}\text { Screening for } \\
\text { recombinants }\end{array}$ \\
\hline SOL09-48822 & 48822 & 9 & $\begin{array}{l}\text { Screening for } \\
\text { recombinants }\end{array}$ \\
\hline SOL09-86887 & 86887 & 9 & $\begin{array}{l}\text { Screening for } \\
\text { recombinants }\end{array}$ \\
\hline SOL09-629861 & 629861 & 9 & $\begin{array}{l}\text { Screening for } \\
\text { recombinants }\end{array}$ \\
\hline SOL09-756693 & 756693 & 9 & $\begin{array}{l}\text { Screening for } \\
\text { recombinants }\end{array}$ \\
\hline SOL09-1928437 & 1928437 & 9 & $\begin{array}{l}\text { Screening for } \\
\text { recombinants }\end{array}$ \\
\hline SOL09-2144983 & 2144983 & 9 & $\begin{array}{l}\text { Screening for } \\
\text { recombinants }\end{array}$ \\
\hline
\end{tabular}


Sequence $\left(5^{\prime}->3^{\prime}\right)$

GGATCATGCAACAATATCACAGCAGCAATGCTAGTGATCGGTACTCTTACAGCGTTAAGGACACCAGCCAAGACAG TGGATGAGAGGAACACAAC[T/C] GCGGTGGCTCCCAACACTCCCAACTGGAAAGTGATAGTCCCCCAAACGATAACTGAGTAATACGCGTTTTCCCCACCCTTGAATGTACTTGCCTCG GGAGACGGCCAACGACTCCTTTATCACCTACCAGTCCATCACCATCAACACCTGTACAGGATACATCTGCAGAAG AATTGTTGTCCAGAAAGATG[A/G]CAGGCAATAGGTTGGCAGAATCTTTATGGCCCTCAACAATGAGGAGTCTGAGTGTTTCTTTTCAGTCTGATTCATTTTCCTTACCTGTTAGTAAGA TCTCAGTTACATCAGTTCCTCACGAGCTCGTCAGCTCCGCGGATGACACTATCCCATTCAAGCCAATTGAATTCCTG TTCGCTCGACGTGAGATC[A/C]AGAAAACAATCAGCAAGAAATTCTCCATGGTCATCGTCGATGACAAGGTCTCCATCGAAGTTGAAGACGAGATAGTAGACCGGATCCTTGGTGGCT

TTGAGTTTTTTTTCAAAGTCAAAATCAAGATTTGACAATAAGGGTGTCAATAATTGTAGGCTGTTGTGGGTGGAT GAGAAAGGGGAAATGGAATT[A/G]CTGAGGAAATTAAGCAGAGGGTGTTTCAGAAATAGTCTTAAGAAGGGTCAGAAGGTTAAAATTGAGTCAGTTAATGATGGTGAAGATGTGTTTGAT GCAATCCCAGATATATTCTTCTCCAAAGTCACTAAATCAAGCTCTGGTCGCTCCAAACTCTTCCCAGAAGGGTCACC AATTCGACCCGTAGCACC[T/C]CCAATAAGCCCCACAGCATTATGCCCACAACGTAAAAACCAAGAAAGCACAATTATACCCAAAAGATTACCAAGGTGTAAGCTTTCAGCAGTCGGG

CTATAATCACCGTAGGATCGATGTATATGAATTGAACTGGGTTAAAACCTTCCTCCATGCCACAAAGTTCCCAGA ACCTCCACCACGATAAGTTCT[A/G] GTATCACAGAAGTCGAAGTTGAAGAAATAACTATTTTGGGAGCTTATTGGAAGTTTTATGAATTGTGATAACCACTTAATGTAAGTTTCTATAA ATTTCAGCTTTAAAATATTCAACAGCAGTACCAGTGATATTTGTGTCAGCCCTTCAGTATCACGTATTCCCTGACAAGT GGGTTAACCTTTATAG[A/G]CCTTTGTGGCTTGTCTCAGCCGTTGTGAACTGTCTCTATTCATTTTATTGGGATCTGACAAGAGATTGGGACTTAAGGTGAGTGAATTAAGTTTTA

AAACTTAAAGCTTCTTATAAAGCGACTACTGGTGGAAAATTTTCTGATGCACTTAGACTATTCCTGAGCATCCTT CACACCATTCCTCTGATTGTG[A/G]TTGAGTCGAGACGAGAAGTGGATGAAGTAAAGGAATTGATTGTCATAGTGAAAGAGTATGTTTTGGGTTTGCAGATGGAGCTTAAGAGGAAGGAA TGGTTCAGTTACACCAGATTTGACCCTGGGAAGGTTGTGGCTGTGGAACACTATGAAGATGAGACCCCAGATGA CACCGAAGATGACGATGAGGG[T/G]GGAAAAGAAGCATCTCTTGGGCGTTATTGTGTCTTCTGTAGTAAACTTGATTTTCAGAAAAATGAAGCAATGCATGATCCAAAATGCACTTGTCAT GCAAGAAGAAGACCCATGAAGAGTTGGATGACTTACCTCCTTATCAATATATTACACAGGAGTACAACCCGGTCAG TAGGCAAAAGGGAAGTAAG[A/G]AGGCCAGCAACCGTACTAGATATGTTTTGCTTCATCTGCTCAAATGTAACTCTATTTTCATCAACCACGCGTCCTGTCAAGTTTTTCTTATACTCT

TTTCTTTTGTAGGAGAGCTGCCATTCTTCTTTGTTTCTATTATTAAGGTGTATAAAATTCAGCTATGTAGGTTCTCATTA CATTGTACTCAAAAA[A/G]GCATAAAGTTCTTGCTCATGAATAAAATTTTACTTTCTATTTCTCTTGAAAGTTCATTTGCTGGTCTTCTCAAAAGTTCTAAAGTGTATTCTTTTC

TGCTGCAGAATTTGTCTGTTGCAAACAACCAGTTAAGTGGAAAAATTACAGAGGAAGTTGGGTTGATTATGTCATT AGAATTTTTGGATCTTTCC[A/G]AGAACATGTTTAGTGGTTCTATACCCTCTAAGCTGACTAGTTTAAAGAACTTAGTATCTCTTAATCTTTCTTTAAATAGTCTCGATGGAATGGTTC

GAGGATGCTATGAGTGCTCCAATTTTGGAAAGAGAGTACATGCAAGGCATCCTAATCAGTGAGGTTGTCTTAAATG AGCGTTTTTCACCACCATC[T/C]GGGAGAGCCAGAAGGAGGCAAAAGAGATTTGTAAGGGAATTAAAGAGACCAGGTGAAGCAATCATAAAGGGTCACAGGAGTTATGATTTAATGCTA AACACCAATATACAGGGTGCATTAATGGCTGTTAGGGATTTAGTTCAGTTCATGGGAAGTATTAAAAGTGGACTATA CAATTCTGTAAGGAGGTA[T/C]ATTTGTAAACTTGAGACTCCTAGTTCTGTTCAGGTGACTTTGTCTTCTCAGACAGATGAGAAGTTACTGATAACTGCAAGTGCAATTACTTTAGCA 


\begin{tabular}{|c|c|c|c|}
\hline Marker & Position (bp) & Chr. & Marker used for \\
\hline SOL09-2840894 & 2840894 & 9 & $\begin{array}{l}\text { Screening for } \\
\text { recombinants }\end{array}$ \\
\hline SOL07-778336 & 778336 & 7 & Fine mapping \\
\hline SOL07-983528 & 983528 & 7 & Fine mapping \\
\hline SOL07-1104812 & 1104812 & 7 & Fine mapping \\
\hline SOL07-1223013 & 1223013 & 7 & Fine mapping \\
\hline SOL07-1890817 & 1890817 & 7 & Fine mapping \\
\hline SOL07-1919491 & 1919491 & 7 & Fine mapping \\
\hline SOL07-2087565 & 2087565 & 7 & Fine mapping \\
\hline SOL07-2354528 & 2354528 & 7 & Fine mapping \\
\hline SOL07-2870461 & 2870461 & 7 & Fine mapping \\
\hline SOL07-3078229 & 3078229 & 7 & Fine mapping \\
\hline SOL07-3207372 & 3207372 & 7 & Fine mapping \\
\hline SOL07-3398993 & 3398993 & 7 & Fine mapping \\
\hline SOL07-3360966 & 3360966 & 7 & Fine mapping \\
\hline SOL07-1000753 & 1000753 & 7 & Fine mapping \\
\hline
\end{tabular}


Sequence $\left(5^{\prime}->3^{\prime}\right)$

GCAACAATAGATGATCTTCTCTCCACTGTATATGTTTGGCATGTCCAAAACCCGCATGCTGGTGACGTTTTGGTTGAT TCTATGAAAAGGTATTA[T/C]GGAAAGTTACCTGCAGTCGTTGAACTGTTTAGTCAAGTTGGAGCACAGGTCGGAGATGATTACTATCACATGATGAGAGATGATGTTGTAGTTCCT

TATCAATCGAGTGAGGGCCCTTGAAGTAGCTAAATACTCTATTGCAGGTTCATAGTATGACAAAAGCCACAC ACAAAGGCATGTCTCATAGAGA[G/A]GCTGTTTAAAGGAAGAAAATAAAATCAGGAAAAAGAAAGAAAGATATATTCTTTTGTAATCTAGCTTCAGGAGGTGGTTGATAGGTTGAATGA

AGGACAAAATAACGTCTCTGCCCACAGACCTGAAGATCTCCGAGTAATTTTTTGTTAAGCACAGGAGCAGCTGAG TAAGGCGAGAGCCCTCGC[A/G]CACCAGTACAGGCTTCCTGCTCCACTCCTGCACTGGTATTTGTGAAGTTACTTAATTGCTATTCAGAATCTTCGTAAACTTCACCATCATCAGA

AAACTTATACTAATCAAAACAAAAAGTTACACATTTGATCACTCAGACAAAAATATTTTACTTACAACTACTAGCC AATATACATATACTATATATA[C/T]ACTAATTATACAATTGTCGATTTATCTTTTTGGGTGAACGACTATTTAAGTTAATTTCTATATTTCATTTTTTTCATTCAAGATTAATTTTTTA

TTAGATAGACTGAGCAACATATGATTTTTCATTGATGGAGGTAAATTTTGTTGTTATCATTTATCACTGAGGTAGTAC CTTTGTCGCGAATGGT[T/A]TATTGTTTTTACCTCTCAGAGTGTCACGATAGAGTTACGAATGAGAAATATGTAAACATACTATGCGGAGTTACCCAGTATCTTTGTCTGT

CTGTTTCACTTTGGTACCGACTGGAAATTTCTCCTTGTTTTAGGTTGGCGATTTGGGGCTATCCAAAGTGAAATGT CAAACACTTATCTCAGG[T/C]GGTGTACGAGGAACTCTTCCCTGGATGGCACCAGAACTTCTCAATGGAAGCAGCAGTCTTGTCTCTGAGAAGGTATAAAAAAAAATTATTTTGT

GCCAAATTTGCAAGGAGAAGTATTTTCAGGACTAAAGAGAAGTGGATCAAAGAAGTTTAATTGGGCAAAAATG ATTTGGAAATCTCAAGAACA[A/G]GATGAATGTTCAATTTGCTTGGATCAATTCAAGATTAGTGATAACTTAATGCAATTGACATGTGCCCACAAATTCCATTCCAAGTGTTTGGTGC

ACTTAAAGCAGGAACCCCTAGTGCAAGGAACAGCAAGAGCTTAGATGAAGAATTGTGAAGCAATGCACTGTAGA CTTCTGTATACACTGCAGC[A/G]CTGAGCCCTCCATAGCCTTTAAGAATCCCAGCAACCGTGCCTCGGCTTAGAGGAAAGTTTCTCATATTAGTCACAAGCACAGTTGTGCTGAACC

TTGACGTAGTCTCTAAATGATTTTAACCCCGCGAGGTAATTTGACTCTTAATCTTTTCCACTTGCTCTTAGCCAAGG ATGGATGCAAGCTGAG[T/C]ACATGTTCTGGCATGAAATCATGCCTTGTAATTATCCCCACAACAGGTATCCTCTGCAGACAAGAGAACCACAATTTCTTGATTCAGTTCAAGA

GAATAAATGAAGTTGAACATTCATGAATATATAGTACCTCAACAGGAGTTGCCAAGATCAGAAGATACTGGATGGCC TCCACGAAAATTCCAG[A/G]TTTGACTTTGGCTAGGCCAACAACGCATATAGCTTGTTCATCGCCACTATATTCAGGACAGTGACCATCCCTAAACAAAACATGATACCATCAA

GGAATTAAACAACTATAACATAACCCCATTTAAAGTACAATGCTGTTGATATAACATGAAAAATTTCTGGAAATCTCA CAATATGCATCAATC[T/C] GAAAGGTTTTCATATAGAAGGCTGTGAAAATGATGCATAGCCTTCTCAACTTGTGGCGCGTAGCGGCCAGAGCAGTAAGCCGGTGATTCAAGCC

AACAGCCAACTCAACAAGGTATGTCCAACTAGCGCGATCGCGGCTATAACGGCCATAACCATCATCTTGCTTTGGG CTTGAAGAAATTTTTGAATAGGGAAGTTCA[A/T]TGCATAGGCAAATAGTTGAGGTATCATCCAAATAGAAAATTTACCAGCCCATTTTGCTATGTCCATAGGCTGGCCAATGAATAGTAGAATTTGAGTTGCAAATAAG TCCTCACTTCTTTTTCCCGCAACTACAAAAACTTAACCTAAAACCCTAAATTACTCTTTTAGCAGAGGCGATCAA TGGCTTCCATCGAACAAATCCAAAATGGTTC[T/G]CTTGTAACGCATGAATTTGAAGATTCTCAAGTGAATCCGGAAGAAGCAGACGGAGGTTTGGTGAAAATCGGACAAGAGGTTTCGATATTGAAGCCGAAATGGCCTGG GCTGGAATAAGTCAATTATAATTCTGACGTAAATTGGAGCAACTTCACCGGCCAGTTAGGGTGATTATCACT TAGGTGAAGAAGAAGTAGTGC[T/C]GAACGAATTTGAATTCTGGTCGGATTGTTTCGAACTTGGCTACAATGAGTTTGGGCTTGTTGGGGACTTTATAAGGTTCGAATTCTTCTATCCA AATCACAAAAGAAAAAGGGAAATCTCTTCAAAAACCTGCCTCTGCAAGTAATCGAAACGGAAACTACCAGCT ATCATCCTTATTTATTTTAACATTCTCAACTTCGATT[T/C]CAACTCATGTTGATTGGCTTAATGACTTGGGAGAGTATCTCGATGCAGGAAAGATGTGTGGTACGTGAAATTGGCTCAGCAGTGGACTACAGGAAGTTGACTTCGGTATAGTATTTAAC 
$62 \mid$ CHAPTER 3

\begin{tabular}{lccc}
\hline Marker & Position (bp) & Chr. & Marker used for \\
\hline SOL07-1031074 & 1031074 & 7 & Fine mapping \\
SOL07-1047255 & 1047255 & 7 & Fine mapping \\
SOL07-1053473 & 1053473 & 7 & Fine mapping \\
SOL07-1168873 & 1168873 & 7 & Fine mapping
\end{tabular}

SOL07-1189063

SOL07-1222096

SOL07-1677474

SOL07-1699978

SOL07-1707706

SOL07-1740467

SOL07-1762987

SOL07-1783593
1189063

1222096

1677474

1699978

1707706

1740467

1762987

1783593
7

Fine mapping

7

Fine mapping

Fine mapping

Fine mapping

Fine mapping

Fine mapping

7

Fine mapping

7
Fine mapping 


\section{Sequence $\left(5^{\prime}->3^{\prime}\right)$}

CACACCTAAAATTGGAAAAAAGAAAAAACAGTACATCATCATTTTATAAGAATCCTTATGTTTACTGGAAGGAA ACACAGTACTACAGGAATGTACCAAGTGCATAAAAGCTAA[G/A]GCACAAATGTCAACTAACAAAAACACTTACTTGTCACGATCAACTCCAGGAAGGTCAGCAGCAATAAGAGCCATTACTCCCATACGGTACATGTGATCAGCTATAGACTCAGG

CATAAAACACAAACCAAACATAATTCCTTAAAACACAAATCACAATGATCAAACTAGTAGTACAAAGTTACCTTACATTAAGACTTCACCATAATATTTATTACTTAATATTTTIC/T]TTGAGGTAGTGAATTTTTTTTCACTAGTGAAATATGACATGCATGCATGGATTTAGTTGCCACCATTTCCTCCACCATACCCACTACCCTGTCCACCTCCATATCCACTACCACTGGA

CATTTCAGGAACCAAGTTAGGTGGATATGGAAGTTTGATGAACTAGATTATCCTATTGATGGCATAGATGAGGTTGTT AGACCTAACAGTTTTGCTAATGCTGCACCATTTTGTC[G/A]AATGATGTATGTTAAAATTTTGACGATTGTATAAACTGCAGATTAGATTCCAAGTCCATAATGTTAGTTATCCATCAATGCCACTGGAGCAAGATAAAGATTCAAAACCATTTG GCCGATGGTCAATTGACATGAATCTACTTCCATATCGTCACCAGTACATAAACCCTTAAGATGAAATGTCATTATAAT GCTAAATCGATGAATGAGCATCAACTAGACCAATAT[A/T]TGCTGAACTGGACTCACCTAGCAATCTTCACTATACTCATAAGAGGGAGGCATAAGAATGGTGAAGGAAGGGGACGTGGTTGTTTTTCTGGACGAGTACTTAAAATCTCCTCCA

AATCAGCAATTATCCCTTCTTCAACCACCTCCACCCCCATTTTCTACTCATGATTCTAGTGGTGGTGGTATTTTC AATTTGAATAACAAGGTTAGTCCAAGTATACTTCTAGT[A/C]ATCATTATTCTTGCTATTATCTTTTTTATATCTGGTTTGCTTCATTTAGCTGTAAGATGTCTATTAAGGCCATCAAATAGAGATCCAGATGATTTAGATAATGTAACAGCCCTTCAAGG CTTCCACCGACGTCATCGACGTCGCCACCACCATCGATTTCCGGCGACCCCAACGTCATCGTTTGATTTGCCTTGT GTTAGTTATTGTGGGTCACAGCAATCTG[C/T]TAGGGATTGTGCGATTTGCTTGGAGGGATTTAAGGATGGAGAAATTTGTAGGAAATTACCTGATTGTGGACACCTTTTTCATGTGAAATGTGTGGATTCTTGG CAGTCAGAAAAAGAAATTGAACCCCATGAAAAAGGTCACAGCTCCTTTTTTTCTTGCAGTGTTTCTGTGGAGCC TTTTGGTTCAAAACAACCTTCAGGACACCTGGAT[T/A]TTTCATTATCAGAAGGAAGATATCACCCTCAGCTTTTGAGACTAGAGTCTCGCTTGAATTCAGACAAGCAAAAGAGTACAGATACTCCGAAGGATGGAGACACTGATGAAAT TGAAGTGTATTTCATTTAATTGTGGTTCTTACCTTTTGATAAAGAATGTGCCAGCTCTTATATGGACTTTAAATGTTCTT GTAGGTATACGTAGATTCTTTGGTCAAGAAGGC[A/G]TATGATAATTGGAATCAAGTCGTTGAATATGATGGCAAGTCATTTCTGAACATCAAGCAAAATCAAAATCCAAGCTCTTCTAGGAACGAGCTTCCTGTTGGGCCAGTGGATTACCC TGATGAACAAATTTCCTCCAGGTTTTCGATTTCATCCTACGGATTATGAGCTAATTAAACATTATTTGGAGAGGAAGC TTGCTAATTTGCCTTTGCATCC[C/T]AATAAGATCTATGAGTTGAATATTTACAAGTATGAGCCCGACACGATTGCTGGTACGTATAAATTTTGAATCCGTCTCTTTGATTATATTCATGAGTTTTGTT

AAATTATTTTAATTTCATAAAGTAGGAAAATGAACATGACTTGTTTAGTTAAAGTTAAAAGCACATGTTCCTAGTCA AATTATAACTAAAAAATGGAAATAATTAATTAAAAT[A/G]ATAACTATTAAACATGACATATATATATATATATATATTATATTATGGTACTATAAATTAGGGGCAAGGTGCACATAGAAAATGAAACATGTTTAGGACTACATGGTACAACATGAGTT

GAGACAACAACGATGAATATTTTGTCGATTTTGATGGTGTAGACAAGGAAAGGATGGAGAGAGCATTAAGAATA GCCATTATCAACCAGCTACAGACATAATG[C/T]AGGAAAGAGAGGAAAATTGGATAGTTAAATCCGACTGTAACAAGAACCTGGAAGAGAAAAGAGGAAAGCAAATGTTACGATCTCTAAAAGATTTAATATCTACTTT CAAGCATGGTTGAGTCCATTGGTGTTTTTAACTTGTTGATCCTCCGAAACGATCTTCTTCCAGAACCAATGCTTTTCCCAAAGACGCATCATCTCTTCAATCGGAACTCCCTT[C/T]GTTTCAGGCAAGAACAGATAGATGAATATCGTCATGACAGCAATCCAACAGGAGAAAAACAGGAAAATCCCGAACCTCATAGCACATAAAAGTGAGAGGAAAGACTGTGCTATC 



\title{
CHAPTER
}

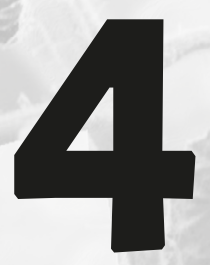

\section{Exploiting the potential use of susceptibility genes} against Clavibacter michiganensis subsp. michiganensis symptoms in tomato

\author{
M.M. Mohd Nadzir, E. Koseoglou, M. Appiano, J.C. Rivas Baeza, \\ R.G.F. Visser, A.W. van Heusden, Y. Bai
}


Clavibacter michiganensis subsp. michiganensis $(\mathrm{Cmm})$ is the causal agent of bacterial canker in tomato. $\mathrm{Cmm}$ occurs worldwide, can lead to economic losses and can be transmitted via seeds. For these reasons, it has been classified as a quarantine organism in Europe and many other countries. No resistant/tolerant cultivars against $\mathrm{Cmm}$ are available on the market. A new alternative for breeding cultivars with enhanced levels of resistance/tolerance is based on silencing susceptibility genes (S-genes). Susceptibility genes are plant genes, whose impairment leads to durable, broad-spectrum resistance. Four candidate S-genes, CESA3, CESA4, PMR6 and WAT1, were tested using the virus-induced gene silencing (VIGS) assay to see the effects on the infection of $\mathrm{Cmm}$. The results showed that silencing the WAT1 orthologue in tomato leads to higher tolerance against the bacterium.

$\widetilde{\sigma}$ Keywords: Cmm, Gram-positive bacterium, Solanum arcanum, VIGS, WAT1 


\section{Introduction}

Canker of tomato caused by the xylem-invading Gram-positive bacterium, Clavibacter michiganensis subsp. michiganensis, is considered to be one of the most economically important bacterial diseases of tomato, as yield losses can be severe (Eichenlaub et al. 2006; Sen et al. 2015). In some years up to $70 \%$ yield reduction has been reported in North Carolina (CABI and EPPO 1999). To regulate the spread of this harmful organism, $\mathrm{Cmm}$ has been classified as a quarantine organism in the EU and other countries (EPPO 2016). The bacterium was first reported in the USA in 1910 and since then it has spread throughout the world causing important losses to both glasshouse and open field tomato crops (Strider 1970; Kawaguchi et al. 2010). The most prominent symptoms of the disease are unilateral wilting of leaflets, formation of cankers on stems and petioles and bird-eye like spots on the fruits. Ultimately, the whole plant wilts and dies (Gartemann et al. 2003).

Levels of tolerance to $\mathrm{Cmm}$ have been found in several wild, crossable species of tomato (van Heusden et al. 1999; Francis et al. 2001; Coaker and Francis 2004; Sen et al. 2013). According to previous studies done in our group, the best source of resistance originates from the accession S. arcanum LA2157. A quantitative trait loci (QTL) analysis showed that the resistance is both polygenic and additive. The QTL on chromosome 7 was most prominent (van Heusden et al. 1999). So far, no $R$-genes against $\mathrm{Cmm}$ have been identified and no resistant/tolerant cultivars are on the market.

Traditional resistance breeding is based on the introgression of $R$-genes from wild species into elite cultivars (Gawehns et al. 2013). These $R$-genes typically encode for intracellular receptors of the nucleotide-binding leucine-rich-repeats (NB-LRR) family, which recognize specific products of the avirulence (Avr) genes of the pathogen. This recognition leads to a complex signalling cascade resulting in resistance, mostly exhibited as a hypersensitive response (HR) (Jones and Dangl 2006). However, the resistance can easily be overcome by the pathogen due to the highly race specific resistance that $R$-genes confer (Pavan et al. 2009).

An alternative approach to breed for resistance is based on the impairment of susceptibility genes (Pavan et al. 2009). Susceptibility genes are plant genes used by the pathogen for its proliferation and promotion of the disease symptoms (Gawehns et al. 2013; van Schie and Takken 2014). Loss-of-function of susceptibility genes is expected to lead to a more durable, broad-spectrum resistance (Pavan et al. 2009; Sun et al. 2016b). However, a major drawback of using S-genes in breeding is that these genes do not merely exist for the pathogen only, but they have evolutionary conserved functions in plant development. Therefore, impairment of such genes could potentially lead to adverse pleiotropic effects (Pavan et al. 2009). Nevertheless, 
successful applications of impaired S-genes in breeding without severe pleiotropic effects are known. The most well-known example is the MLO gene in barley (Buschges et al. 1997). Since its discovery in barley, $M L O$ has been identified and characterised in several other species (Consonni et al. 2006; Feechan et al. 2009; Zheng et al. 2013; Pessina et al. 2014; Acevedo-Garcia et al. 2017), enhancing the hypothesis that $S$-genes are conserved across plant species. The natural loss-of-function mlo allele has been used in breeding for the last 40 years. It provided broad-spectrum and durable resistance against all known isolates of barley powdery mildew (Jørgensen 1992; Buschges et al. 1997).

Due to the complex genetic background of resistance to $\mathrm{Cmm}$, the use of traditional breeding approaches to obtain high levels of resistance is very challenging. In this paper, we studied the potential use of silenced S-genes against $\mathrm{Cmm}$. Arabidopsis S-gene orthologues in tomato, Cellulose synthase 3 (CESA3), Cellulose synthase 4 (CESA4), Powdery Mildew Resistance 6 (PMR6) and Walls Are Thin 1 (WAT1), were identified through an in silico analysis and virus-induced gene silencing (VIGS) was used to silence the identified genes and to study the effects of silencing on the tomato- $\mathrm{Cmm}$ interaction.

\section{Materials and methods}

\section{Identification of candidate $S$-genes}

The identification of candidate $S$-genes potentially involved in tomato$\mathrm{Cmm}$ interactions was done in two ways. Firstly, candidate S-genes located in the QTL region of chromosome 7 and chromosome 9 were chosen (van Heusden et al. 1999) and secondly S-genes were chosen based on a literature study (van Schie and Takken 2014). These genes are CESA3 and PMR6 (Table 1). The genes from the literature study were filtered based on two criteria: (a) genes known to be involved in interactions with vascular pathogens in Arabidopsis thaliana and in other Solanaceae (b) the protein variation between Solanum lycopersicum cv. Moneymaker and S. arcanum LA2157 (referred to as Moneymaker resp. LA2157). The genes for this category are CESA4 and WAT1. In order to identify the orthologues and homologs, the Arabidopsis protein sequences, obtained from TAIR (https://www.arabidopsis.org/Blast/), were used as a query on the Solanum Genomics Network (SGN) database (https://solgenomics. net/tools/blast/). For each of the $A$. thaliana genes, the homolog with the highest score and lowest evalue was selected from the list of homologs provided by SGN. Protein variation between Moneymaker and LA2157 was determined using the inhouse HaploSmasher software developed by Plant Breeding, Wageningen University \& Research, Wageningen, the Netherlands (http://xapps.plantbreeding.nl:5001). 
HaploSmasher is a prediction tool which predicts the effects of genetic variants of the annotated genes in tomato. Differences in allelic variations between LA2157 and Heinz 1706 (with which Moneymaker has high similarity) were determined based on filtering the impact prediction starting from High impact (variant causes disruptive change in the protein), Moderate impact (variant causes a non-disruptive change in the protein) to Low impact (variant unlikely changes protein behaviour) (http://snpeff.sourceforge.net/SnpEff_manual.html). Finally, the Wageningen UR 150 Tomato Genome Resequencing project (Aflitos et al. 2014) provided the sequences and JBrowse was used to identify SNPs and other mutations, such as deletions and insertions, between Moneymaker and LA2157. Additionally, to find a possible trend of gene expression in different tissues in Moneymaker an in silico transcriptomic analysis was performed by accessing the Tomato Functional Genomics Database (http://ted.bti.cornell.edu/cgi-bin/TFGD/digital/home.cgi) where the expression levels of the candidate genes in cv. Heinz are stored.

\section{Virus-induced gene silencing (VICS) and Cmm inoculation}

The best target region for the VIGS constructs (CESA3: Solyc07g005840.2, CESA4: Solyc09g072820.2, PMR6: Solyc09g008380.2 and WAT1: Solyc04g080940.2) were identified using the SGN VIGS tool (http://vigs.solgenomics.net/). The target region is in the coding region (CDS), with at least 21 basepair (bp) unique to a specific gene which is used to identify the targeted region. Primers were designed to amplify a 150-200 bp region of the candidate genes (Table 2). The PCR reaction was set up to a final volume of $50 \mu \mathrm{l}$ : $10 \mu \mathrm{l}$ of HF buffer (5x), $2 \mu \mathrm{l} 5 \mathrm{mM}$ deoxynucleoside triphosphates (dNTPs), $0.15 \mu$ of DreamTaq DNA Polymerase (Thermo Scientific, USA) (5 U/ul), $0.38 \mu$ l of Phusion ${ }^{\circledR}$ High-Fidelity DNA Polymerase (Thermo Scientific, USA), $1.25 \mu \mathrm{l}$ of forward primer $(10 \mu \mathrm{M}), 1.25 \mu \mathrm{l}$ of reverse primer $(10 \mu \mathrm{M})$ and $2.5 \mu \mathrm{l}$ of $\mathrm{cv}$. Moneymaker cDNA $(10 \mu \mathrm{M})$. Touchdown PCR with 25 cycles $98^{\circ} \mathrm{C}, 30 \mathrm{~s} ; 60(-0.4){ }^{\circ} \mathrm{C}$, $25 \mathrm{~s} ; 72{ }^{\circ} \mathrm{C}, 30 \mathrm{~s}$ and 10 cycles $98{ }^{\circ} \mathrm{C}, 30 \mathrm{~s} ; 55^{\circ} \mathrm{C}, 25 \mathrm{~s} ; 72{ }^{\circ} \mathrm{C}, 30 \mathrm{~s}$. Fragments targeting the candidate genes for silencing were amplified and cloned into pENTR-TOPO (Thermo Scientific, USA), sequenced for confirmation and subsequently cloned into TRV2 vector (Liu et al. 2002) using the Gateway system. Plasmids were transformed into Agrobacterium tumefaciens strain GV3101. TRV infection was done through Agrobacterium-mediated infiltration on cotyledons of 10-day old Moneymaker seedlings using needleless syringes (ten plants per treatment). The TRV2 vector, containing the $\beta$-glucuronidase gene (GUS), a gene that has no homology with any endogenous gene in tomato, was used as control (TRV2::GUS plants).

Inoculation with $\mathrm{Cmm}$ was done approximately two weeks after agroinfiltration of the plants (third to fourth leaf stage). The Cmm strain IPO3356 (Culture Collection of Wageningen Plant Research), is highly virulent and rifampicin resistant (Rif+). The 
petiole of the first and second leaf of the tomato plants were cut with knives and dipped into $10^{8} \mathrm{cfu} / \mathrm{ml}$ bacterial suspension. The leaves were collected for a gene expression analysis. Disease index (DI) was scored based on the following scale: 0 = no symptoms; $1=$ up to $25 \%$ leaf wilting; $2=26$ to $50 \%$ leaf wilting; $3=51$ to $75 \%$ leaf wilting; $4=76$ to $100 \%$ leaf wilting; $5=$ dead plants (Sen et al. 2013). Scoring of the plants was done at several time points post inoculation (dpi). The agroinfiltration and inoculation were replicated. The first experiment was performed using four silencing constructs of four different genes, and any successful silencing was repeated. The second experiment consisted of two silencing constructs of the WAT1 gene designed to target different exons; namely exon 1 (TRV2::WAT1) and exon 4 (TRV2::93).

\section{Gene expression analysis}

The first two true leaves from each plant were sampled for RNA isolation as described above. Total RNA isolation was done using the MagMax ${ }^{\text {TM }} 96$ Total RNA Isolation Kit (QIAGEN) in combination with a KingFisher processor, and CDNA was synthesized using iScript ${ }^{\mathrm{TM}}$ CDNA Synthesis Kit (Bio-Rad) using $1 \mu \mathrm{g}$ RNA. For the gene expression analysis qPCR was performed using a CFX96 Real-Time PCR machine (Bio-Rad Laboratories, U.S.A). Primer pairs were designed in an intron-exon junction region to avoid amplification of any remaining genomic DNA in the samples, and to specifically amplify the target genes (Table 3). The APT tomato was used as reference gene (GenBank: BT012816) (Expósito-Rodríguez et al. 2008).

\section{Total bacterial DNA isolation and quantification}

Stem pieces were collected above the inoculation point from all the plants. The stems were placed in BIOREBA ${ }^{\mathrm{TM}}$, crashed with a hammer and suspended with Ringer (three times the weight of the stem). The suspension was used for total bacterial DNA isolation. DNA isolation was done using a BioSprint ${ }^{\circledR}$ One-For- All Vet Kit (384) Kit (QIAGEN) in combination with a Kingfisher processor. Bacterial quantification was done using a TaqMan assay as described by Sen et al. (2013). 


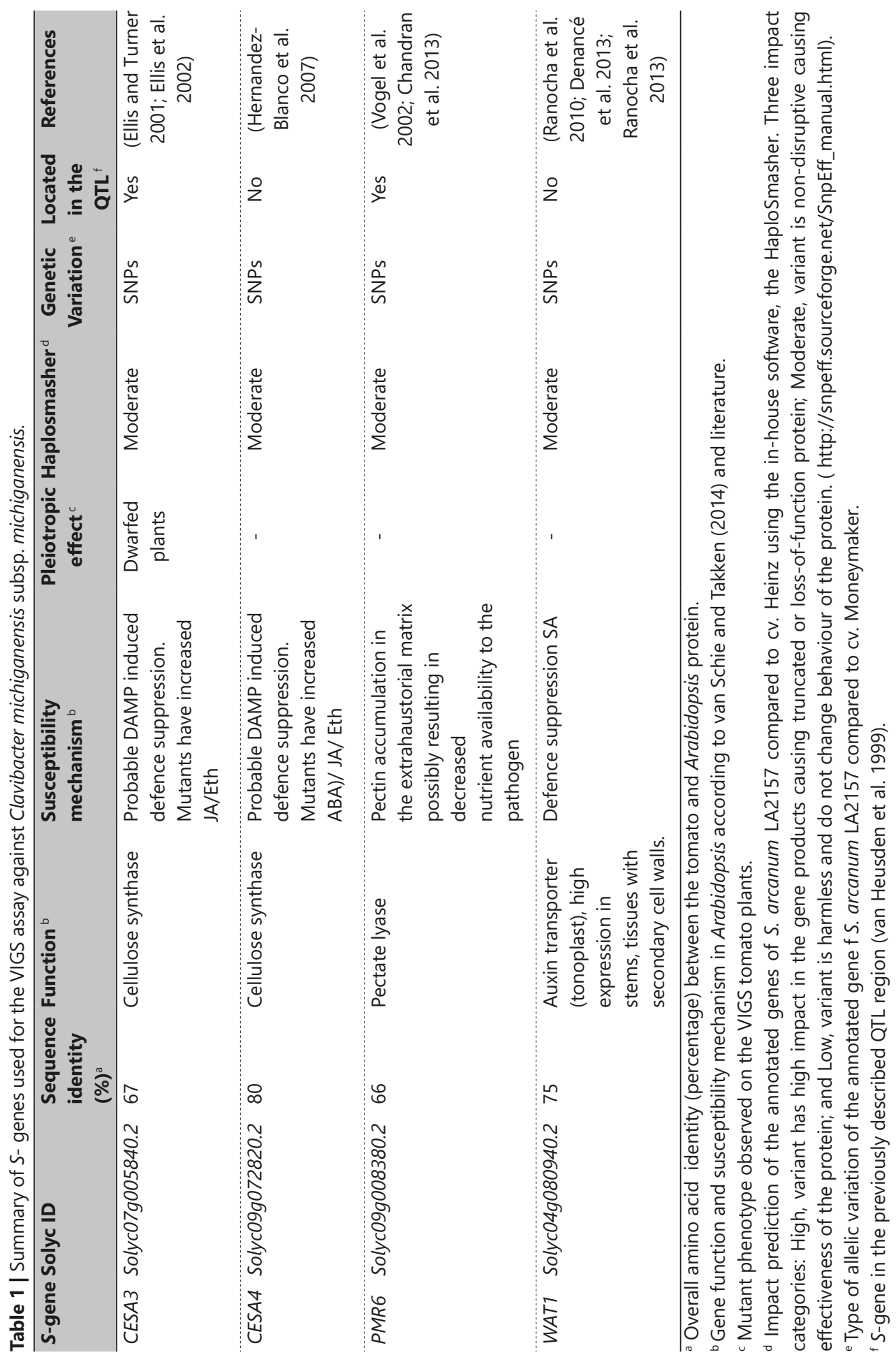


Table 2 | Primer pairs designed for the amplification of the four candidate $S$ - genes.

\begin{tabular}{|c|c|c|c|}
\hline Gene & Annotated gene & Primer name & Sequence $\left(5^{\prime} \rightarrow 3^{\prime}\right)$ \\
\hline \multirow[t]{2}{*}{ CESA4 } & Solyc09g072820.2 & CESA4F1 & сасcCCTGTCGAGAAGGTTAGCTGTT \\
\hline & & CESA4R1 & TCGGGTGCTCTAGGCTCTAC \\
\hline \multirow[t]{4}{*}{ WAT1 } & Solyc04g080940.2 & WAT1F1 & caccATGGCAGATACTAGTGGTTCATCC \\
\hline & & WAT1R1 & TGCAGCTCTAGAGACAACATGA \\
\hline & & KH_093_Fw ${ }^{\text {a }}$ & caccGGCCCAACAATTTACAGCCC \\
\hline & & KH_093_Rv & CCCTCAGGCTTGGCTAGTTC \\
\hline \multirow[t]{2}{*}{ CESA3 } & Solyc07g005840.2 & CESA4MF1 & caccCGTCTTAAAGGGAGTCCAAGG \\
\hline & & CESA4MR1 & AGGAGGGTACTGAGCGGAAT \\
\hline \multirow[t]{2}{*}{ PMR6 } & Solyc09g008380.2 & PMR6F2 & caCCTACTCTTCCTGGTCAACATCCTG \\
\hline & & PMR6R2 & GGTCACATCGCCAACAATCA \\
\hline
\end{tabular}

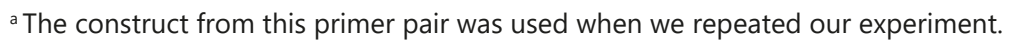

Table 3 | The qPCR primers of the target genes and the housekeeping gene to check the silencing level in the VIGS plants.

\begin{tabular}{lll}
\hline Gene & Primer name & Sequence $\left(\mathbf{5}^{\prime} \rightarrow \mathbf{3}^{\prime}\right)$ \\
\hline PMR6 & qAtPMR6F2 & TAAAGAGGTAACAAAAAGAG \\
\hline CESA3 & qAtPMR6R2 & AATTTCTCCATTTTCCTTCA \\
\hline & qCESA4MF1 & GGGTTCCACCTTCGTCGAG \\
\hline CESA4 & qCESA4MR1 & ATCCATCCCAGCTCCAAACC \\
& qCESA4F2 & GCTTTGGTTAGCGAGTAGCT \\
\hline WAT1 & qCESA4R2 & CATGGCTTCTCTAACTGCCT \\
\hdashline & qWAT1F1 & GGGGGTCCAGTTTTTGTTGC \\
\hline APT & qWAT1R1 & CTCCGATTATCCCGCCCAAG \\
\hdashline & qAPTF & CCATGAGGAAACCCAAGAAGT \\
\hline & qAPTR & CCTCCAGTCGCAATTAGATCAT \\
\hline
\end{tabular}




\section{Results}

\section{Potential use of $S$-genes against $\mathrm{Cmm}$}

The concept of using $\mathrm{S}$-genes in tomato to lower the effects of an infestation of $\mathrm{Cmm}$ has never been tested before. This is the first study to investigate the possibilities of using impaired $\mathrm{S}$-genes as source of tolerance towards $\mathrm{Cmm}$. The genes tested were CESA3 (Solyc07g005840.2), CESA4 (Solyc09g072820.2), PMR6 (Solyc09g008380.2) and WAT1 (Solyc04g080940.2) (Figure S1). The tomato CESA3 protein has 67\% homology and PMR6 has $66 \%$ homology with their Arabidopsis orthologues. CESA3 and PMR6 were chosen because they are in the QTL regions of chromosome 7 and 9 , respectively. The differences in protein sequences between Moneymaker and LA2157 were predicted using the HaploSmasher software. The impact variant is moderate, meaning that there is an amino acid difference in LA2157 that may affect the protein, but it is non-disruptive. The other two genes, CESA4 and WAT1, have $80 \%$ and $75 \%$ protein homology with Arabidopsis orthologues. Impairment of CESA4 gene in Arabidopsis leads to resistance against Ralstonia solanacearum (HernandezBlanco et al. 2007), and the Arabidopsis wat1 mutant exhibits broad-spectrum resistance to several vascular pathogens ( $R$. solanacearum, Verticillium dahliae and $V$. albo-altrum) (Denancé et al. 2013). The impact variant of the amino acid sequence of these proteins in LA2157 is moderate (Table 1).

Out of the four genes, the experiment with the WAT1 gene resulted in less wilting towards $\mathrm{Cmm}$ (Figure 1a). The disease index of the WAT1 plants are lower and significantly different $(P=0.05)$ than other treatments (Figure $1 \mathrm{~b})$. The silencing level of individual WAT1 plants was checked by comparing it with the level of the GUS control plants (Figure 1c). Six of the silenced plants had low DI scores and a nonsilenced plant had a high DI score (Figure 1c). There are three silenced plants with high DI score which might be due to the patchiness of the silencing level.

No reduced susceptibility was found in CESA3, CESA4 and PMR6 inoculated plants. The DI scores in these cases were similar to the GUS control from $12 \mathrm{dpi}$ (first wilting symptoms) till $19 \mathrm{dpi}$ (harvest) (Figure $1 \mathrm{~b}$ ). No association was found between the silencing level and DI scores in CESA4 and PMR6 silenced plants. No enhanced resistance was found in CESA3, CESA4 and PMR6 inoculated plants. The DI scores in these cases were like the GUS control from 12 dpi (first wilting symptoms) till 19 dpi (harvest) (Figure 1b). The gene expression analysis was not performed on CESA3 silenced plants due to the adverse pleiotropic effects (Figure 1a).

There was no significant difference between the bacterial titres in all silenced and control plants. A Pearson's correlation test gave no significant correlation between the symptom scoring and the Cmm DNA bacterial titre $(r=0.015)$. 
a)

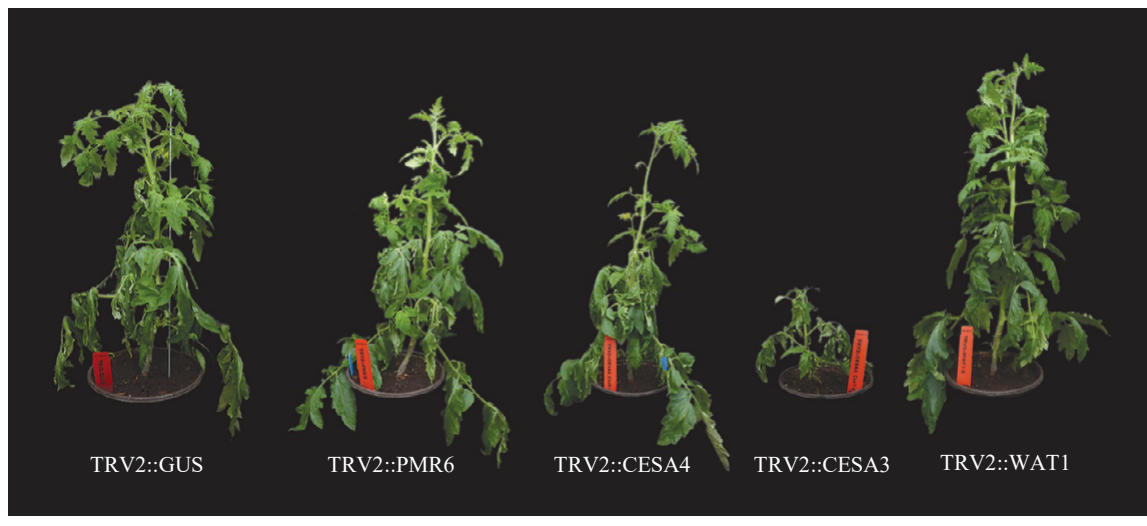

b)

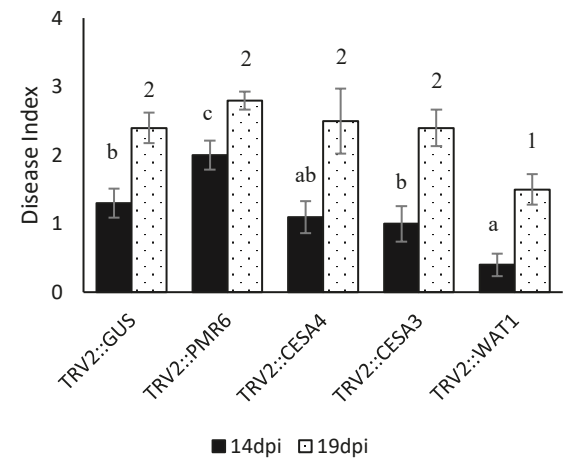

c)

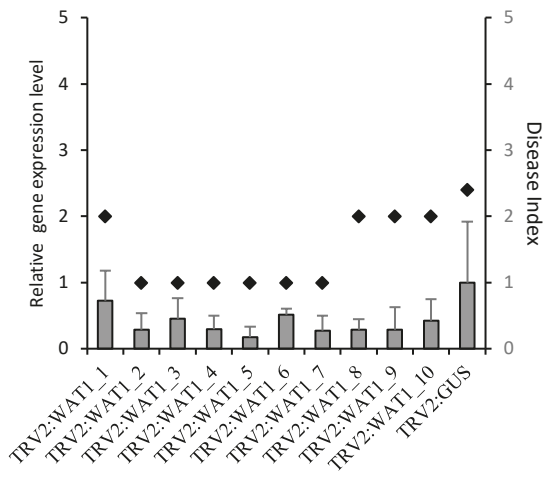

口Expression level $\bullet$ Disease Index

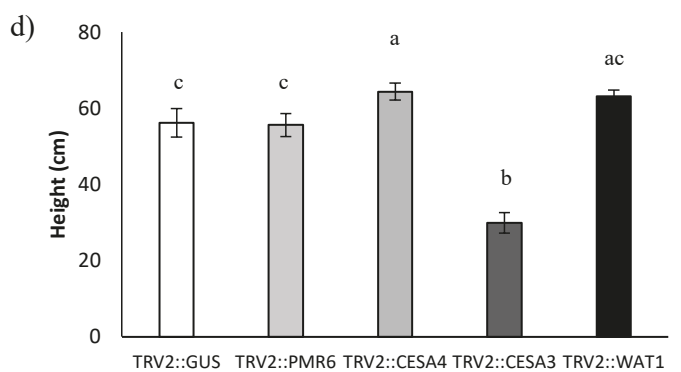

Figure 1 | Screening of the tomato VIGS plants. a) Wilting observed on the control (TRV2::GUS) and other TRV2 constructs (TRV2::PMR6, TRV2::CESA4, TRV2::CESA3, TRV2::WAT1). b) Disease index on the 14 and $19 \mathrm{dpi}$. The bars represent average score of each genotype $(n=10)$ and vertical lines represent standard errors. Within each chart, bars sharing the same letter or numbers are not significantly different $(P=$ 0.05). c) Relative gene expression and DI (19 dpi) of the 10 individual TRV2::WAT1 plants. Each column represents the average relative gene expression of two technical replicates and vertical lines represent standard errors. Diamond shaped markers represent the DI score. The average relative gene expression and average DI score of ten biological replicates of GUS control plants are given in comparison to the other plants. d) Average height $(\mathrm{cm})$ of the TRV2 constructs plants. Bars represent average score of each genotype $(n=10)$ and vertical lines represent standard errors. Within each chart, bars sharing the same letter are not significantly different $(P=0.05)$. 


\section{Pleiotropic effect}

Silencing a gene may affect the plant phenotype. In this experiment a strong pleiotropic effect was observed in CESA3 silenced plants. The CESA3 plants were stunted in growth and the average height of CESA 3 inoculated plants was significantly lower $(P<0.001)$ than the other silenced plants. Similar pleiotropic effects were not observed in other silenced plants (Figure 1d). The CESA4 and WAT1 plants are even somewhat higher than the control.

\section{WAT1 as a potential S-gene against $\mathrm{Cmm}$}

To confer that silencing the WAT1 gene leads to a higher tolerance to $\mathrm{Cmm}$, the experiment was repeated. Additionally, a new construct (TRV2::93), which was designed at another location of the WAT1 gene, was used as well (Figure S2). Repeated analysis (expression level and disease test) confirmed the tolerance of WAT1 plants compared to GUS control plants (Figure S3a). TRV2::WAT1 plants have a lower average disease index which is significantly different $(P=0.05)$ than TRV2::93 and TRV2:: GUS plants. Average disease index of TRV2::93 plants was not as low as TRV2::WAT1 plants, but lower than TRV2::GUS plants. The silencing level of each individual plant was checked by comparing it with the level of the GUS control plants (Figure S3b, c). Seven of the TRV2::WAT1 silenced plants had lower DI scores and three silenced plants had a higher DI score (Figure S3b). There were four silenced TRV2::93 plants with variation in DI and six non-silenced plants (Figure S3c). No pleiotropic effects were observed.

\section{Discussion}

The coding sequence of the four chosen tomato S-genes (CESA3 (Solyc07g005840.2), CESA4 (Solyc09g072820.2), PMR6 (Solyc09g008380.2) and WAT1 (Solyc04g080940.2) showed several SNPs between Moneymaker and LA2157 (Table 1). The differences in the nucleotide or protein sequences between these orthologues might be responsible for an enhanced tolerance towards $\mathrm{Cmm}$. To find the right genes all potential $S$-genes have to be silenced one by one in a susceptible cultivar and after pathogen challenge be evaluated. A VIGS assay can be used for this purpose as it provides rapid and high throughput screening of many genes (Liu et al. 2002). However, VIGS is never complete and partial and patchy tissue distributions are to be expected (Lu et al. 2003; Orzaez et al. 2009). Furthermore, it is possible that sometimes a silenced phenotype is not observed because the function of the target gene is still supported by the residual low level of mRNA in the virus vector-infected plants or other homologs of the gene are still functional (Lu et al. 2003). The results of VIGS provide only an indication about the gene function and not a proof (Lu et al. 
2003). Stable mutants generated through RNAi or CRISPR/Cas9 techniques should be obtained for further confirmation.

In parallel to these loss-of-function approaches, overexpression of the genes in a tolerant genotype can be used (Prelich 2012). Expression of a candidate S-gene can verify if susceptibility can be restored in a resistant mutant. This can be done by generating transgenic plants overexpressing the candidate $S$-gene from the susceptible cultivar (Berg et al. 2015). Assuming that the differences between these orthologues are responsible for the resistance in genotype LA2157, overexpression of the genes would restore the susceptibility in LA2157.

From previous studies, tolerance towards $\mathrm{Cmm}$ was found in LA2157. S-gene(s) localized in the detected QTL region may play a role in tolerance to $\mathrm{Cmm}$. Examples of this have been found in other studies (Fukino et al. 2013; Berg et al. 2015). We used two S-genes located in the QTL regions (CESA3 and PMR6) but CESA3 and PMR6 silenced plants did not have higher levels of tolerance to $\mathrm{Cmm}$.

Silencing of the CESA3 homolog leads to severe pleiotropic effects in tomato. Silencing this gene in Arabidopsis leads also to reduced growth, due to the constitutive activation of the jasmonic acid (JA) signalling pathway (Ellis and Turner 2001). Constitutive activation of JA defences represents an important example of "growth-defence tradeoff" in plants, as it severely restricts plant growth (Ellis and Turner 2001; Yang et al. 2012; Vos et al. 2013; Huot et al. 2014). That an induction of defence responses can be associated with plant fitness shows that simply breeding for constitutively active defences is not always a feasible option (Huot et al. 2014). CESA3 is obviously not a suitable gene for $S$-gene breeding as silenced plants exhibited strong pleiotropic effects and no reduced susceptibility.

The other two genes, WAT1 and CESA4, are not located in the QTL, nevertheless their impairment could enhance resistance. Silencing the gene WAT1 conferred a higher tolerance to Cmm. The Arabidopsis WAT1 (Walls Are Thin 1) is a gene involved in secondary cell wall formation (Ranocha et al. 2010). In wat1 Arabidopsis mutants, a severe reduction in secondary wall thickness, but not xylem vessels has been observed (Miedes et al. 2014). Knocking-out/down WAT1 leads to specific, broad-spectrum resistance to vascular pathogens in Arabidopsis including $R$. solanacearum, Verticillium dahliae and $V$. albo-altrum, but not to non-vascular pathogens (Denancé et al. 2013). One would assume that wat 1 mediated resistance must be caused by alterations of the strength of the cell walls, but it has been shown that the resistance conferred by a mutated WAT1 involves the activation of immune responses, mainly localized in the vascular system of the plants (Miedes et al. 2014). In the case of wat 1 mutants, it is suggested that salicylic acid (SA) is responsible for the resistance to vascular pathogens. This is further supported by the fact that wat 1 roots contain constitutively 
higher amounts of SA, compared to the Col-0 Arabidopsis plants. Furthermore, it is shown that the introduction of NahG, a bacterial gene whose product converts SA to catechol, in wat 1 plants leads to full susceptibility of the mutant plants (Denancé et al. 2013).

In our experiment, Moneymaker plants infiltrated with the construct targeting the WAT1 gene showed a significantly lower susceptibility to $\mathrm{Cmm}$ than the control plants. This result suggests that the molecular mechanisms contributing to the tolerance against $\mathrm{Cmm}$ are affected by the silencing of WAT1. The fact that silencing of the gene did not lead to any severe pleiotropic effects further increases the possibility of using WAT1 in S-gene breeding. It is interesting that despite being tolerant to $\mathrm{Cmm}$, the silenced WAT1 plants still contain a high bacterial density. Wilting symptoms and bacterial titre are not correlated in the $\mathrm{Cmm}$-tomato interaction. A recent study indicates that highly tolerant wild tomato relatives contain considerable amounts of bacteria (Sen et al. 2013), which is in line with what we have observed in our experiment. The virulence factors of $\mathrm{Cmm}$ can cause wilting in tomato plants (Eichenlaub and Gartemann 2011; Savidor et al. 2012). We speculate that silencing the WAT1 gene does not inhibit the bacterial growth, but in fact reduces the $\mathrm{Cmm}$ virulence factors. Our results showed that it is highly possible that $\mathrm{SA}$ is involved in resistance against $\mathrm{Cmm}$. It has been long established that plant hormones such as SA, JA and ethylene (ET) are involved in the regulation of plant defence responses (Ton et al. 2002). The signalling pathways of these hormones are interconnected in complex networks, allowing plants to rapidly adapt to their biotic environments, in order to grow and survive in a cost-efficient way (Pieterse et al. 2012). Silencing of WAT1 has been shown to lead to accumulation of SA (Denancé et al. 2013). Furthermore, CESA3 and CESA4 mutants have been shown to activate the JA/ ET and ABA pathways, respectively. Mutations of the PMR6 gene lead to resistance against pathogens through a JA, SA or ET independent pathway (Vogel et al. 2002).

In the case of the Cmm-tomato interaction, no studies are known about the involvement of SA, JA or ABA in the resistance mechanisms. It has been shown that there is an elevated ethylene production in tomato plants infected with $\mathrm{Cmm}$ (Savidor et al. 2012). The ACD mutant in tomato had an impairment (up to $90 \%$ reduction) of the ethylene production. When the ACD mutant was challenged with $\mathrm{Cmm}$ they exhibited delayed wilting. Delayed wilting is also observed on the tomato ethylene insensitive Never ripe ( $\mathrm{Nr}$ ) mutant (Balaji et al. 2008). Ethylene production in tomato is a major signal that regulates disease progression and is not used by $\mathrm{Cmm}$ for virulence or proliferation. Time course experiments specifically designed to study the involvement of signalling hormones in $\mathrm{Cmm}$-tomato interactions might shed light in this. The expression of marker genes in different signalling pathways at different time points could be studied, to elucidate the effect of hormones on tolerance against $\mathrm{Cmm}$. 


\section{Acknowledgements}

We would like to thank Dr. Henk Schouten (Plant Breeding, Wageningen University \& Research) for supplying the list of candidate $S$-genes mapped on the tomato genome and Katharina Hanika MSc (Plant Breeding, Wageningen University \& Research) for TRV2::93 construct and the map of the WAT1 gene. Nunhems, vegetable seeds of BASF, the Netherlands; Universiti Putra Malaysia and the Ministry of Higher Education Malaysia, Malaysia are thanked for their financial support. 


\section{Supplementary material}

a)

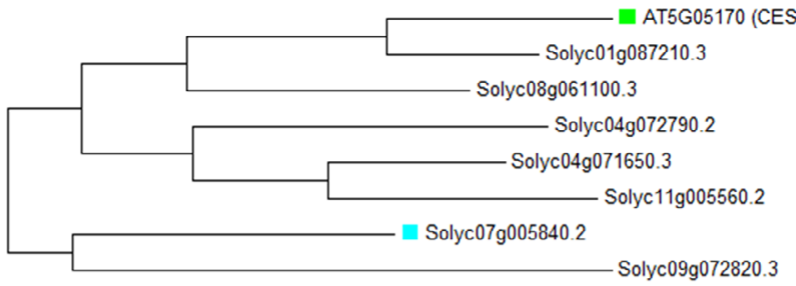

$\longmapsto 0.05$

b)

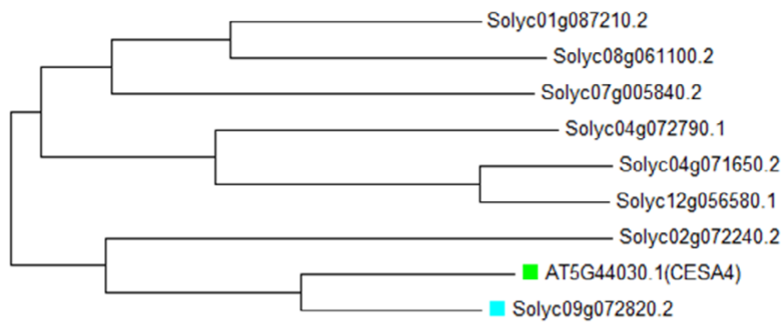

$\longmapsto 0.05$

c)

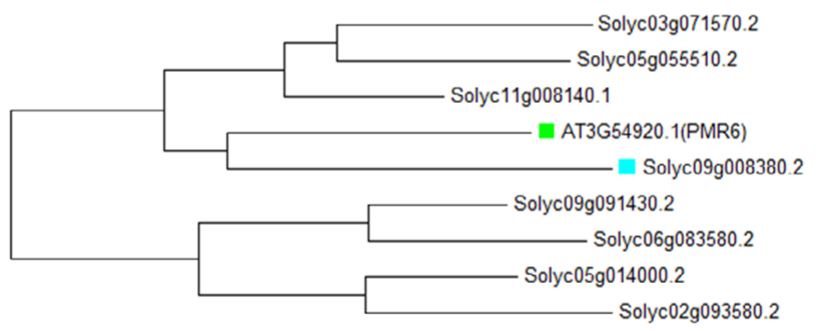

$\longmapsto 0.05$

d)

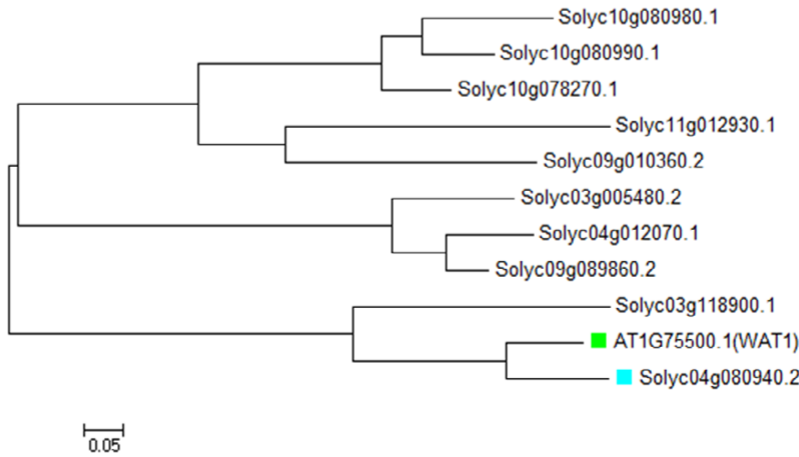

Figure S1 | Neighbour-joining phylogenetic tree of the Arabidopsis protein sequences (green squares) and their tomato orthologues. The constructs we designed are indicated with blue squares. a) CESA3, b) CESA4, c) PMR6, and d) WAT1. The scale bar shows 0.05 amino acid substitutions per site. 


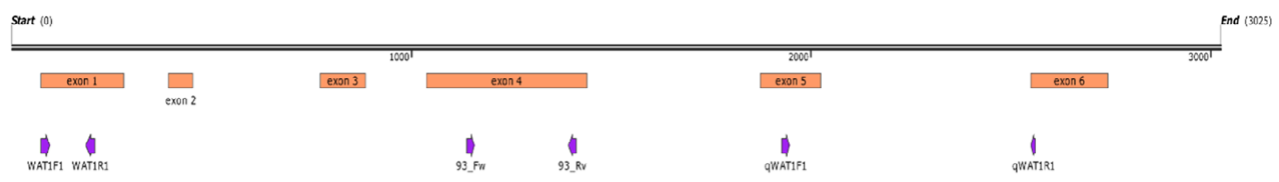

$\underset{3025 \text { bp }}{\text { Solyco } 4 g 08090}$

Figure S2 | Schematic diagram of the WAT1 gene and the primers designed (purple arrows) to produce the TRV2 constructs (TRV2::WAT1 and TRV3::93) and to check the relative gene expression.

a)

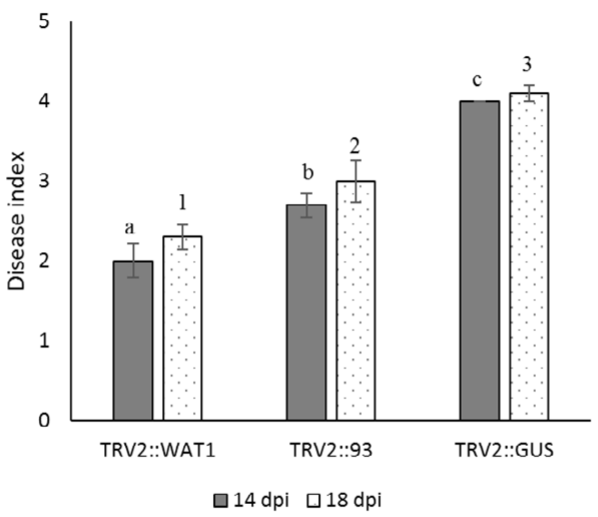

c)

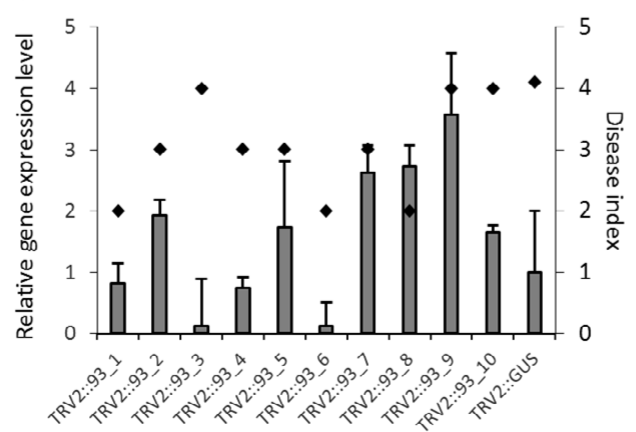

ロExpression level • Disease Index b)

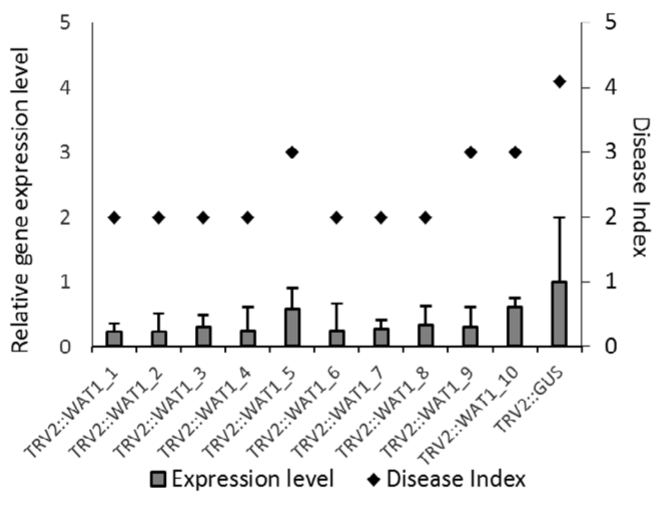

Figure S3 | Screening of WAT1 plants $(n=10)$ of the repeated experiment. a) Symptom score on 14 and $18 \mathrm{dpi}$. The bars represent average scores of each genotype $(n=10)$ and vertical lines represent standard errors. Within each chart, bars sharing the same letter or numbers are not significantly different $(P=0.05)$. Relative gene expression and DI (18 dpi) b) TRV2::WAT1 construct from the first experiment located on exon 1, and new c) TRV2::93 construct located on exon 4. Each column represents the average relative gene expression of two technical replicates and vertical lines represent standard errors. Diamond shaped markers represent the DI score. The average relative gene expression and average DI score of ten biological replicates of GUS control plants are given in comparison to the other plants. 


\section{CHAPTER}

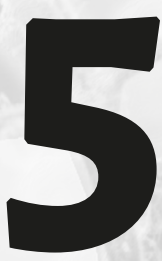

\section{Alternative ways to reduce}

Clavibacter michiganensis subsp. michiganensis disease symptoms in tomato

M.M. Mohd Nadzir, W.T.A.M de Laat, S. Subedi, J.C. Rivas Baeza, A. Naznin, R.G.F. Visser, A.W. van Heusden, J.M. van der Wolf 
To develop an integrated strategy for minimizing effects after infection with Clavibacter michiganensis subsp. michiganensis $(\mathrm{Cmm})$ in tomato, we studied the effect of grafting using the highly tolerant Solanum arcanum LA2157 and the use of Pseudomonas spp. consortia as a biocontrol agent. Two types of $\mathrm{Cmm}$ inoculation were tested; root inoculation and stem inoculation. After a root infection, a significant reduction of wilting (by 25 \%) was seen on reciprocal grafted Solanum lycopersicum cv. Moneymaker on S. arcanum LA2157 rootstock but not on self-grafted cv. Moneymaker. After stem inoculation, no reduction of wilting symptoms was observed. A comparable observation was made with plants of $\mathrm{cv}$. Moneymaker treated with Pseudomonas spp. consortia. Two types of consortia were used throughout the experiment, enhancer 1 (E1) contained eight Pseudomonas strains and enhancer 5 (E5) contained six Pseudomonas strains. A reduction in wilting (up to $50 \%$ ) symptoms was found between treated and non-treated plants but only when $\mathrm{Cmm}$ was root inoculated. Only a small reduction of leaf wilting was seen on cv. Moneymaker plants after infection via the stem when the Pseudomonas spp. consortia were added weekly to the root.

$\widetilde{\sigma}$ Keywords: Clavibacter, Cmm, Tomato, Grafting, Biocontrol 


\section{Introduction}

Clavibacter michiganensis subsp. michiganensis $(\mathrm{Cmm})$ is one of the most threatening bacteria infecting tomato and it is a quarantine organism in Europe (Grund et al. 1990; Eichenlaub et al. 2006; Eichenlaub and Gartemann 2011; EPPO 2016). This Grampositive bacterium causes wilting and canker on its host (Solanum lycopersicum) (Davis et al. 1984). It can enter the host plant via roots, natural openings and wounds (Chang 1991; Carlton et al. 1994; Sharabani et al. 2013a). Contaminated seeds and infected plant debris in the soil are the main sources of infection (Strider 1969; de León et al. 2009; Vega and Romero 2016).

The quarantine status and difficulty to manage the pathogen make it problematic to many parties. Seed companies need to sell $\mathrm{Cmm}$-free seeds, plant growers need to supply $\mathrm{Cmm}$-free tomato seedlings and farmers would like to have plants that are preferably not infected by the pathogen. Measures to control $\mathrm{Cmm}$ so far are $\mathrm{Cmm}$ free seed/plants and good agricultural practices. Currently there are no commercial tomatoes that are resistant/ highly tolerant against $\mathrm{Cmm}$. In our group, Solanum arcanum LA2157 was used as tolerance source (van Heusden et al. 1999). The genotype is highly tolerant towards $\mathrm{Cmm}$; no disease symptoms occurred but considerably high bacterial density still present. We still do not know which genes underlie some of the identified tolerances.

The use of wild resistant/tolerant genotypes for grafting could be an alternative approach to reduce symptom development by $\mathrm{Cmm}$. Grafting is an old horticultural method that connects the root system (rootstock) of one plant to the shoot (scion) of another (Warschefsky et al. 2016). The introduction of vegetable grafting took place at the turn of the $20^{\text {th }}$ century to manage soilborne pathogens and it still is used frequently (Sakata et al. 2007; Louws et al. 2010). It can also be used to limit the effects of foliar pathogens (Sakata et al. 2006; Albert et al. 2017).

Another alternative to potentially reduce infections and symptom expression is the use of microorganisms against $\mathrm{Cmm}$. Its application is attractive since it can substitute the use of environmentally unfriendly copper-based chemical treatments to control $\mathrm{Cmm}$. (Werner et al. 2002; Hausbeck 2017). Furthermore, chemical treatments fail to control the pathogen (Hausbeck et al. 2000; Jiang et al. 2015). Our study focuses on the use of Pseudomonas spp. provided by BioscienZ: Inventers of the patent WO2017178529A1 (de Laat et al. 2017). The Pseudomonas species used are P. protegens, P. brassicacearum, two $P$. putida strains, two $P$. moraviensis strains, $P$. reinekei and $P$. extremaustralis. The species were initially tested in vitro to see if culturing a single Pseudomonas species or several species (consortia) together with $\mathrm{Cmm}$ can inhibit the pathogen growth. Consortia that gave the highest effects in vitro were tested in planta in this study. 
From literature, many of the species have been tested with different pathogens and they resulted in disease suppression in the plants. Pseudomonas species have been shown to promote plant growth, reduce disease incidence by changing the host phenolic profile, by secreting secondary metabolites, and/or production of antibiotics. Pseudomonas protegens produces the antimicrobial secondary metabolite 2,4-diacetylphloroglucinol (DAPG) that plays an important role in the biocontrol of plant diseases (Ramette et al. 2011). Similarly, P. brassicacearum LBUM300 produces DAPG and hydrogen cyanide (HCN) and have shown antagonistic activity against the plant pathogens Verticillium dahliae, Phytophthora cactorum, and $\mathrm{Cmm}$ (Paulin et al. 2009; Lanteigne et al. 2012; Novinscak et al. 2016; Paulin et al. 2017). Pseudomonas putida induces chlorogenic acid, caffeic acid, catechin and rutin in tomato infected by Cmm (Park et al. 1988; Aksoy et al. 2017; Sun et al. 2017). Pseudomonas moraviensis produces important secondary metabolite to have antifungal properties like phenazine-1- carboxylic acid, phenazine-1-carboxamide, pyoluteorin and pyrrolnitrin (Ait Bahadou et al. 2018). Pseudomonas reinekei has been shown to reduce the percentage of sclerotia on potato tubers caused by Rhizoctonia solani (Mrabet et al. 2013). Finally, P. extremaustralis has been shown to promote growth of wheat plants (Triticum durum) (Kudoyarova et al. 2017).

In this study two strategies for reduction of $\mathrm{Cmm}$ symptoms were explored. Firstly, grafted tomato plants were tested, in which a tolerant rootstock is combined with a susceptible scion. To our knowledge, grafting has never been tested against $\mathrm{Cmm}$ before. Secondly, the efficacy of Pseudomonas consortia as biocontrol agents was tested against $\mathrm{Cmm}$ after root- and stem inoculations.

\section{Materials and methods}

\section{Plant materials}

The susceptible Solanum lycopersicum cv. Moneymaker (MM) and the highly tolerant S. arcanum LA2157 (LA) were used for the grafting experiment. To see the effect of Pseudomonas consortia on different tomato genotypes, cv. Moneymaker (MM), and the near isogenic line (NIL) containing a small introgression with the main QTL of $S$. arcanum LA2157 were used. 


\section{Grafting procedures}

Four grafting treatments were performed (root:shoot); reciprocal grafted plants (LA:MM and MM:LA) and self-grafted plants (MM:MM and LA:LA) acted as controls. Plants were grown in the greenhouse $\left(12 \mathrm{~h}\right.$ day light, $25^{\circ} \mathrm{C}$ day and $18{ }^{\circ} \mathrm{C}$ night temperature). Seedlings were grown in plug trays and grafting was performed on three-leaves stage plants. A rootstock and scion of similar size were selected. Cotyledons and first leaves were removed, stems were cut with a blade approximately at a $45^{\circ}$ angle above the cotyledons. After cutting, the scion was attached to the rootstock with a grafting clip. Grafted plants were then covered for about two weeks with plastic ( $90 \%$ relative humidity) to promote the formation of the graft union. Stem or root inoculation were performed afterward.

\section{Inoculations of $\mathrm{Cmm}$}

The virulent rifampicin resistant $\mathrm{Cmm}$ strain IPO3356 (Culture Collection of Plant Research International) was used for inoculation (Lelis et al. 2014). Two types of inoculations were performed on the grafting and biocontrol agents experiments; the root inoculation was done by removing the soil from the roots of the seedlings grown in plug trays and roots were dipped into $50 \mathrm{ml}$ of $10^{8} \mathrm{cfu} \mathrm{ml}^{-1}$ bacterial suspension for $30 \mathrm{~min}$ and the stem inoculation was done by cutting the petioles of the first two leaves of fourth leaf stage seedlings with knives dipped into a bacterial suspension $\left(10^{8} \mathrm{cfu} \mathrm{ml}^{-1}\right)$. Ten plants were used for each treatment with water inoculated plants as controls. Experiments were done once for each study. Wilting symptoms were recorded based on the following scale on several days: $0=$ no symptoms; $1=0$ to $25 \%$ leaf wilting; $2=26$ to $50 \% ; 3=51$ to $75 \% ; 4=76$ to $100 \% ; 5=$ dead plants.

\section{Supplementing the plants with Pseudomonas consortia}

Freeze-dried biocontrol consortia were provided by BioscienZ (Breda, The Netherlands). Two types of consortia were used throughout the experiment, enhancer 1 (E1) which contained P. protegens PR01, P. brassicacearum BR01, two $P$. putida strains (\#27 and \#87), two P. moraviensis strains (\#11 and \#17), P. reinekei \#55 and $P$. extremaustralis \#29 and enhancer 5 (E5) which contained all of the above except the two $P$. putida strains. Plants were grown in the greenhouse ( $12 \mathrm{~h}$ day light, $25^{\circ} \mathrm{C}$ day and $18{ }^{\circ} \mathrm{C}$ night temperature). Plants not treated with consortia acted as controls. Two experiments were performed: 1) To test the effect of consortia with a weekly application on cv. Moneymaker. Plants were supplemented four weeks with consortia by diluting the freeze-dried cells with demi water $(2 \mathrm{~g} / \mathrm{l}), 10 \%$ of the pot volume. A week after the fourth application, a stem or root inoculation was done with $\mathrm{Cmm}$. One day after inoculation with $\mathrm{Cmm}$, plants were treated with consortia 
for another two weeks. 2) To test the effect of minimal and direct application of consortia on cv. Moneymaker and NILs, plant roots were dipped in the consortia by diluting the freeze-dried cells with demi water $(2 \mathrm{~g} / \mathrm{l})$ or water (control) for an hour during the first leaf stage before transplanting to bigger pots and the plants were sprayed with consortia one week later. A week after the treatment, stem inoculation was performed.

\section{Total bacterial DNA isolation and quantification}

Plants parts were collected for quantifying $\mathrm{Cmm}$ in the grafting experiment. The plant parts were placed in extraction bags with a synthetic intermediate layer (Bioreba, Switzerland), crashed with a hammer and suspended with Ringers solution (Sigma) three times the weight of the plant part. The suspension was used for total bacterial DNA isolation. DNA isolation was done using a BioSprint ${ }^{\circledR}$ One-For- All Vet Kit (384) Kit (QIAGEN) in combination with a Kingfisher processor. Bacterial quantification (DNA copy number) was done using a TaqMan assay as described by Sen et al. (2013).

\section{Detecting the presence of Pseudomonas consortia in in vitro plants}

Moneymaker (MM) seeds were sown and grown in vitro. The seeds were sterilized in $70 \%$ ethanol for 2 min, $1 \% \mathrm{NaOCl}$ (Sigma-Aldrich, St. Louis, MO) for $20 \mathrm{~min}$ and washed with sterile water for $5 \mathrm{~min}$. Seeds were arranged in petri dishes on sterile and wet filter paper. Seeds were incubated for 3 days at $4{ }^{\circ} \mathrm{C}$ and then for approximately 2 weeks in a growth chamber (Technisch Buro I.K.S. B.V, Leerdam, The Netherlands) at $25^{\circ} \mathrm{C}$ with a relative humidity of $40-70 \%$, and a $16 \mathrm{~h} / 8 \mathrm{~h}$ day/ night photoperiod. Germinated seedlings were transferred to tubes containing sterile vermiculite (1.5 g) and rooting medium (MS30B5) (4.3 g MS salts/L, $112 \mathrm{mg}$ Vitamin B5/L, $30 \mathrm{~g}$ sucrose/L; $\mathrm{pH}$ 5.8). Pseudomonas consortia (E1 and E5) were supplied to the in vitro plantlets weekly for two weeks with consortia by diluting the freeze-dried cells with demi water $(2 \mathrm{~g} / \mathrm{l}), 10 \%$ of the vermiculite volume. Untreated in vitro plants served as control.

To check the presence of Pseudomonas consortia in the in vitro plants, five treated and untreated plants were collected 21 days after the first application of enhancers. The roots were removed and the shoots (stems and leaves) were sterilized with $70 \%$ ethanol. The surface of shoots was blotted dry and placed in extraction bags (Bioreba, Reinach, Switzerland), macerated with hammer, homogenized in $100 \mu$ l Ringer buffer ( $2 \mathrm{ml} \mathrm{g}^{-1}$ of tissue). $20 \mu \mathrm{l}$ of the plant suspension were plated on Cetrimide agar (20 $\mathrm{g}$ gelatine peptone/L, $1.4 \mathrm{~g}$ magnesium chloride/L, $10 \mathrm{~g}$ potassium sulphate/L, $0.3 \mathrm{~g}$ cetrimide/L, $13.6 \mathrm{~g}$ agar/L). Plates were incubated at $35^{\circ} \mathrm{C}$ for two days. 


\section{Statistical analyses}

A Kruskal-Wallis analysis using the SPSS 23.0 statistical software package (SPSS Inc., Chicago, IL) was used to determine the difference between the disease index of different graft treatments. The sameanalysis was also used to see the difference between the treated and non-treated plants with the biocontrol consortia. Effects were significant at $\mathrm{P}=0.05$.

\section{Results}

\section{Effect of grafting against $\mathrm{Cmm}$}

The effect of different rootstocks with different inoculation methods was studied to determine if grafting enhanced tolerance on the susceptible cv. Moneymaker (root:shoot; LA:MM and MM:MM) against $\mathrm{Cmm}$ symptoms after stem respectively root inoculation. MM:LA plants were used to see if grafting the tolerant scion on susceptible rootstock will affect the wilting symptoms.

When grafted plants were stem inoculated with $\mathrm{Cmm}$, the first wilting symptoms were observed on 11 dpi on MM:MM and on LA:MM. On 29 dpi, there was a significant difference in the wilting symptoms among MM:MM, LA:LA, MM:LA and LA:MM $\chi^{2}$ $(3)=19.90, p=0.000$, but there was no significant difference in wilting symptoms between LA:MM and MM:MM (Table S1, Figure $1 b, d$ ). No severe wilting symptoms were observed on LA:LA and MM:LA (Figure 1a, c).

Symptom expression after root infection developed slower than after stem inoculation. The first wilting symptoms were observed on MM:MM at $21 \mathrm{dpi}$. On 36 dpi, a significant difference in wilting symptom among MM:MM, LA:LA, MM:LA and LA:MM was present $\chi 2(3)=29.51, p=0.000$, and there was a significant difference in wilting between LA:MM ( $M$ rank 26.10, average score 2) and MM:MM ( $M$ rank 33.10, average score 3) (Table S2, Figure 1f, h). On 36 dpi no severe wilting symptom were observed on LA:LA and MM:LA (Figure 1e, g).

Bacterial density measurements (TaqMan assay) showed differences between roots and shoots of root inoculated grafted plants. There is a significant difference in $\mathrm{Cmm}$ DNA copy number $\chi 2(3)=21.037, p=0.000$ of the root samples between MM:MM and MM:LA. The roots of MM:MM $\left(1.18 \times 10^{6}\right)$ contained higher bacterial density than MM:LA $\left(2.97 \times 10^{3}\right)$. The bacterial density of the roots of LA:LA and LA:MM could not reliably be determined because they were below the detection limit $\left(<10^{3}\right)$ (Table S3). 


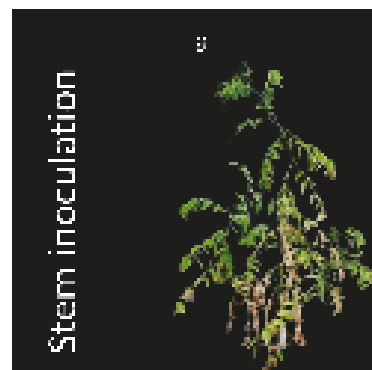

벤ㄷㄴ

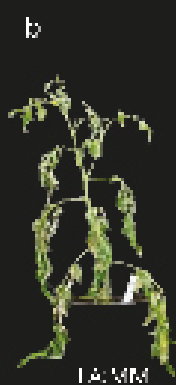

1 is: SARS

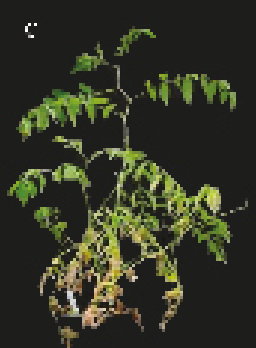

$1.4: 1,6$ d

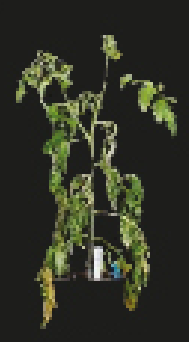

Rstrat:t.tr.1

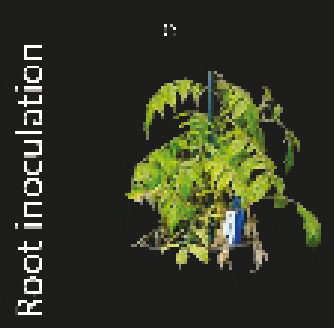

BIP IA

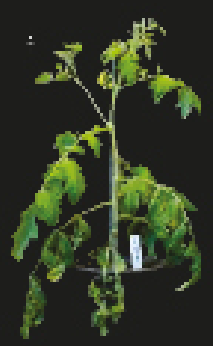

I is: :sis

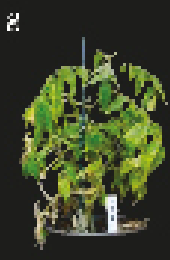

IA:

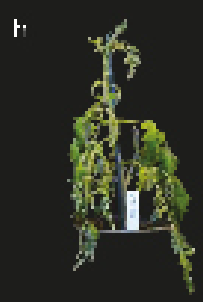

Rstrot:ta1|st

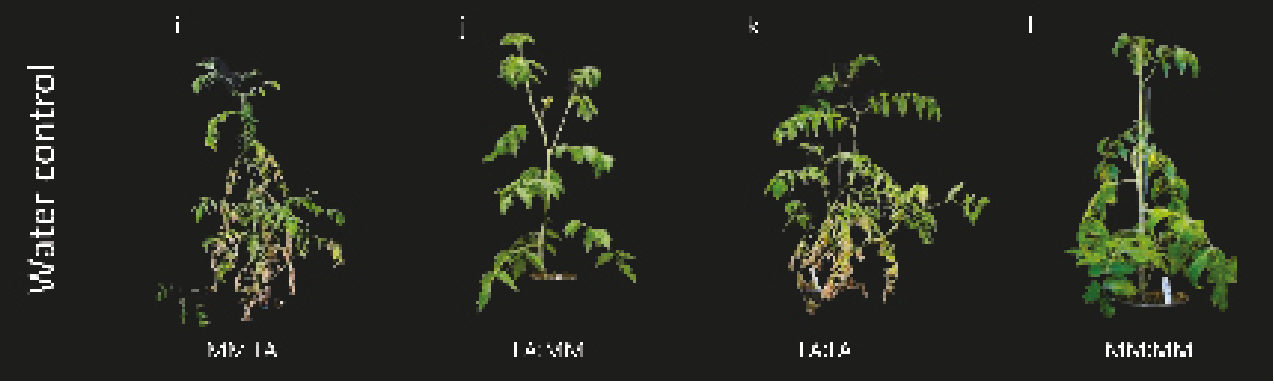

Figure 1 | Wilting symptom after different treatments (root:shoot) of Solanum lycopersicum cv. Moneymaker (MM) and Solanum arcanum LA2157 (LA) with stem inoculation (a, b, c, d), root inoculation $(e, f, g, h)$ and water control $(i, j, k, l)$.

For the shoots, there was a significant difference $\chi 2(3)=14.61, p=0.003$ in bacterial density among MM:LA, LA:MM and MM:MM. The shoots of LA:MM $\left(2.45 \times 10^{3}\right)$ and MM:LA $\left(2.89 \times 10^{3}\right)$ had a lower bacterial density and were significantly different from the density in MM:MM $\left(1.68 \times 10^{6}\right)$. The density of $\mathrm{Cmm}$ in LA:LA shoots could not be determined. 
a)

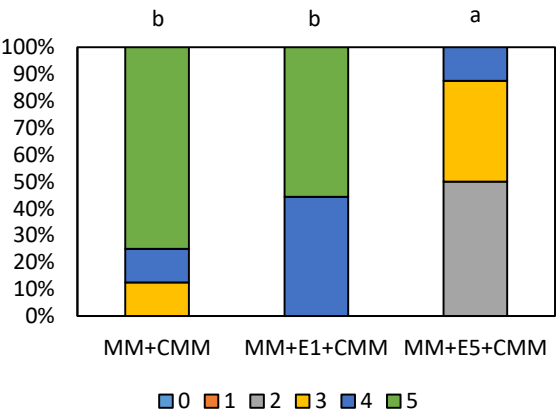

b)

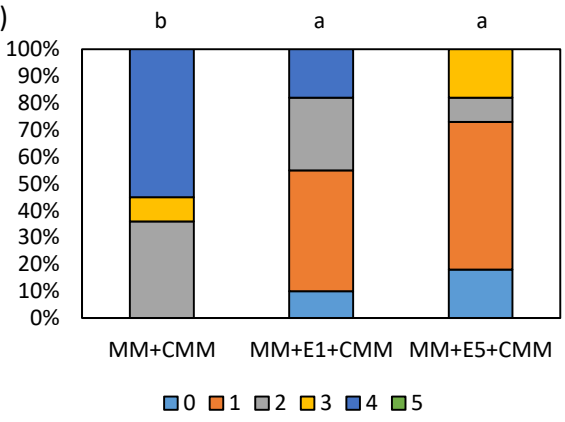

Figure 2 | The effect of applying Pseudomonas sp. consortia (E1 and E5) on cv. Moneymaker (MM). Plants were treated by supplying $10 \%$ of the pot volume with E1, E5 or water for four weeks. Inoculation was performed a week after and plants were subsequently supplied with the different treatments for two more weeks. Coloured bars show the percentage of plants for each disease index. Disease index is $0=$ no symptoms; $1=0$ to $25 \%$ leaf wilting; $2=26$ to $50 \% ; 3=51$ to $75 \% ; 4=76$ to $100 \% ; 5=$ dead plants. a) stem inoculation with $\mathrm{Cmm}$ during the fourth leaf stage on $28 \mathrm{dpi}$, b) root inoculation with $\mathrm{Cmm}$ during the fourth leaf stage on $35 \mathrm{dpi}$. Within each chart, bars sharing the same letter are not significantly different with Kruskal-Wallis at $P=0.05$ using stepwise step-down analysis.

\section{Effect of supplying the Pseudomonas consortia weekly to plants}

The effect of different Pseudomonas consortia (E1 and E5) was tested to see if application of the consortia could enhance the tolerance of the susceptible cv. Moneymaker after stem or root infections. The first wilting symptoms were observed 14 dpi.

On $28 \mathrm{dpi}$ (the last day of the experiment) we evaluated the stem inoculated plants and found a significant difference $\chi 2(2)=15.155, p=0.001$ in wilting between the control plants and plants that had been in contact with consortia $(\mathrm{MM}+\mathrm{E} 1+\mathrm{CMM}$ and $\mathrm{MM}+\mathrm{E} 5+\mathrm{CMM}$ ) (Figure 2a). For every treatment variation in wilting severity was present and the percentage of plants within each disease index scale was calculated. Half of the plants that were treated with $\mathrm{E} 5(\mathrm{MM}+\mathrm{E} 5+\mathrm{CMM})$ wilted up to $50 \%$, the remaining plants were more severely wilted. All plants that were not treated $(\mathrm{MM}+\mathrm{CMM})$ or treated with $\mathrm{E} 1(\mathrm{MM}+\mathrm{E} 1+\mathrm{CMM})$ were severely wilted (score 3 and above) at the end of the experiment.

For plants inoculated with $\mathrm{Cmm}$ through the roots the first wilting symptoms were spotted $14 \mathrm{dpi}$, the progress of the wilting severity was slower and the final score was done $35 \mathrm{dpi}$. There was a significant difference $\chi 2(2)=9.330, p=0.009$ in wilting of the plants treated with consortia and non-treated plants. The treated plants with consortia $(\mathrm{MM}+\mathrm{E} 1+\mathrm{CMM}$ and $\mathrm{MM}+\mathrm{E} 5+\mathrm{CMM})$ wilted significantly less than non-treated plants $\mathrm{MM}(\mathrm{MM}+\mathrm{CMM})$ (Figure 2b). Only $18 \%$ of $\mathrm{MM}+\mathrm{E} 1+\mathrm{CMM}$ and $\mathrm{MM}+\mathrm{E} 5+\mathrm{CMM}$ and $64 \%$ of $\mathrm{MM}+\mathrm{CMM}$ plants were severely wilted (score 3 and above). All plants that were not inoculated with $\mathrm{Cmm}$ remained healthy (data not shown). 


\section{Effect of dipping the roots and spraying the shoots with Pseudomonas consortia}

The effect of applying Pseudomonas consortia (E1 and E5) was tested to see if a minimal and direct application on the roots and shoots would enhance tolerance of $\mathrm{cv}$. Moneymaker against $\mathrm{Cmm}$ after stem infection. The highly tolerant NIL was included to see if there was any complementary effect of the Pseudomonas consortia.

On $28 \mathrm{dpi}$, there was no significant difference in wilting symptoms of stem inoculated plants which were treated with consortia and non-treated MM plants. More than half of the plants were severely wilted (score 3 or higher) for each treatment (Figure 3a). The final scoring for the NILs was $35 \mathrm{dpi}$. All NIL plants except one were still healthy (score 0). All plants that were not inoculated with $\mathrm{Cmm}$ remained also healthy.

a)

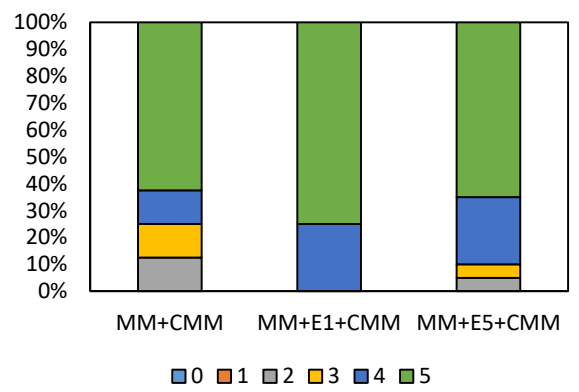

b)

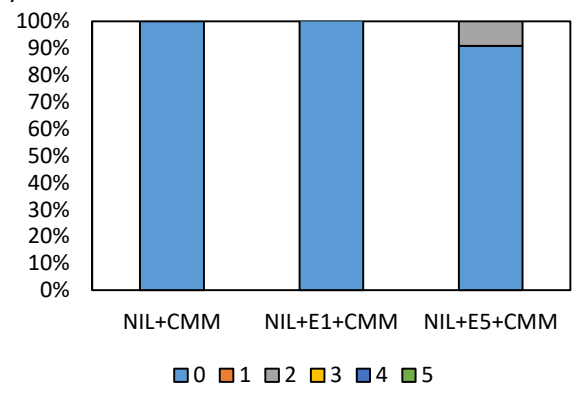

Figure 3 | The effect of applying Pseudomonas sp. consortia (E1 and E5) on cv. Moneymaker (MM) and Near-isogenic line (NIL). Plant roots were dipped in E1, E5 or water for 30 minutes before transplanting, a week after the shoots were sprayed with the treatments. Stem inoculation with $\mathrm{Cmm}$ was performed during the fourth leaf stage. Coloured bars show the percentage of plants for each disease index. Disease index is $0=$ no symptoms; $1=0$ to $25 \%$ leaf wilting; $2=26$ to $50 \% ; 3=51$ to $75 \% ; 4=76$ to $100 \% ; 5=$ dead plants. a) disease index of MM at $28 \mathrm{dpi}$ b) disease index of $\mathrm{MM}$ at $35 \mathrm{dpi}$.

\section{Presence of Pseudomonas consortia in the in vitro plants}

To determine if the Pseudomonas consortia present in the tomato stems and leaves, E1 and E5 were supplemented to in vitro growing tomato seedlings. This avoids the potential presence of other Pseudomonas species. We observed growth of Pseudomonas on Cetrimide agar containing suspension of in vitro plantlets supplemented by E1 and E5. No Pseudomonas growth was observed on untreated plants. 


\section{Discussion}

In this study, we tested two approaches that might be useful in an integrated strategy to reduce symptom expression of $\mathrm{Cmm}$ in tomato. These techniques were grafting and the use of a biocontrol agent.

Solanum arcanum LA2157 was used as rootstock as it has been shown to be the most tolerant genotype found so far with limited leaf wilting after infection with Cmm (van Heusden et al. 1999; Sen et al. 2013). This genotype has been used in our breeding program to identify a major QTL conferring tolerance to $\mathrm{Cmm}$. Furthermore, S. arcanum LA2157 was shown to be resistant against early blight (Alternaria solani) (Chaerani et al. 2007; Shinde et al. 2017). We tested the effect of grafting to control $\mathrm{Cmm}$ symptoms because of the success of grafting against soil and foliar pathogens (Sakata et al. 2006; Louws et al. 2010) and it is a fast way to exploit the resistance/ tolerance for available commercial cultivars. The genetic and biochemical mechanisms behind this resistance mechanism in grafting is unclear. Our results showed that grafting reduces wilting when the pathogen enters through the root. Previous studies showed that there can be an exchange of genetic material between the scion and the rootstock of grafted plants. Some proteins and RNAs can translocate over the graft junctions (Stegemann and Bock 2009). However, this translocation is restricted to the graft site and no translocation to distal plant tissue was found (Stegemann and Bock 2009). Stem inoculation was done at the petiole of first and second leaves, above the graft union site. Conceivably, the effect conferring tolerance in the rootstock of S. arcanum LA2157 did not translocate to the $\mathrm{cv}$. Moneymaker scion above the graft junction which explained the appearance of disease symptoms on cv. Moneymaker. Recently, graft-transmitted resistance of cherry pepper to powdery mildew (Leveillula taurica) was shown to be due to elevated accumulation of reactive oxygen species (ROS), NADPH oxidase and pathogenesis-related (PR) gene expression (Albert et al. 2017). Their enhancement is likely due to an unknown graft-transmissible signal. If this signal occurred in our situation, it did not prevent $\mathrm{Cmm}$ proliferation and virulence.

If we look at another bacterial vascular pathogen of tomato, grafting is widely used to avoid disease symptoms caused by Ralstonia solanacearum. The success of grafting against $R$. solanacearum in tomato may be due to restriction of bacterial root colonization in the resistant cultivar (Prior 1993; Caldwell et al. 2017). Resistant roots of $\mathrm{cv}$. Hawaii 7996, delay colonization in the root vasculature. Once the pathogen invasion occurs, it is spatially confined to a smaller area within the root vascular cylinder. Bacterial colonization is not substantial in larger meta-xylem and cell wall deterioration is not conspicuous. The delay in colonization of the root vascular cylinder may facilitate the activation of defence response faster in the resistant 
cultivar (Caldwell et al. 2017). Other defence mechanisms may also play a role to suppress bacterial wilt. As observed in another resistant cultivar S. lycopersicum var. cerasiforme cv. CRA66, $R$. solanacearum bacteria colonized large meta-xylem vessels, and in this genotype the pathogen spread within the vasculature was not inhibited. Resistance in different resistant genotypes may be due to different genes and mechanisms. (Caldwell et al. 2017). The reason why there is a reduction of wilting after root inoculation in a grafted Moneymaker shoot on a S. arcanum LA2157 rootstock is unclear. It could be a tolerance factor of S. arcanum LA2157 or its xylem vessels structure hinders the progression of $\mathrm{Cmm}$ to the scion. Previous histological studies showed that some tolerant genotypes like Irat L3 and Hawaii 7998, have more and bigger tyloses than susceptible genotypes like Moneymaker and Lyconorma. (Stüwe and Tiedemann 2013). Tyloses are protuberances on parenchyma cells of xylem vessels that can block the spread of pathogens (Brodersen and McElrone 2013). Tyloses are a common defence mechanism in xylem vessels against several vascular pathogens, for example Verticillium albo-atrum and Fusarium oxysporum f.sp. lycopersici (Hutson and Smith 1980; Yadeta and Thomma 2013). We do not know whether tylose formation plays a role in S. arcanum LA2157. Microscopical studies should be performed to support this hypothesis.

There are many studies about the possibilities of antagonistic microorganisms against $\mathrm{Cmm}$, but there is no report on its practical application yet. Bottlenecks can be reproducibility, the costs of producing the antagonistic microorganisms on a large scale, and the best way to apply them on tomato plants. Many studies characterised the interaction of $\mathrm{Cmm}$ and antagonistic bacteria in vitro and subsequently tested them in planta. Inoculation in planta was through combining antagonistic bacteria and Cmm (Boudyach et al. 2001; Amkraz et al. 2010; El et al. 2017) or inoculating Cmm right after/before the treatment with antagonistic bacteria (Utkhede and Koch 2004; Lanteigne et al. 2012). This type of inoculation mimics the situation that happens in petri dishes where $\mathrm{Cmm}$ and other microorganisms are both present. In nature, $\mathrm{Cmm}$ does not cohabit with antagonistic bacteria thus the pathogen could enter the host through primary and secondary spread at any moment. Hence, we think that inoculating $\mathrm{Cmm}$ together with a biocontrol agent together is biased and does not depict what really happens in nature. As for that, in our study we have a "rest" period in which a week after the application of the biocontrol agents, the inoculation of $\mathrm{Cmm}$ was done. In the few studies that did the experiments in a similar way, the disease symptoms of treated plants remained high (Ślusarski 2009; Romero et al. 2014; Aksoy et al. 2017). Only plants that have been treated with Pseudozyma aphidis, a fungal biocontrol agent, show less $\mathrm{Cmm}$ disease symptoms. Plants were sprayed with the fungus on the shoot and three days later inoculation of $\mathrm{Cmm}$ was done by petiole clipping (Barda et al. 2015). In that study, Pseudozyma aphidis triggered 
pathogenesis-related genes and activated a resistance response in a salicylic-acidindependent manner (Barda et al. 2015).

Our results show that application of Pseudomonas spp. consortia resulted in higher wilting reduction on the root inoculated plants that have been weekly treated with the biocontrol agents. This might be due to the antagonistic interaction of Pseudomonas spp. consortia and $\mathrm{Cmm}$. Some of the Pseudomonas species used in this study are shown to have antimicrobial activity that could prevent pathogen growth (Ramette et al. 2011; Lanteigne et al. 2012; Novinscak et al. 2016; Paulin et al. 2017; Sun et al. 2017). Thus, the direct contact of $\mathrm{Cmm}$ and Pseudomonas spp. consortia in the rhizosphere or root may delay the pathogen to colonize the xylem vasculature. There is little to no effect on the stem inoculated plants if they were weekly treated with Pseudomonas spp. consortia and there is no effect on stem inoculated cv. Moneymaker with minimal application of Pseudomonas spp. consortia. We hypothesized that even if the Pseudomonas spp. consortia presented on the shoots or in the xylem vessels, their population would not be enough to inhibit $\mathrm{Cmm}$ proliferation. Applying the consortia on the foliar weekly (for about six weeks) may increase the Pseudomonas spp. populations in the shoot and reduce the disease symptoms (Kritzman 2014). To determine the effectiveness of applying the Pseudomonas spp. against $\mathrm{Cmm}$ in the rhizosphere, a longer scoring time, bigger tomato populations and studies on population dynamics of the biocontrol agents are needed.

Combination of different Pseudomonas species can improve effectiveness against many plant pathogens because of the combination of different disease-suppressive mechanisms (de Boer et al. 2003; Bakker et al. 2007). It is interesting to note that enhancer 5 (E5) could reduce wilting symptoms even without two P. putida strains. Different consortia combinations of the available Pseudomonas spp. could be tested in planta to see the synergistic effect against $\mathrm{Cmm}$. Induced systemic resistance (ISR), is an essential component for resistance of beneficial microbes in the rhizosphere by priming the whole plant body against a broad-spectrum of pathogens and insect herbivores (Pieterse et al. 2014). We hypothesized that $\mathrm{Cmm}$ is not affected by ISR as the resistance mechanism is effective against necrotrophic pathogens and insects that are sensitive to jasmonic acid (JA) and ethylene (ET) dependent defences (van Wees et al. 2008). Clavibacter michiganensis susbp. michiganensis is mainly a biotrophic pathogen although it can develop into a necrotrophic lifestyle at a later stage (Eichenlaub et al. 2006). Our NIL plants did not exhibit severe wilting symptom with or without the treatment with Pseudomonas spp. consortia showing that the tolerance mechanism from S. arcanumum LA2157 is very effective to fight Cmm. So far, we still do not know what causes the NIL to be highly tolerant towards the pathogen. 
Our study shows the use of grafting and biological control agents in reducing wilting symptoms but only if $\mathrm{Cmm}$ enters trough the root. In the future, more rootstocks could be tested and combining both grafting and biological control agents together could be done to see if it will give a stronger effect towards reducing disease symptoms caused by $\mathrm{Cmm}$.

\section{Acknowledgements}

We would like to thank Nunhems, vegetable seeds of BASF, The Netherlands; Universiti Putra Malaysia and Ministry of Higher Education Malaysia, Malaysia for financial support and Joyce Arnouts of BioscienZ, Breda, The Netherlands for providing the Pseudomonas spp. consortia and fruitful discussions on the applications. 


\section{Supplementary material}

Table S1 | Effect of stem inoculation with Clavibacter michiganensis subsp. michiganensis of grafted plants with different combinations of rootstocks and scions between S. lycopersicum cv. Moneymaker (MM) and S. arcanum LA2157 (LA) on the disease effect

\begin{tabular}{lllll}
\hline \multirow{2}{*}{ Treatment $^{\mathbf{x}}$} & \multicolumn{4}{c}{ Disease index $^{\mathbf{y}}$} \\
\cline { 2 - 5 } & $\mathbf{1 4} \mathbf{d p i}$ & $\mathbf{1 9} \mathbf{~ d p i}$ & $\mathbf{2 4} \mathbf{~ d p i}$ & $\mathbf{2 9} \mathbf{~ d p i}$ \\
\hline MM:LA & $0.0 \mathrm{a}^{\mathrm{z}}$ & $0.9 \mathrm{a}$ & $1.9 \mathrm{a}$ & $2.2 \mathrm{a}$ \\
\hdashline LA:MM & $1.1 \mathrm{c}$ & $2.4 \mathrm{~b}$ & $4.3 \mathrm{~b}$ & $4.3 \mathrm{~b}$ \\
\hline LA:LA & $0.0 \mathrm{ab}$ & $1.0 \mathrm{ab}$ & $2.0 \mathrm{a}$ & $2.0 \mathrm{a}$ \\
\hline MM:MM & $0.9 \mathrm{bc}$ & $2.5 \mathrm{~b}$ & $3.9 \mathrm{~b}$ & $4.1 \mathrm{~b}$ \\
\hline
\end{tabular}

${ }^{x}$ Treatment (rootstock:scion)

yAverage symptom score of each treatment $(n=10)$.

${ }^{z}$ Mean separation within column by Kruskal-Wallis at $\mathrm{P}=0.05$ using stepwise step-down analysis. Within each column, disease score sharing the same letter are not significantly different.

Table S2 | Effect of root inoculation with Clavibacter michiganensis subsp. michiganensis of grafted plants with different combinations of rootstocks and scions between S. lycopersicum cv. Moneymaker (MM) and S. arcanum LA2157 (LA) on the disease effect.

\begin{tabular}{lllll}
\hline \multirow{2}{*}{ Treatment $^{\mathbf{x}}$} & \multicolumn{4}{c}{ Disease index $^{\mathbf{z}}$} \\
\cline { 2 - 5 } & $\mathbf{2 1} \mathbf{d p i}$ & $\mathbf{2 6} \mathbf{~ d p i}$ & $\mathbf{3 1} \mathbf{~ d p i}$ & $\mathbf{3 6} \mathbf{~ d p i}$ \\
\hline MM:LA & 0.0 & $0.0 \mathrm{ab}$ & $0.1 \mathrm{a}$ & $0.3 \mathrm{a}$ \\
\hdashline LA:MM & 0.0 & $0.3 \mathrm{bc}$ & $0.9 \mathrm{~b}$ & $2.0 \mathrm{~b}$ \\
\hline LA:LA & 0.0 & $0.0 \mathrm{a}$ & $0.0 \mathrm{a}$ & $0.1 \mathrm{a}$ \\
\hline MM:MM & 0.1 & $1.0 \mathrm{c}$ & $1.8 \mathrm{~b}$ & $3.0 \mathrm{c}$ \\
\hline
\end{tabular}

xTreatment (rootstock:scion).

${ }^{y}$ Average symptom score of each treatment $(n=10)$.

${ }^{\mathrm{z}}$ Mean separation within column by Kruskal-Wallis at $\mathrm{P}=0.05$ using stepwise step-down analysis. Within each column, disease score sharing the same letter are not significantly different.

Table S3 | DNA copy number of Clavibacter michiganensis subsp. michiganensis of root inoculated grafted plants on $36 \mathrm{dpi}$.

\begin{tabular}{lcll}
\hline Treatment $^{\mathbf{x}}$ & Disease index $^{\mathbf{y}}$ & Plant part & Bacterial titre \\
\hline MM:LA & 0.3 & Shoot & $2.89 \times 10^{3}$ \\
& Root & $2.97 \times 10^{3}$ \\
\hline LA:MM & 2.0 & Shoot & $2.45 \times 10^{3}$ \\
& & Root & n/a \\
\hline LA:LA & 0.1 & Shoot & n/a \\
\cline { 1 - 3 } & & Root & n/a \\
\hline MM:MM & 3.0 & Shoot & $1.68 \times 10^{6}$ \\
& & Root & $1.18 \times 10^{6}$ \\
\hline
\end{tabular}

${ }^{x}$ Treatment (rootstock:scion)

'Average symptom score of each treatment $(n=10)$. 



\section{CHAPTER}

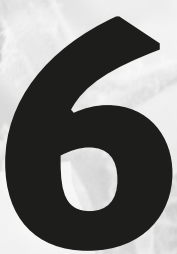

General discussion 


\section{In pursuit of symptomless tomato plants after infection with Clavibacter michiganensis subsp. michiganensis}

Our group started to search for resistance against bacterial canker in tomato caused by Clavibacter michiganensis subsp. michiganensis (Cmm) in the 1980's (van Steekelenburg 1985), and in the 1990's a mapping study was executed and three Quantitative Trait Loci (QTL) were found (van Heusden et al. 1999). Solanum arcanum LA2157 was the source of resistance. During these studies it became clear that our source of resistance is highly tolerant towards $\mathrm{Cmm}$. That means even though wilting and canker symptoms do not appear, bacterial density in the infected plant is still considerably high (Sen et al. 2013). This makes breeding companies reluctant to use this type of resistance since the bacteria can spread unnoticed from symptomless tolerant plants to susceptible cultivars. Nevertheless, highly tolerant tomato plants that remain symptomless after $\mathrm{Cmm}$ infection for a long period are valuable for farmers.

In our pursuit of developing tomato varieties that stay symptomless after $\mathrm{Cmm}$ infection, we came closer to the genes that are involved and we found out that also $S$-genes can add to tolerance. Furthermore, the use of grafting and biological control reduced wilting symptoms if $\mathrm{Cmm}$ infection came via the roots. In the following topics, we will discuss in details the potentiality of the approaches that we used in this thesis to get symptomless resp. reduced symptom tomato plants. Afterwards we will discuss other possibilities of getting tolerant tomato plants and the future perspectives.

\section{In vitro assay}

To screen for resistance resp. tolerance requires a lot of plants and a large space, which is a challenge when it comes to $\mathrm{Cmm}$. Already for a long time $\mathrm{Cmm}$ is a quarantine organism and the regulations to work with it became stricter. In the past, screening of tomato plants against $\mathrm{Cmm}$ could be carefully done in a normal greenhouse and after cleaning this greenhouse it could be used for other purposes. More space makes it possible to screen larger populations for extended periods making the distinction between highly tolerant, middle tolerant and susceptible more clear. For our experiments we could only use a small quarantine compartment. This made it impossible to screen many plants at the same time, partly because cross-contamination can occur if too many plants are in a small compartment. In our search for an alternative method we developed an in vitro assay where in small containers individual plantlets can be screened in a climate room. This in vitro assay makes it possible to screen larger populations in one experiment (Chapter 2). 
Screening for resistant genotypes using in vitro assays is not new (Svabova et al. 2005). In the Cmm-tomato interaction, it has been used to generate resistant/ tolerant somaclones (van den Bulk et al. 1991) and to screen somaclones with $\mathrm{Cmm}$ in vitro (Sotirova et al. 1999). Other studies that use in vitro assays are listed in Table 1. Those studies used the dual culture of the host and pathogen in vitro to avoid cross-contamination of the pathogen (O'Herlihy et al. 2012), the easiness to see the symptoms on the in vitro plants (Barlass et al. 1986; Russo and Slack 1998; van Vuuren and Woodward 2001; Mazier et al. 2004; Winterhagen et al. 2007; RodríguezMoreno et al. 2008; Al Abdallat et al. 2010; Miazzi et al. 2010; Hanus-Fajerska et al. 2014; Xu et al. 2015; Azadmanesh et al. 2016), and the speed of the screening system (Loreti et al. 2008; Sedlák et al. 2016). However, some drawbacks can be present (Table 1). Nonetheless, an in vitro screening method is an efficient method to screen large sample numbers using limited experimental space. 
Table 1 | In vitro methods used for screening for resistance in several crops.

\begin{tabular}{|c|c|c|}
\hline Crop & Pathogen & Remark \\
\hline \multirow[t]{3}{*}{$\begin{array}{l}\text { Tomato } \\
\text { (Solanum lycopersicum) }\end{array}$} & Tomato yellow leaf curl virus (TYLCV) & $\begin{array}{l}\text { Development of in vitro method } \\
\text { for TYLCV inoculation of tomato }\end{array}$ \\
\hline & Ralstonia solanacearum & $\begin{array}{l}\text { Dual culture of } 5000 \text { mutants with } \\
R \text {. solanacearum in vitro }\end{array}$ \\
\hline & $\begin{array}{l}\text { Meloidogyne incognita, M. javanica } \\
\text { and M. arenaria }\end{array}$ & $\begin{array}{l}\text { Development of in vitro culture of } \\
\text { tomato with nematodes }\end{array}$ \\
\hline $\begin{array}{l}\text { Lettuce } \\
\text { (Lactuca sativa L.) }\end{array}$ & Lettuce mosaic virus (LMV) & $\begin{array}{l}\text { Development of in vitro method } \\
\text { for LMV inoculation of lettuce }\end{array}$ \\
\hline \multirow[t]{3}{*}{$\begin{array}{l}\text { Grapevine } \\
\text { (Vitis vinifera) }\end{array}$} & Plasmopara viticola & $\begin{array}{l}\text { Dual culture of grapevine with } \\
\text { downy mildew for in vitro } \\
\text { screening }\end{array}$ \\
\hline & Grapevine fanleaf virus (GFLV) & $\begin{array}{l}\text { In vitro screening method for } \\
\text { detecting Grapevine fanleaf virus } \\
\text { (GFLV) from ectoparasitic vector } \\
\text { nematode Xiphinema index } \\
\text { (Longidoridae) }\end{array}$ \\
\hline & Erysiphe necator & $\begin{array}{l}\text { In vitro screening to evaluate the } \\
\text { susceptibility of different grapevine } \\
\text { cultivars to powdery mildew }\end{array}$ \\
\hline Daphne & Thielaviopsis basicola & $\begin{array}{l}\text { In vitro root culture to screen } \\
\text { different Daphne genotypes } \\
\text { against fungal pathogen }\end{array}$ \\
\hline $\begin{array}{l}\text { Cassava } \\
\text { (Manihot esculenta Crantz) }\end{array}$ & Meloidogyne javanica & $\begin{array}{l}\text { In vitro screening method for } \\
\text { root-knot nematodes resistance in } \\
\text { different cassava cultivars }\end{array}$ \\
\hline $\begin{array}{l}\text { Water spinach } \\
\text { (Ipomoea aquatica) }\end{array}$ & $\begin{array}{l}\text { Meloidogyne incognita, M. javanica } \\
\text { and M. arenaria }\end{array}$ & $\begin{array}{l}\text { Development of in vitro culture of } \\
\text { water spinach roots with nematode }\end{array}$ \\
\hline \multirow[t]{2}{*}{$\begin{array}{l}\text { Potato } \\
\text { (Solanum tuberosum) }\end{array}$} & Potato virus Y (PVY) & $\begin{array}{l}\text { Development of in vitro inoculation } \\
\text { for screening PVY resistant } \\
\text { transgenic potato plants }\end{array}$ \\
\hline & Pectobacterium carotovorum & $\begin{array}{l}\text { In vitro screening method to } \\
\text { evaluate } 46 \text { potato genotypes for } \\
\text { resistance to bacterial soft rot }\end{array}$ \\
\hline $\begin{array}{l}\text { Apple } \\
\text { (Malus pumila) }\end{array}$ & Erwinia amylovora & $\begin{array}{l}\text { Development of in vitro inoculation } \\
\text { for testing apple resistance to fire } \\
\text { blight }\end{array}$ \\
\hline $\begin{array}{l}\text { Olive } \\
\text { (Olea europaea) }\end{array}$ & $\begin{array}{l}\text { Pseudomonas savastanoi pv. savastanoi } \\
\text { and } P \text {. savastanoi pv. nerii }\end{array}$ & $\begin{array}{l}\text { Pathogenicity test of in vitro } \\
\text { olive plants on } P \text {. savastanoi pv. } \\
\text { savastanoi and } P \text {. savastanoi pv. nerii }\end{array}$ \\
\hline $\begin{array}{l}\text { Pear } \\
\text { (Pyrus communis) }\end{array}$ & Erwinia amylovora & $\begin{array}{l}\text { In vitro protocol to evaluate the } \\
\text { resistance of pear cultivars against } \\
\text { Erwinia amylovora }\end{array}$ \\
\hline
\end{tabular}

\footnotetext{
${ }^{a}$ The disadvantage of the in vitro screening as reported. $\mathrm{n} / \mathrm{a}=$ not available.
} 


\section{Bottleneck $^{\mathrm{a}}$}

$\mathrm{n} / \mathrm{a}$

$\mathrm{n} / \mathrm{a}$

$\mathrm{n} / \mathrm{a}$

$\mathrm{n} / \mathrm{a}$

- Differences between different degrees of resistance were not apparent

- Takes a long time to establish sufficient plant cultures

- Infection rate is lower due to shorter incubation time

\section{Reference}

(Al Abdallat et al. 2010)

(O'Herlihy et al. 2012)

(Xu et al. 2015)

(Mazier et al. 2004)

(Barlass et al. 1986)

(Winterhagen et al. 2007)

- Limited development of root-knot nematodes on MS (Murashige \& Skoog) medium

- Populations of M. javanica and M. arenaria are less than

(Xu et al. 2015)

$M$. incognita on the water spinach roots. Could be due to host preference of the species

n/a (Sedlák et al. 2016) 


\section{Cenetic analysis of tolerance against $\mathrm{Cmm}$}

Several studies have been done to understand the nature of tolerance in tomato against $\mathrm{Cmm}$ and different types of interactions were found: additive (van Heusden et al. 1999; Coaker and Francis 2004), polygenic (Thyr 1972), incomplete dominance (Thyr 1976) and dominant (Vulkova and Sotirova 1993). For our group, we aimed for resistance and in principle now that we found out that the bacterial density is still high in the symptomless plants, tolerance instead of resistance is a better term to use. Previously an intraspecific backcross population between the susceptible S. arcanum LA2172 and the highly tolerant S. arcanum LA2157 was used to map loci putatively involved in tolerance (Sandbrink et al. 1995), and five regions were identified (on chromosomes 1, 6, 7, 8 and 10). The QTL mapping of the interspecific F2 population between S. lycopersicum cv Solentos and S. arcanum LA2157 revealed QTL on chromosomes 5,7 and 9. The tolerance loci were additive and co-dominant, and the QTL on chromosome 7 conferred the largest part of the variation (van Heusden et al. 1999).

About fifteen years later fine mapping studies were done by adding more markers in the QTL regions. The different QTL regions were reduced to $28 \mathrm{Mb}$ on chromosome 5, 1.2 Mb on chromosome 7 and the QTL region on chromosome 9 was not reduced (Sen 2014). Our current fine mapping effort has reduced the QTL on chromosome 7 to $211 \mathrm{~kb}$ and it was shown that a Nearly Isogenic Line (NIL) containing this QTL is highly tolerant (Chapter $\mathbf{3}$ ). This was not expected based on the F2 mapping results where at least one additional QTL besides the QTL on chromosome 7 was needed. This newly fine mapped region can be further delimited by adding more markers or an extra fine mapping effort. An alternative to find the genes underlying the tolerance is to do functional studies: 1) virus-induced gene silencing (VIGS) assays in our Nearly Isogenic Lines (NILs); silencing the right genes will lead to susceptibility (Balaji et al. 2011; Esparza-Araiza et al. 2015), 2) stable silencing of the candidate genes in the NILs by genetic transformation and 3) overexpression of the candidate genes in susceptible tomatoes to see whether overexpression can lead to symptomless plants (Balaji and Smart 2012).

Another source that confers tolerance is S. habrochaites LA407. S. habrochaites LA407 was used due to the fact that it can be easily crossed to cultivated tomato (Francis et al. 2001). Mapping studies using an inbred backcross population (IBC) resulted in the identification of loci on chromosomes 2 ( $R \mathrm{~cm} \mathrm{2.0)}$ and 5 (Rcm 5.1) (Kabelka et al. 2002). Follow up studies from the same group were done to fine map and to identify the genetic effects. Fine mapping narrowed $R \mathrm{~cm} 2.0$ to a 4.4 $\mathrm{CM}$ interval and Rcm 5.1 to a $2.2 \mathrm{cM}$ interval. The two loci exhibit additive gene action and interact epistatically (Coaker and Francis 2004). In another experiment a 
QTL, controlling stem morphology, originated from S. habrochaites LA407 was also mapped on chromosome 2. It was speculated that this QTL might be involved in tolerance against $\mathrm{Cmm}$ (Coaker et al. 2002). However, no proof could be found that the Rcm 2.0 and the vascular morphology QTL were controlled by the same gene(s).

\section{Susceptibility gene(s) as source of tolerance}

Additionally, we tried to introduce tolerance by using susceptibility genes ( $S$-genes). Combining the tolerance factor(s) with non-functional S-genes might make the plant more and more durable tolerant. Exploiting $S$-genes for resistance is not new, but it was never done for the tomato-Cmm interaction (Chapter 4). We choose two $S$-genes located in the QTL of chromosomes 7 and 9 to see whether their localization in the QTL is coincidental or that they are involved in conferring tolerance. We hypothesized that S-genes, involved in Cmm tolerance, are non-functional in S. arcanum LA2157. This approach was successful to find the $S$-gene causing resistance to powdery mildew in cucumber (Berg et al. 2015).

In our study, virus-induced gene silencing (VIGS) assays in tomato with the two $S$-genes, located in the QTL regions, did not result in different levels of tolerance. Two other S-genes were selected based on previous studies in host plants challenged with vascular pathogens (van Schie and Takken 2014). One of these, the WAT1 gene, looked promising as the silenced tomato plants have a higher tolerance to $\mathrm{Cmm}$ than the control plants. We do not know the mechanism in which wat 1 functions in preventing wilting and canker symptoms. One of the limiting factors is the VIGS assay, even though the application of a VIGS assay can expedite the screening of many candidate genes, the patchiness of the silencing level in the different parts of the plants affects the score of the tolerance. After identifying the best candidate genes with VIGS, stable transformants must be made using gene silencing techniques like RNAi, or knocking-out genes using the CRISPR-Cas9 system. Stable transformants can then be used to determine the role of WAT1 in preventing symptoms (Arora and Narula 2017). Currently, our group is testing more $S$-genes to see if there are other genes that could lead to reduced susceptibility.

Utilizing both tolerance factors and S-genes might improve the durability of tolerance against $\mathrm{Cmm}$. The region of the WAT1 gene was not found in our mapping studies but this might be due to a functional WAT1 gene was in both tomato as well as in S. arcanum LA2157. A combination of the QTL on chromosome 7 and an impaired WAT1 gene in a single plant might enhance the tolerance. 


\section{Alternative ways to manage the spread of the pathogen}

In the process of looking at preventing $\mathrm{Cmm}$ outbreaks, $R$-genes and $\mathrm{S}$-genes can play an important role but a more holistic approach should also include agronomic considerations like cultural practises and the use of biocontrol agents. The use of grafting techniques and biocontrol agents (Pseudomonas species) were tested to see if they could be used as an alternative or complementary way to prevent symptom development (Chapter 5). For the experiment involving grafting, we hypothesized that there could be a translocation of genes involving tolerance or signals from the rootstock of S. arcanum LA2157 to the scion of cv. Moneymaker that could lead to tolerance. Unfortunately, that was not the case. Reduction of wilting symptoms only occurred on the scion of cv. Moneymaker grafted on S. arcanum LA2157 rootstock when $\mathrm{Cmm}$ entered through the root but not stem. The reason behind reduction of wilting symptoms is unclear. It could be that the tolerance factor of $S$. arcanum LA2157 or the structure of its xylem vessels hinder the progression of $\mathrm{Cmm}$ to the scion. Further microscopy studies could be done to confirm this hypothesis. Even though we did not see reduction of wilting symptom in the stem inoculated of cv. Moneymaker (scion) grafted on S. arcanum LA2157 (rootstock), we cannot rule out the possibility of grafting as an alternative method to reduce $\mathrm{Cmm}$ symptoms. More rootstocks that could reduce $\mathrm{Cmm}$ symptoms, prevent other pathogens and improve plant vigour and yield can be tested.

For our study on biocontrol agents, instead of focusing on one species, a consortium of different species, was used to study the antagonistic effect, or the enhancement of plant immunity. We observed reduction of wilting symptoms only after root-, but not after stem inoculation. The fact that less wilting was observed from root entry but not stem entry might be due to antagonistic behaviour and not due to induced systemic resistance (ISR). Pseudomonas spp. may hinder the pathogen to colonize the xylem vasculature in the rhizosphere or root as seen for some pseudomonas species (Ramette et al. 2011; Lanteigne et al. 2012; Ait Bahadou et al. 2018). Even though beneficial microbes are known to induce systemic resistance (ISR), we hypothesized that $\mathrm{Cmm}$ is not affected by it. Induced systemic resistance is effective against necrotrophic pathogens and insects that are sensitive to jasmonic acid (JA) and ethylene (ET) dependent defences (van Wees et al. 2008). Clavibacter michiganensis susbp. michiganensis is mainly a biotrophic pathogen although it can evolve into a necrotrophic lifestyle at a later stage (Eichenlaub et al. 2006). Screening of more biocontrol agents could be tested with the available Pseudomonas species to test their synergistic effect to reduce $\mathrm{Cmm}$ disease symptoms. 


\section{Tomato tolerance against $\mathrm{Cmm}$}

\section{The mystery of S. arcanum LA2157}

In our group we are focusing on S. arcanum LA2157 as a resistance source. In our search for the best donor, we have screened solely on wilting symptoms (van Steekelenburg 1985; van Heusden et al. 1999), and the resistance was thus characterised by a lack of wilt symptoms. Recently we found that Solanum arcanum LA2157 is not really resistant but rather tolerant to $\mathrm{Cmm}$. It is possible that $\mathrm{Cmm}$ interacts differently with S. arcanum LA2157 than with cultivated tomatoes and wilting could not be seen clearly because of the morphology of the leaves. Previous studies (De Jong and Honma 1976) state that the criteria to determine non-resistance should include wilting, stunting and the presence of canker. In certain genotypes and environments, wilting alone is not the best observation to determine susceptibility against $\mathrm{Cmm}$. One should examine other traits as well if wilting is not obvious enough to determine susceptibility. Neither stem discoloration nor canker was seen on infected S. arcanum LA2157 plant, but minor stunting did occur on some plants. In Chapters 2 \& 3, we included both leaf wilting and stem canker as phenotyping criteria. We observed that many of our in vitro plantlets developed canker which is rarely seen in our greenhouse plants. It is likely that the high humidity in the in vitro conditions is affecting the canker development on susceptible plants. Our plants from the NIL population do not have wilting symptoms (at the most only a few leaflets) and do not stunt or have stem discolorations or cankers

Up to now, the underlying tolerance mechanism in S. arcanum LA2157 is still a mystery. Some innate genes in the QTL region of S. arcanum LA2157 might differ from those of tomato or Cmm is non-adapted to S. arcanum LA2157. Taking these two aspects into account, the tolerance in S. arcanum LA2157 might be a nonhost resistance (Senthil-Kumar and Mysore 2013; Gill et al. 2015). There are few points to support this hypothesis. Firstly, the C. michiganensis subspecies specifically infects one type of host and the common host of $\mathrm{Cmm}$ is tomato (Solanum lycopersicum) (Eichenlaub et al. 2006). The pathogen is thought to be a relatively new pathogen which developed from endophytic bacterial species and not many genetic differences were found between different Cmm strains (Eichenlaub and Gartemann 2011; Thapa et al. 2017; Sen et al. 2018). Solanum arcanum LA2157 is a distinct relative of cultivated tomato, it might be that $\mathrm{Cmm}$ has not adapted to be virulent on this Solanum species (Grandillo et al. 2011). Other S. arcanum accessions are also highly tolerant (Sen et al. 2013), with the exception S. arcanum LA2172 (Sandbrink et al. 1995). However, S. arcanum LA2172 was considered tolerant by another group (Lara-Ávila et al. 2011). Despite the ambiguity in these findings, Cmm may not yet adapted to the S. arcanum LA2157. Previous QTL analysis suggested, that several genes were associated with tolerance pointing in the direction of nonhost resistance (van Heusden et al. 1999; Senthil-Kumar and Mysore 2013). 
There are three layers of defence for nonhost resistance (Senthil-Kumar and Mysore 2013). The first one restricts the entry of the pathogen (physical barrier) and usually is already present or it can be induced. The second layer of defence acts as soon as the pathogen reaches the apoplastic region. This step involves both constitutive as induced defences. The constitutive layer of defence could be due to the antimicrobial compounds produced by the host coupled with overall apoplastic physiological incompatibility. The last layer involves inducible defence responses triggered in the plant cytoplasmic region and executed in the cell wall region or apoplast. The induced plant defence responses described above require perception of pathogen-associated molecular patterns (PAMPs), virulence factors etc. In the S. arcanum LA2157 Cmm interaction, it is possible that after infection, the small xylem vessel and the cell wall composition act as preformed defence barriers and restrict $\mathrm{Cmm}$ spreading (Romero et al. 2014; Esparza-Araiza et al. 2015). Induced defences may occur from tylose formation as observed in a previous study (Stüwe and Tiedemann 2013). The high accumulation of antimicrobial $\alpha$-tomatine in S. arcanum LA2157, may act as a preformed defence in the second step against tomatinase, an enzyme which is encoded by the tomA gene from $\mathrm{Cmm}$. A high level of $\alpha$-tomatine in S. arcanum LA2157 makes it resistant against Alternaria solani (Shinde et al. 2017). Whether tomA is required for $\mathrm{Cmm}$ virulence is not clear (Eichenlaub and Gartemann 2011). tomA mutants cause wilting and have similar bacterial densities as the controls (Kaup et al. 2005). This may be due to the low $\alpha$-tomatine in Moneymaker which does not affect the growth of the pathogen (Kaup et al. 2005). Despite this, we cannot rule out the possibility that a high $\alpha$-tomatine concentration in S. arcanum LA2157 inhibits Cmm growth or colonization.

It is unclear if there is any induced defence occurring in S. arcanum LA2157 against $\mathrm{Cmm}$ in the third layer of defence. For Proteobacteria, the virulence factors/effectors enter the plant cell through the type 3 secretion system (T3SS). Effectors (avirulence factors) are recognized directly through NB-LRR (nucleotide binding and leucine-richrepeats) or indirectly in resistant plants by a hypersensitive reaction (HR) preventing the spreading of the pathogen in the plant tissue (Jones and Dangl 2006). However, Cmm has a type 2 secretion system (T2SS) but not a T3SS, and no genes encoding effector proteins resembling those identified in Gram-negative bacterial pathogens were found in $\mathrm{Cmm}$ (Gartemann et al. 2008). Thus, just like the tomato- $\mathrm{Cmm}$ interaction model discussed in the general introduction, S. arcanum LA2157 may not have resistance genes leading to effector-triggered immunity (ETI) to $\mathrm{Cmm}$.

To identify what kind of genes underlie the tolerance in S. arcanum LA2157, we delimited our QTL on chromosome 7. This led to a region of $211 \mathrm{~Kb}$ containing 15 annotated genes. We speculated that the gene(s) in the region might have different expression levels in S. arcanum LA2157 compared to tomato and therefore make it more tolerant. So far there is only one study that compares the differential gene expression between 
Solanum arcanum LA2157 and tomato when infected with $\mathrm{Cmm}$. That study revealed protein transport protein Sec23 is expressed ten times more in S. arcanum LA2157 (8 dpi) compared to $S$. lycopersicum after infection. This protein is expressed five times more in S. arcanum LA2157 than in S. lycopersicum without Cmm infection (Lara-Ávila et al. 2011). This protein is not in our fine mapped region, but it would be interesting to see if this gene contributes to tolerance against $\mathrm{Cmm}$. The Sec23 protein is a component of the coat protein complex II (COPII) that promotes the formation of transport vesicles from the endoplasmic reticulum (ER) to the Golgi apparatus (Zeng et al. 2015). In recent studies in Arabidopsis, it was found that two components of the Sec23 homologs, the AtSec23A and AtSec23D, play essential roles in pollen wall formation as the mutant plants had an impaired exine pattern (Aboulela et al. 2018). So far, no study has shown the potential use of this protein under biotic stress and it is not clear whether this protein is involved in tolerance against $\mathrm{Cmm}$. A VIGS assay or stable knock-down/out transformation of the Sec23 gene in S. arcanum LA2157 will show whether silencing/knocking-out the gene leads to susceptibility (Esparza-Araiza et al. 2015). If it does, overexpression of the gene in a susceptible tomato could enhance tolerance.

Different metabolites and differentially expressed genes might be the reason why S. arcanum LA2157 is highly tolerant towards Cmm. However, comparing metabolites and gene expression between S. arcanum LA2157 and S. lycopersicum will lead to many differences. To focus on genes involved in tolerance, it is better to do comparative metabolomic studies and differential gene expression studies between the NIL containing the small introgression of S. arcanum LA2157 in a background of Moneymaker. A combination of these studies with the knowledge of the genes identified in the fine mapping experiment will pinpoint the gene products or metabolites that are responsible for the tolerance mechanism of this specific QTL.

\section{Other ways to get tolerance in S. lycopersicum}

The group of phytopathogenic Clavibacter michiganensis subspecies is considered as recently developed from endophytic bacterial strains (Eichenlaub and Gartemann 2011). The divergence between $\mathrm{Cmm}$ and Clavibacter michiganensis subsp. sepedonicus (Cms) was calculated to have occurred less than 1.2 million years ago (Bentley et al. 2008). It is hypothesized that $\mathrm{Cmm}$ acquired its virulence factors via horizontal gene transfer (Gartemann et al. 2008; Chalupowicz et al. 2010). Recently, it was found that different $\mathrm{Cmm}$ strains use different virulence factors thus there is a need of breeding tomato cultivars that can withstand multiple strains (Thapa et al. 2017). Other ways to get tolerance can also be achieved by manipulating the genes of S. lycopersicum (Pavan et al. 2009; Balaji and Smart 2012). 
Balaji et al. (2008) describe gene expression profiles in tomato of $\mathrm{Cmm}$-infected stem tissue during the endophytic stage ( $4 \mathrm{dpi})$ and in a later stage $(8 \mathrm{dpi})$. One hundred and twenty-two genes were differentially expressed in at least one time point which represents $1.3 \%$ of the genes analysed. More genes are likely to be differently expressed during the interaction as the array used in the study contained approximately one-fourth (9,254 genes) of the total estimated tomato genes (35,000 genes). Table 2 summarizes part of the differentially expressed genes. Genes in the table are more than 15 times upregulated in the tomato cultivar Rio Grande after inoculation with $\mathrm{Cmm}$.

Based on the S-gene concept, we could use innate genes of the susceptible genotype for tolerance against $\mathrm{Cmm}$ (Sun et al. 2014; van Schie and Takken 2014; Sun et al. 2016a). According to the $\mathrm{S}$-gene theory, $\mathrm{Cmm}$ uses tomato gene products to facilitate susceptibility and to contribute to the infection process. These susceptibility genes might be upregulated after $\mathrm{Cmm}$ infection. For instance, the Mildew Locus O (MLO) gene is upregulated upon pathogen infection (Berg et al. 2015; Pessina et al. 2016). Upon inoculation with cucumber powdery mildew pathogen, Podosphaera xanthii, there is transcriptionally upregulated expression of CsaMLO8 in the cucumber hypocotyl (Berg et al. 2015). The same observation was seen in grapevine as VVMLO7, 11 and 13 are upregulated during grape powdery mildew (Erysiphe necator) infection (Pessina et al. 2016).

However, not all upregulated genes are $\mathrm{S}$-genes. A good example is that upon $\mathrm{Cmm}$ infection, a subset of tomato genes involved in ethylene biosynthesis and response was induced (Balaji et al. 2008). The ACD mutant of tomato causes an ethylene reduction up to 90\%. After inoculation with $\mathrm{Cmm}$ the ACD mutant plants had a delayed wilting. Delayed wilting is also observed on the tomato ethylene insensitive Never ripe $(\mathrm{Nr})$ mutant. Ethylene production in tomato is a major signal that regulates disease progression, and is not used by $\mathrm{Cmm}$ for virulence or proliferation. Two other upregulated proteins, the RING/U-box superfamily protein and extensin-like protein, are also not $S$-genes. When these genes were silenced, the plants exhibited wilting symptoms after $\mathrm{Cmm}$ inoculation (Balaji et al. 2011).

Additionally, not all known S-genes in Table 2 that cause enhancement of resistance against other pathogens, can potentially be used against $\mathrm{Cmm}$. The DMR6 gene encodes 2-oxoglutarate (2OG) and Fe (II) oxygenase protein. It is shown that the Arabidopsis dmr6 mutant confers resistance to the downy mildew pathogen Hyaloperonospora arabidopsis/parasitica (van Damme et al. 2005), Pseudomonas syringae and Phytophthora capsici (Zeilmaker et al. 2015) and recent studies in silencing the gene in potato led to resistance against Phytophthora infestans (Sun et al. 2016b). DMR6 gene acts as a suppressor of plant immunity and silencing it activates the plant defence responses by increasing the level of salicylic acid (SA) (van Damme et al. 2008; Zeilmaker et al. 2015). We tested the tomato dmr6 RNAi line mutant against $\mathrm{Cmm}$, and did not see 
enhancement of resistance (data not shown in the thesis). Another $S$-gene that enhances resistance against pathogens is the PROTEIN DISULFIDE ISOMERASE (PDI) gene family. It plays a role as chaperone which helps in the arrangement of disulfide bonds for correct protein folding (Houston et al. 2005). In barley (Hordeum vulgare), the naturally recessive resistance against Bymoviruses, the barley yellow mosaic virus (BaYMV) and barley mild mosaic virus (BaMMV), is found in locus rym 11. The susceptibility factor in this locus is the PROTEIN DISULFIDE ISOMERASE LIKE 5-1 (HVPDIL5-1). Inhibition of PDI activity in the host suppressed the Bymovirus replication or infection in barley (Yang et al. 2014b). It is not known whether inhibiting this protein could also work against $\mathrm{Cmm}$ due to the different life cycle. Nevertheless, to determine if this gene or other upregulated genes shown in Table 2 can be potentially used against $\mathrm{Cmm}$ by using the S-gene concept, a VIGS assay could first be done. Virus-induced gene silencing can be tested on the susceptible genotype for a faster screening process. Follow up experiments should then include making stable transformation of the genes that not only confer resistance/tolerance in the VIGS screening but ideally also show no pleiotropic effects. This will confirm that inhibition of the gene(s) will lead to resistance/ tolerance to $\mathrm{Cmm}$.

A complementary approach of making use of the upregulated genes in Table 2 is to do overexpression studies. If silenced plants from the VIGS screening exhibit severe wilting, the genes that have been silenced might be important to fight the pathogen. Thus, overexpressing those genes may lead to resistance/tolerance just like the tomato mutant overexpressing the extensin-like protein exhibited a higher tolerance towards $\mathrm{Cmm}$ (Balaji and Smart 2012). Other overexpressed genes in Table 2 that enhance resistance against other pathogens are WRKY80, CAT1 and NAC6. Just like the expression pattern in tomato, the rice WRKY8O gene (OsWRKY80) is highly upregulated after infection of rice sheath blight disease (Rhizoctonia solani). The strong induction of OsWRKY8O expression by exogenous application of JA,ET and pathogen inoculation suggests that this gene may be involved in JA/ET-dependent defence signalling pathways. Overexpression of the gene in rice significantly enhanced disease resistance to the rice sheath blight disease (Peng et al. 2016). The same goes for CAT1 as overexpression of CAT1 in Arabidopsis resulted in a better resistance against $P$. syringae. This resistance might be due to activation of SA (Yang et al. 2014a). Furthermore, overexpression of the NAC transcription factors, the HVNAC6, increases the number of penetration resistant cells against Blumeria graminis f.sp. hordei (Bgh). HvNAC6 may act downstream of abscisic acid (ABA) biosynthesis, mediate early non-specific biotic stress sensing signals and influence stomata movement (Jensen et al. 2007). The genes mentioned above could be potential candidates to fight $\mathrm{Cmm}$. It would be interesting to see whether overexpression of these genes in tomato could also enhance resistance/tolerance against $\mathrm{Cmm}$. 
Table 2 | Differentially expressed tomato genes in response to infection by $\mathrm{Cmm}$. The table is based on and modified from Balaji et al. (2008)a.

\begin{tabular}{|c|c|c|c|c|c|c|}
\hline \multirow{2}{*}{$\begin{array}{l}\text { GenBank } \\
\text { Accession } \\
\text { Number }\end{array}$} & \multirow{2}{*}{ SGN ITAG 3.2} & \multirow{2}{*}{ Description $^{b}$} & \multicolumn{2}{|c|}{$\begin{array}{c}\text { Expression } \\
\text { ratio }\end{array}$} & \multicolumn{2}{|c|}{ VIGSc } \\
\hline & & & 4 dpi & $8 \mathrm{dpi}$ & $\begin{array}{c}\text { Pleitropic } \\
\text { effect }\end{array}$ & $\begin{array}{c}\text { Wilt } \\
\text { symptom }\end{array}$ \\
\hline U89256 & Solyc02g077370.1 & Ethylene Response Factor C.5 & 21.6 & 163.2 & No phenotype & Susceptible \\
\hline BT013271 & Solyc06g073080.3 & $\begin{array}{l}\text { 2-oxoglutarate (2OG) and } \\
\text { Fe(II)-dependent oxygenase } \\
\text { superfamily protein }\end{array}$ & 20.9 & 94.8 & & \\
\hline
\end{tabular}

\begin{tabular}{ccccc} 
AF272366 Solyc09g005080.7 & $\begin{array}{l}\text { verticillium wilt disease } \\
\text { resistance 2 }\end{array}$ & 50.2 & 87.5 \\
\hline Al776170 Solyc02g077040.4 & $\begin{array}{l}\text { phytophthora-inhibited } \\
\text { protease 1 }\end{array}$ & 32 & 80.8 \\
\hline
\end{tabular}

\begin{tabular}{|c|c|c|c|c|c|c|}
\hline BI204920 & Solyc03g 117860.3 & $\begin{array}{l}\text { RING/U-box superfamily } \\
\text { protein }\end{array}$ & 7.2 & 70.3 & Mild crinkling & Susceptible \\
\hline X85138 & Solyc01g107820.2 & TOMATO WOUND-INDUCED 1 & 8.5 & 66.2 & & \\
\hline
\end{tabular}

BI205190 Solyc09g092500.1 Glycosyltransferase $\quad 1.1 \quad 59.2$

$\begin{array}{llll}\text { BG629612 Solyc05g050130.3 Acidic endochitinase } & 19 & 55.4\end{array}$

BT014226 Solyc05g056400.3 Protein disulfide isomerase $15.5 \quad 52$

\begin{tabular}{c|l|l|l|} 
AW032318 Solyc03g033840.3 & $\begin{array}{l}\text { P-loop containing nucleoside } \\
\text { triphosphate hydrolases } \\
\text { superfamily protein }\end{array}$ & 8.1 & 38.1 \\
\hline AJ831935 Solyc03g095770.3 & WRKY transcription factor 80 & 3.5 & 36.4
\end{tabular}


Over-

- DMR6 gene catalyzes 2-oxoglutarate (2OG) and Fe(II)-dependent oxygenase

- Arabidopsis thaliana dmr6 mutants exhibits reduced susceptibility against Hyaloperonospora arabidopsis/parasitica, Pseudomonas syringae and Phytophthora capsici..

- Silencing the gene leads to resistance against potato late blight (Phytophthora infestans)

- However, tomato dmr6 RNAiline plants were susceptible against $\mathrm{Cmm}$ when tested by our group (results not shown in the thesis)

- Resistance against Verticillium wilt

- A pathogenesis-related (PR) protein.

- It is closely related to tomato apoplastic Cys protease, the Rcr3. It functions in fungal resistance and targeted by the protease inhibitor Avr2 of Cladosporium fulvum
(Kawchuk et al. 2001)

(Tian et al. 2006)

(van Damme et al. 2005; van Damme et al. 2008; Zeilmaker et al. 2015; Sun et al. 2016b)

- Defence-related gene which responds rapidly to wound and (O'Donnell et al. pathogen-related signals.

1998)

- Effector-triggered immunity (ETI) marker gene.

(Pombo et al. 2014;

- It exhibits high induction in tomato only during ETI Pseudomonas Pombo et al. 2017) syringae pv. Tomato

- Pathogenesis-related protein 11

(Andolfo et al. 2014;

Manzo et al. 2016)

- It catalyzes the correct folding of proteins and prevents the (Houston et al. 2005; aggregation of unfolded or partially folded precursors.

Yang et al. 2014b)

- Suppression of the protein delays replication to plant viruses.

- Susceptibility factor to Bymoviruses

- Natural loss-of- function alleles of HVPDIL5-1 in barley confer resistance to Bymoviruses

- Upregulated gene upon infection (24 hpi) against Phytophthora infestans and Botrytis cinerea

(Rezzonico et al. 2017)

- Overexpression of Oryza sativa WRKY80 gene (OsWRKY80)

(Peng et al. 2016) significantly enhanced disease resistance to Rhizoctonia solani

- Upregulated gene in $P$. infestans infected tissue.

(Rezzonico et al.

- Potential gene belonging to major resistance $(R)$ gene 2017)

- The Arabidopsis AtCRT1/2 and AtCRT3 are involved in regulating plant (Qiu et al. 2012) defence against Pseudomonas syringae

- ACE35 protein is required for nonhost resistance to Xanthomonas oryzae (Li et al. 2012) pv. Oryzae but not required for the Cf-4/Avr4-dependent HR. 


\begin{tabular}{|c|c|c|c|c|c|c|}
\hline \multirow{2}{*}{$\begin{array}{l}\text { GenBank } \\
\text { Accession } \\
\text { Number }\end{array}$} & \multirow{2}{*}{ SGN ITAG 3.2} & \multirow{2}{*}{ Description ${ }^{b}$} & \multicolumn{2}{|c|}{$\begin{array}{l}\text { Expression } \\
\text { ratio }\end{array}$} & \multicolumn{2}{|c|}{ VIGSc } \\
\hline & & & 4 dpi & 8 dpi & $\begin{array}{l}\text { Pleitropic } \\
\text { effect }\end{array}$ & $\begin{array}{c}\text { Wilt } \\
\text { symptom }\end{array}$ \\
\hline Al780536 & Solyc07g056200.3 & $\begin{array}{l}\text { Heavy metal transport/ } \\
\text { detoxification superfamily } \\
\text { protein }\end{array}$ & 9.3 & 33.9 & & \\
\hline Y10149 & Solyc08g079870.3 & subtilisin & 11.6 & 33.4 & & \\
\hline BI206504 & Solyc09g015770.3 & WRKY transcription factor 81 & 8.5 & 31.8 & & \\
\hline BE354113 & Solyc04g048900.3 & Calreticulin & 8.3 & 30.3 & & \\
\hline CN385704 & Solyc03g 115930.2 & $\begin{array}{l}\text { Calcium-binding EF-hand } \\
\text { family protein }\end{array}$ & 7.6 & 28.7 & & \\
\hline BG630825 & Solyc04g048900.3 & Calreticulin & 8.3 & 27.7 & & \\
\hline BI210305 & Solyc $10 g 055740.2$ & Amino acid transporter & 5.1 & 27.1 & & \\
\hline CN385590 & Solyc03g 116890.3 & WRKY transcription factor 39 & 2.4 & 24.7 & & \\
\hline K03291 & Solyc03g020080.3 & $\begin{array}{l}\text { Pin-II type proteinase } \\
\text { inhibitor } 69\end{array}$ & 18.1 & 24 & & \\
\hline BT012691 & Solyc 12g006380.2 & $\begin{array}{l}\text { 2-oxoglutarate-dependent } \\
\text { dioxygenase }\end{array}$ & 3.9 & 22.5 & & \\
\hline BG627176 & Solyc03g 114890.3 & COBRA-like protein & 4.3 & 19.9 & & \\
\hline
\end{tabular}

\begin{tabular}{lllll} 
AJ133600 Solyc01g006390.2 Extensin-like protein & 11.6 & 19.5 & No phenotype Susceptible \\
\cline { 1 - 3 } BT014403 Solyc10g055760.2 NAC domain protein NAC6 & 4.5 & 17.4 &
\end{tabular}

\begin{tabular}{|c|c|c|c|c|}
\hline BT013533 & Solyc06g008620.1 & tolB protein-like protein & 2.3 & 16.8 \\
\hline M69247 & Solyc09g007010.1 & Pathogenesis-related protein 1 & 1.8 & 16.2 \\
\hline AW033860 & Solyc08g066310.2 & Receptor-like protein kinase & 2.6 & 15.6 \\
\hline X79337 & Solyc05g007950.3 & $\begin{array}{l}\text { LERNALE L.esculentum } \\
\text { ribonuclease le }\end{array}$ & 10.6 & 15.5 \\
\hline
\end{tabular}

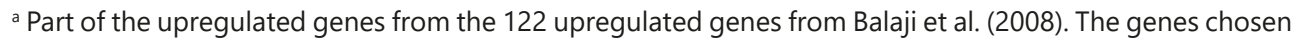
in this table are more than 15 times differentially regulated in cv Rio Grande inoculated with $\mathrm{Cmm}$. Genes are in descending order of fold ratio at 8 dpi.

${ }^{\mathrm{b}}$ Annotated genes from the Sol Genomics Network ITAG 3.2.

c Genes tested for virus-induced gene silencing (VIGS) assay on Nicotiana benthamiana, pleiotropic effect observed (if any), and wilt symptom after challenged with Cmm (Balaji et al. 2011).

${ }^{\mathrm{d}}$ Overexpression of the gene in cv Mountain Fresh and wilt symptom observed upon Cmm infection (Balaji and Smart 2012).
} 
Over-

expression $^{\mathrm{d}}$

- The Arabidopsis subtilase gene, the SBT3.3, may be linked to

(Ramírez et al. 2013) pathogen recognition and activation of signalling processes

- EPI1 protein of $P$. infestans inhibits and interacts with pathogenesis-

(Tian et al. 2005) related protein $\mathrm{P} 69 \mathrm{~B}$ subtilase

- Overexpression of the Arabidopsis CATIONIC AMINO ACID

(Yang et al. 2014a)

TRANSPORTER1 (CAT1) improved disease resistance against $P$. syringae

- Common jasmonic acid (JA) marker

(Li 2002; Ataide et al. 2016)

- Regulating the orientation of cell expansion.

(Schindelman et al.

- Arabidopsis COBRA mutants have reduced level of crystalline cellulose 2001) microfibils which suggested a role of the gene in crystallization or cellulose deposition.

\section{Tolerance}

- Positive regulator of penetration resistance.

(Jensen et al. 2007)

- Overexpression of the gene in barley leads to resistance towards powdery mildew fungus Blumeria graminis f.sp. hordei (Bgh)

- Marker gene for the systemic acquired resistance (SAR) response.

(López-Gresa et al.

- Expression of PR1 is salicylic acid (SA) responsive 2016)

- Large superfamily of proteins with similar structure. Involved in broad (Goff and Ramonell array of plants responses which include resistance to pathogens 2007) 


\section{The future of $\mathrm{Cmm}$ tolerance}

The quarantine status of the pathogen in Europe does not make it easy to screen big populations of tomato plants for resistance/tolerance against $\mathrm{Cmm}$. Furthermore, the tight regulations on $\mathrm{Cmm}$ in the Netherlands are necessary but hinder the research on tolerance and the tolerance mechanism of tomato against $\mathrm{Cmm}$. Different strategies have to be executed to by-pass this challenge. New protocols using in vitro plantlets as described in Chapter $\mathbf{2}$ help with the screening process. It reduces the space and cost to accommodate big populations and also the time period to monitor the symptoms. This application has helped with our fine mapping process in Chapter 3. However, the relation between results of in vitro and greenhouse studies depends on the tomato genotypes. A confirmation of the wilt symptoms of the in vitro technique with the greenhouse or field data should be done. The two parental genotypes that we were using for our breeding program exhibited similar disease symptoms in vitro and greenhouse assay. In our ongoing study, a modification of this protocol will be used to screen a large number of in vitro tomato seedlings with different Pseudomonas consortia against $\mathrm{Cmm}$ (Chapter 5). This helps us to identify the best combination of different Pseudomonas strains to fight $\mathrm{Cmm}$ using minimal space.

The use of next-generation sequencing enabled us to partly elucidate the mystery behind the tolerance against $\mathrm{Cmm}$. From a genomic perspective, many tomato genotypes have been resequenced or de novo sequenced (Víquez-Zamora et al. 2013; Aflitos et al. 2014). This included the parental genotypes that we have been using for our study (cv Moneymaker and S. arcanum LA2157). The available information expedited marker development for the fine mapping process. With the use of the RNA-sequencing method, we can look at the genes that play a role in tolerance. As discussed earlier, differential gene expression between cV. Moneymaker and the NIL can be an approach to see how the genes in the fine mapped region $(211 \mathrm{~Kb})$ behave. Using our NIL collection, we could delimit the size by looking at the differential gene expression of the NIL by comparing the transcriptomic data from cv. Moneymaker and the NIL. This shows also whether the not annotated genes in the region might play a role. In parallel to this work, the genes that are upregulated or unique in the susceptible genotypes could be potential candidate $S$-genes. Testing these genes by doing VIGS assays, followed by RNAi approaches or Crispr/Cas9 genome editing strategies might be interesting to see if there are novel $S$-genes that can be used against $\mathrm{Cmm}$. Using the RNA-seq technology to find new candidate $S$-genes to fight $\mathrm{Cmm}$ is currently ongoing in our group. 


\section{Take-home messages}

The tolerance against $\mathrm{Cmm}$ has good sides: the tolerance is good for the tomato to combat $\mathrm{Cmm}$ and for $\mathrm{Cmm}$ to grow and multiply. Without pathogenicity $\mathrm{Cmm}$ is just a bacterium like so many other naturally harmless bacteria. The problem is that worldwide all tomato cultivars are sensitive to $\mathrm{Cmm}$. In the dynamic world of seed companies, it might be possible to introduce more and more tolerant varieties. But it is not yet unravelled what the best and most direct method to make tolerant or even resistant varieties. The strict regulations on $\mathrm{Cmm}$ slow down the research progress and testing in field conditions must be done in countries where it is allowed. Our newly developed disease screening will help in research. With our fine mapping work, we reduced the region responsible for resistance/tolerance conferred by $S$. arcanum LA2157, but we still do not know what the genes are responsible for it. Whether this is needed for the development of tolerant cultivars is questionable. The use of the next-generation sequencing could help with speeding up answering the mechanism behind the tolerance and whether the tolerance level can be optimised. Maybe it is needed to optimise the tolerance level by introducing susceptibility genes in tomato. This will make breeding more complicated because $S$-genes are recessive. If we do not have resistant cultivars we should also investigate other ways of prevention. We have tested two alternative methods, but there are more ways that could be used to prevent the spread of $\mathrm{Cmm}$. In the future we hope to understand the interaction between tomato and $\mathrm{Cmm}$ better and that this will allow us to make truly resistant varieties. 



\section{References}

Aboulela M, Nakagawa T, Ohshima A, Nishimura K, Tanaka Y (2018) The Arabidopsis COPII components, AtSEC23A and AtSEC23D, are essential for pollen wall development and exine patterning. J Exp Bot 69:1615-1633. doi: 10.1093/jxb/ery015

Acevedo-garcia J, Kusch S, Panstruga R (2014) Magical mystery tour : MLO proteins in plant immunity and beyond. 273-281

Acevedo-Garcia J, Spencer D, Thieron H, Reinstädler A, Hammond-Kosack K, Phillips AL, Panstruga R (2017) mlo-based powdery mildew resistance in hexaploid bread wheat generated by a non-transgenic TILLING approach. Plant Biotechnol. J. 15:367-378

Aflitos $S$, Schijlen $E$, De Jong $H$, De Ridder $D$, Smit S, Finkers R, Wang J, Zhang G, Li N, Mao L, Bakker F, Dirks R, Breit T, Gravendeel B, Huits $H$, Struss $D$, Swanson-Wagner $R$, Van Leeuwen $\mathrm{H}$, Van Ham RCHJ, Fito L, Guignier L, Sevilla M, Ellul P, Ganko E, Kapur A, Reclus E, De Geus B, Van De Geest H, Te Lintel Hekkert B, Van Haarst J, Smits L, Koops A, SanchezPerez G, Van Heusden AW, Visser R, Quan Z, Min J, Liao L, Wang X, Wang G, Yue Z, Yang X, Xu N, Schranz E, Smets E, Vos R, Rauwerda J, Ursem R, Schuit C, Kerns M, Van Den Berg J, Vriezen W, Janssen A, Datema E, Jahrman T, Moquet F, Bonnet J, Peters S (2014) Exploring genetic variation in the tomato (Solanum section Lycopersicon) clade by wholegenome sequencing. Plant J 80:136-148. doi: 10.1111/tpj.12616

Ait Bahadou S, Ouijja A, Karfach A, Tahiri A, Lahlali R (2018) New potential bacterial antagonists for the biocontrol of fire blight disease (Erwinia amylovora) in Morocco. Microb Pathog 117:7-15. doi: 10.1016/j. micpath.2018.02.011

Aksoy HM, Kaya Y, Ozturk M, Secgin Z, Onder H, Okumus A (2017) Pseudomonas putida - Induced response in phenolic profile of tomato seedlings (Solanum lycopersicum L.) infected by Clavibacter michiganensis subsp. michiganensis. Biol Control 105:6-12. doi: 10.1016/j.biocontrol.2016.11.001

Al Abdallat AM, Al Debei HS, Asmar H, Misbeh S, Quraan A, Kvarnheden A (2010) An efficient in vitro-inoculation method for Tomato yellow leaf curl virus. Virol J 7:1-9 . doi: 10.1186/1743-422X-7-84

Albert R, Künstler A, Lantos F, Ádám AL, Király L (2017) Graft-transmissible resistance of cherry pepper (Capsicum annuum var. cerasiforme) to powdery mildew (Leveillula taurica) is associated with elevated superoxide accumulation, NADPH oxidase activity and pathogenesis-related gene expres. Acta Physiol Plant 39:53. doi: 10.1007/ s11738-017-2353-5

Amkraz N, Boudyach EH, Boubaker H, Bouizgarne B, Ait Ben Aoumar A (2010) Screening for fluorescent pseudomonades, isolated from the rhizosphere of tomato, for antagonistic activity toward Clavibacter michiganensis subsp. michiganensis. World J Microbiol Biotechnol 26:1059-1065. doi: 10.1007/ s11274-009-0270-5

Andolfo G, Ferriello F, Tardella L, Ferrarini A, Sigillo L, Frusciante L, Ercolano MR (2014) Tomato genome-wide transcriptional responses to Fusarium wilt and Tomato Mosaic Virus. PLoS One 9: . doi: 10.1371/journal.pone.0094963

Arora L, Narula A (2017) Gene editing and crop improvement using CRISPR-Cas9 system. Front Plant Sci 8. doi: 10.3389/fpls.2017.01932

Ataide LMS, Pappas ML, Schimmel BCJ, LopezOrenes A, Alba JM, Duarte MVA, Pallini A, Schuurink RC, Kant MR (2016) Induced plant-defenses suppress herbivore reproduction but also constrain predation of their offspring. Plant Sci 252:300-310. doi: 10.1016/j.plantsci.2016.08.004

Augustin B, Graf V, Laun N (2002) Temperature influencing efficiency of grafted tomato cultivars against root-knot nematode (Meloidogyne arenaria) and corky root (Pyrenochaeta lycopersici). Zeitschrift fur Pflanzenkrankheiten und Pflanzenschutz 109:371-383

Azadmanesh S, Mozafari J, Hasanzadeh N, Moslemkhani C (2016) In vitro evaluation of potato genotypes for resistance against bacterial soft rot (Pectobacterium carotovorum) - a new tool for studying disease resistance. J Plant Prot Res 57:1-8 . 
doi: 10.1515/jppr-2017-0001

Bakker PAHM, Pieterse CMJ, van Loon LC (2007) Induced systemic resistance by fluorescent Pseudomonas spp. Phytopathology 97:239243 . doi: 10.1094/PHYTO-97-2-0239

Balaji V, Mayrose M, Sherf O, Jacob-Hirsch J, Eichenlaub R, Iraki N, Manulis-Sasson S, Rechavi G, Barash I, Sessa G (2008) Tomato transcriptional changes in response to Clavibacter michiganensis subsp. michiganensis reveal a role for ethylene in disease development. Plant Physiol 146:1797-809. doi: 10.1104/pp.107.115188

Balaji V, Sessa G, Smart CD (2011) Silencing of host basal defense response-related gene expression increases susceptibility of Nicotiana benthamiana to Clavibacter michiganensis subsp. michiganensis. Phytopathology 101:349-357. doi: 10.1094/ PHYTO-05-10-0132

Balaji V, Smart CD (2012) Over-expression of snakin-2 and extensin-like protein genes restricts pathogen invasiveness and enhances tolerance to Clavibacter michiganensis subsp. michiganensis in transgenic tomato (Solanum lycopersicum). Transgenic Res 21:23-37. doi: 10.1007/s11248-011-9506-x

Balass M, Cohen Y, Bar-Joseph M (1993) Temperature-dependent resistance to downy mildew in muskmelon: structural responses. Physiol Mol Plant Pathol 43:11-20. doi: https://doi.org/10.1006/pmpp.1993.1036

Barda O, Shalev O, Alster S, Buxdorf K, Gafni A, Levy M (2015) Pseudozyma aphidis induces salicylic-acid-independent resistance to Clavibacter michiganensis in tomato plants. Plant Dis 621-626

Barlass M, Miller RM, Antcliff AJ (1986) Development of methods for screening grapevines for resistance to infection by downy mildew . I . Dual Culture in vitro. Am J Enol Vitic 37:61-66

Bello A, López J, Sanz R, Escuer M, Herrero J (2000) Biofumigation and organic amendments. In: Regional Workshop on Methyl Bromide Alternatives for North African and Southern European Countries, UNEP, Rome, Italy. Rome, Italy, pp 113-141

Bentley SD, Corton C, Brown SE, Barron A, Clark L, Doggett J, Harris B, Ormond D, Quail MA, May
G, Francis D, Knudson D, Parkhill J, Ishimaru CA (2008) Genome of the actinomycete plant pathogen Clavibacter michiganensis subsp. sepedonicus suggests recent niche adaptation. J Bacteriol 190:2150-2160. doi: 10.1128/JB.01598-07

Berg JA, Appiano M, Santillán Martínez M, Hermans FWK, Vriezen WH, Visser RGF, Bai Y, Schouten HJ (2015) A transposable element insertion in the susceptibility gene CsaMLO8 results in hypocotyl resistance to powdery mildew in cucumber. BMC Plant Biol 15:1-17. doi: 10.1186/s12870-015-0635-x

Bermpohl A, Dreier J, Bahro R, Eichenlaub R (1996) Exopolysaccharides in the pathogenic interaction of Clavibacter michiganensis subsp. michiganensis with tomato plants. Microbiol Res 1996 151:391-399

Bolanos-carriel C, Gallegos P, Ochoa JB, Insuasti M (2017) Bacterial canker caused by Clavibacter michiganensis subsp. michiganensis in naranjilla in Ecuador. 17:221-227

Borneman W, Akin D (1990) Lignocellulose degradation by rumen fungi and bacteria: ultrastructure and cell wall degrading enzymes. In: Microbial and plant opportunities to improve lignocellulose utilization by ruminants. Elsevier, Nueva York, pp 325-339

Borras O, Santos R, Matos AP, Cabral RS, Arzola M (2001) A first attempt to use a Fusarium subglutinans culture filtrate for the selection of pineapple cultivars resistant to fusariose disease. Plant Breed 120:435-438. doi: 10.1046/j.1439-0523.2001.00626.x

Boudyach EH, Fatmi M, Akhayat O, Benizri E, Ait Ben Aoumar A (2001) Selection of antagonistic bacteria of Clavibacter michiganensis subsp. michiganensis and evaluation of their efficiency against bacterial canker of tomato. Biocontrol Sci Technol 11:141-149. doi: 10.1080/09583150020029817

Brodersen C, McElrone A (2013) Maintenance of xylem network transport capacity: a review of embolism repair in vascular plants. Front Plant Sci 4:108. doi: 10.3389/fpls.2013.00108

Burger A, Gräfen I, Engemann J (2005) Identification of homologues to the pathogenicity factor Pat-1, a putative serine protease of Clavibacter michiganensis subsp. 
michiganensis. Microbiol Res 160:417-427

Buschges R, Hollricher K, Panstruga R, Simons G, Wolter $M$, Frijters $A$, van Daelen $R$, van der Lee T, Diergaarde P, Groenendijk J, Topsch S, Vos P, Salamini F, Schulze-Lefert P (1997) The barley Mlo gene: a novel control element of plant pathogen resistance. Cell 88:695-705

CABI, EPPO (1999) Data sheets on quarantine pests Clavibacter michiganensis subsp. michiganensis

Caldwell D, Kim B-S, lyer-Pascuzzi AS (2017) Ralstonia solanacearum differentially colonizes roots of resistant and susceptible tomato plants. Phytopathology 107:528-536. doi: 10.1094/PHYTO-09-16-0353-R

Cardon P V. (1934) Bulletin No. 250 - Summary report of progress: July 1, 1932 to June 30, 1934. UAES Bull Paper 208:

Carlson R, Vidaver A (1982) Bacterial mosaic, a new corynebacterial disease of wheat. Plant Dis 66:76-79

Carlton W, Gleason M, Braun E (1994) Effects of pruning on tomato plants supporting epiphytic populations of Clavibacter michiganensis subsp. michiganensis. Plant Dis 78:742-745

Černý M, Kuklová A, Hoehenwarter W, Fragner L, Novák O, Rotková G, Jedelský PL, Žáková $K$, Šmehilová $M$, Strnad $M$, Weckwerth W, Brzobohatý B (2013) Proteome and metabolome profiling of cytokinin action in Arabidopsis identifying both distinct and similar responses to cytokinin down- and up-regulation. J Exp Bot 64:4193-4206. doi: 10.1093/jxb/ert227

Chaerani R, Smulders MJM, Van Der Linden CG, Vosman B, Stam P, Voorrips RE (2007) QTL identification for early blight resistance (Alternaria solani) in a Solanum lycopersicum $\times$ S. arcanum cross. Theor Appl Genet 114:439-450. doi: 10.1007/s00122-0060442-8

Chalupowicz L, Barash I, Reuven M, Dror O, Sharabani G, Gartemann K-H, Eichenlaub R, Sessa G, Manulis-Sasson S (2016) Differential contribution of Clavibacter michiganensis subsp. michiganensis virulence factors to systemic and local infection in tomato. Mol Plant Pathol 8:n/a-n/a. doi: 10.1111/ mpp. 12400

Chalupowicz L, Cohen-Kandli M, Dror O, Eichenlaub R, Gartemann KH, Sessa G, Barash I, ManulisSasson S (2010) Sequential expression of bacterial virulence and plant defense genes during infection of tomato with Clavibacter michiganensis subsp. michiganensis. Phytopathol 2010 100:252-261

Chalupowicz L, Zellermann E-M, Fluegel M, Dror O, Eichenlaub R, Gartemann K-H, Savidor A, Sessa G, Iraki N, Barash I, Manulis-Sasson S (2012) Colonization and movement of GFPlabeled Clavibacter michiganensis subsp. michiganensis during tomato infection. Phytopathology 102:23-31. doi: 10.1094/ PHYTO-05-11-0135

Chandran D, Rickert J, Cherk C, Dotson BR, Wildermuth MC (2013) Host cell ploidy underlying the fungal feeding site is a determinant of powdery mildew growth and reproduction. Mol Plant Microbe Interact 26:537-545. doi: 10.1094/MPMI-10-120254-R

Chang R (1991) Dissemination of Clavibacter michiganensis subsp. michiganensis by practices used to produce tomato transplants. Phytopathology 81:1276. doi: 10.1094/Phyto-81-1276

Chang R, Ries S, Pataky J (1992a) Local sources of Clavibacter michiganensis ssp. michiganensis in the development of bacterial canker on tomatoes. Ecol. Epidemiol. 82:553-560

Chang R, Ries S, Pataky J (1992b) Effects of temperature, plant age, inoculum concentration, and cultivar on the incubation period and severity of bacterial canker of tomato. Plant Dis 76:1150-1155

Coaker GL, Francis DM (2004) Mapping, genetic effects, and epistatic interaction of two bacterial canker resistance QTLs from Lycopersicon hirsutum. Theor Appl Genet 108:1047-55. doi: 10.1007/s00122-0031531-6

Coaker GL, Meulia T, Kabelka EA, Jones AK, Francis DM (2002) A QTL controlling stem morphology and vascular development in Lycopersicon esculentumx Lycopersicon hirsutum (Solanaceae) crosses is located on chromosome 2. Am J Bot 89:1859-1866. doi: 
10.3732/ajb.89.12.1859

Consonni C, Humphry ME, Hartmann HA, Livaja M, Durner J, Westphal L, Vogel J, Lipka V, Kemmerling B, Schulze-Lefert P, Somerville SC, Panstruga R (2006) Conserved requirement for a plant host cell protein in powdery mildew pathogenesis. Nat Genet 38:716-720. doi: $10.1038 / n g 1806$

Copping LG, Duke SO (2007) Natural products that have been used commercially as crop protection agents. Pest Manag Sci 63:524554. doi: 10.1002/ps.1378

Cortada L, Sorribas FJ, Ornat C, Kaloshian I, Verdejo-Lucas S (2008) Variability in infection and reproduction of Meloidogyne javanica on tomato rootstocks with the Mi resistance gene. Plant Pathol 57:1125-1135. doi: 10.1111/j.1365-3059.2008.01906.x

Daferera DJ, Ziogas BN, Polissiou MG (2003) The effectiveness of plant essential oils on the growth of Botrytis cinerea, Fusarium sp. and Clavibacter michiganensis subsp. michiganensis. Crop Prot 22:39-44. doi: 10.1016/S0261-2194(02)00095-9

Dal Bosco C, Lezhneva L, Bieh A, Leister D, Strotmann H, Wanner G, Meurer J (2004) Inactivation of the chloroplast ATP synthase $\gamma$ subunit results in high non-photochemical fluorescence quenching and altered nuclear gene expression in Arabidopsis thaliana. J Biol Chem 279:1060-1069. doi: 10.1074/jbc. M308435200

Davis MJ, Gillaspie AG, Vidaver AK, Harris RW (1984) Clavibacter: a new genus containing some phytopathogenic coryneform bacteria, including Clavibacter xyli subsp. xyli sp. nov., subsp. nov. and Clavibacter xyli subsp. cynodontis subsp. nov. pathogens that cause. Int J Syst Bacteriol 34:107-117

de Boer $M$, Bom P, Kindt F, Keurentjes JJB, van der Sluis I, van Loon LC, Bakker PAHM (2003) Control of fusarium wilt of radish by combining Pseudomonas putida strains that have different disease-suppressive mechanisms. Phytopathology 93:626-632. doi: 10.1094/PHYTO.2003.93.5.626

de Jong J, Honma S (1976) Evaluation of screening techniques and determination of criteria for assessing resistance to Corynebacterium michiganense in tomato. Euphytica 25:405-414. doi: https://doi.org/10.1007/ BF00041573

de Laat WTAM, Suir E, de Haan A, Arnouts JJE (2017) Pseudomonas strains and consortia thereof for use in protection against plant diseases. WO2017178529

de León L, Rodríguez A, Llop P, López MM, Siverio F (2009) Comparative study of genetic diversity of Clavibacter michiganensis subsp. michiganensis isolates from the Canary Islands by RAPD-PCR, BOX-PCR and AFLP. Plant Pathol 58:862-871. doi: 10.1111/j.13653059.2009.02117.x

Denancé $N$, Ranocha $P$, Oria $N$, Barlet $X$, Rivière $M P$, Yadeta KA, Hoffmann L, Perreau F, Clément G, Maia-Grondard A, Van Den Berg GCM, Savelli B, Fournier S, Aubert Y, Pelletier S, Thomma BPHJ, Molina A, Jouanin L, Marco Y, Goffner D (2013) Arabidopsis wat1 (walls are thin1)mediated resistance to the bacterial vascular pathogen, Ralstonia solanacearum, is accompanied by cross-regulation of salicylic acid and tryptophan metabolism. Plant J 73:225-239. doi: 10.1111/tpj.12027

Desveaux D, Singer AU, Dangl JL (2006) Type III effector proteins: doppelgangers of bacterial virulence. Curr Opin Plant Biol 9:376-382. doi: https://doi.org/10.1016/j.pbi.2006.05.005

Dreier J, Meletzus D, Eichenlaub R (1997) Characterization of the plasmid encoded virulence region pat- 1 of phytopathogenic Clavibacter michiganensis subsp. michiganensis. Mol Plant-Microbe Interact 1997 10:195-206

EFSA (2014) Scientific Opinion on the pest categorisation of Clavibacter michiganensis subsp. michiganensis (Smith) Davis et al. EFSA J 12:3721. doi: 10.2903/j.efsa.2014.3721

Eichenlaub R, Bermpohl A, Meletzus D (1990) Genetic and physiological aspects of the pathogenic interaction of Clavibacter michiganense subsp. michiganense with the host plant. Adv Mol Genet plant-microbe Interact

Eichenlaub R, Burger A, Gartemann K, Burger A (2006) Clavibacter michiganensis, a group of Gram-positive phytopathogenic bacteria. In: Gnanamanickam SS (ed) Plant- 
Associated Bacteria. Springer, Dordrecht, The Netherlands, pp 385-421

Eichenlaub R, Gartemann K-H (2011) The Clavibacter michiganensis subspecies: molecular investigation of Gram-positive bacterial plant pathogens. Annu Rev Phytopathol 49:445-464. doi: 10.1146/ annurev-phyto-072910-095258

El S, Haggoud A, Benbouaza A, Bouaichi A, Hassan E (2017) Plant growth promotion and bacterial canker control of Lycopersicon esculentum $L$. cv . Campbell 33 by biocontrol agents. J Crop Prot 6:235-244

Elenkov E (1965) Die selektion von tomaten auf resistenz gegen die bakterienwelke. Intern Z Landwirtschaft 594-597

Ellis C, Ellis C, Karafyllidis I, Karafyllidis I, Wasternack C, Wasternack C, Turner JG, Turner JG (2002) The Arabidopsis mutant cev1 links cell wall signaling to jasmonate and ethylene responses. Society 14:1557-1566. doi: 10.1105/tpc.002022.1558

Ellis C, Turner JG (2001) The Arabidopsis mutant cev 1 has constitutively active jasmonate and ethylene signal pathways and enhanced resistance to pathogens. Plant Cell 13:10251033. doi: $10.1105 /$ tpc.13.5.1025

Emmatty DA, John CA (1973) Evaluation of resistance to bacterial canker of H2990, a new tomato variety. Plant Dis. Rep. 57:584586

EPPO (2016) PM 7/42 (3) Clavibacter michiganensis subsp. michiganensis. EPPO Bull 46:202-225. doi: 10.1111/epp.12302

Esparza-Araiza MJ, Bañuelos-Hernández B, Argüello-Astorga GR, Lara-Ávila JP, Goodwin $\mathrm{PH}$, Isordia-Jasso $\mathrm{Ml}$, Castillo-Collazo $\mathrm{R}$, Rougon-Cardoso A, Alpuche-Solís ÁG (2015) Evaluation of a SUMO E2 conjugating enzyme involved in resistance to Clavibacter michiganensis subsp. michiganensis in Solanum peruvianum, through a tomato mottle virus VIGS assay. Front Plant Sci 6:111. doi: $10.3389 /$ fpls.2015.01019

Evans DA (1986) Somaclonal and gametoclonal variation. In: Biotechnology for Solving Agricultural Problems. Springer Netherlands, Dordrecht, pp 63-96
Expósito-Rodríguez M, Borges AA, Borges-Pérez A, Pérez JA (2008) Selection of internal control genes for quantitative real-time RT-PCR studies during tomato development process. BMC Plant Biol 8:131. doi: 10.1186/14712229-8-131

Feechan A, Jermakow AM, Dry IB (2009) Grapevine MLO candidates required for powdery mildew pathogenicity? Plant Signal. Behav. 4:522-523

Flores PS, Otoni WC, Dhingra OD, de Souza Diniz SPS, dos Santos TM, Bruckner $\mathrm{CH}$ (2012) In vitro selection of yellow passion fruit genotypes for resistance to Fusarium vascular wilt. Plant Cell Tissue Organ Cult 108:37-45. doi: 10.1007/s11240-011-0009-5

Forster RR., Echandi E (1973) Relation of age of plants, temperature and inoculum concentration to bacterial canker development in resistant and susceptible Lycopersicon spp. Phytopathology 63:773777. doi: 10.1094/Phyto-63-773

Francis DM, Kabelka E, Science C, Bell J, Franchino B, St Clair D (2001) Resistance to bacterial canker in tomato (Lycopersicon hirsutum LA407) and its progeny derived from crosses to $L$. esculentum. Plant Dis 85:1171-1176

Frenkel O, Bornestein M, Shulhani R, Sharabani G, Sofer M, Abo-Moch F, Lofthouse M, ManulisSasson S, Shtienberg D (2015) Secondary spread of Clavibacter michiganensis subsp. michiganensis in nurseries and the conditions leading to infection of tomato seedlings. Eur J Plant Pathol. doi: 10.1007/s10658-0150795-4

Fukino $N$, Yoshioka $Y$, Sugiyama $M$, Sakata $Y$, Matsumoto S (2013) Identification and validation of powdery mildew (Podosphaera xanthii)-resistant loci in recombinant inbred lines of cucumber (Cucumis sativus L.). Mol Breed 32:267-277. doi: 10.1007/s11032-0139867-3

Gardner H (1991) Recent investigations into the lipoxygenase pathway of plants. Biochim Biophys Acta (BBA)-Lipids Lipid Metab 1084:221-239

Gartemann K-H, Abt B, Bekel T, Burger A, Engemann J, Fluegel M, Gaigalat L, Goesmann A, 
Graefen I, Kalinowski J, Kaup O, Kirchner O, Krause L, Linke B, McHardy A, Meyer F, Pohle $S$, Rückert C, Schneiker-Bekel S, Zellermann E-M, Pühler A, Eichenlaub R, Kaiser O, Bartels D, Flügel M, Gräfen I, Schneiker S (2008) The genome sequence of the tomato-pathogenic actinomycete Clavibacter michiganensis subsp. michiganensis NCPPB382 reveals a large island involved in pathogenicity. J Bacteriol 190:2138-49. doi: 10.1128/ JB.01595-07

Gartemann KH, Kirchner O, Engemann J, Grafen I, Eichenlaub R, Burger A (2003) Clavibacter michiganensis subsp. michiganensis: first steps in the understanding of virulence of a Gram-positive phytopathogenic bacterium. J Biotechnol 106:179-191

Gawehns F, Cornelissen BJC, Takken FLW (2013) The potential of effector-target genes in breeding for plant innate immunity. Microb Biotechnol 6:223-229. doi: 10.1111/17517915.12023

Ge Y, Johnson W, Roberts JJ, Rajaram S (1998) Temperature and resistance gene interactions in the expression of resistance to Blumeria Graminis f. sp. Tritici. Euphytica 99:103-109. doi: 10.1023/A:1018392725474

Gill US, Lee S, Mysore KS (2015) Host versus nonhost resistance: distinct wars with similar arsenals. Phytopathology 105:580-587. doi: 10.1094/PHYTO-11-14-0298-RVW

Gleason ML, Braun EJ, Carlton WM, Peterson RH (1991) Survival and dissemination of Clavibacter michiganensis subsp. michiganensis in tomatoes. Phytopathology 81:1519-1523 . doi: 10.1094/Phyto-81-1519

Gleason MLM, Gitaitis R, Ricker M (1993) Recent progress in understanding and controlling bacterial canker of tomato in eastern North America. Plant Dis 77:1069-1076. doi: 10.1094/PD-77-1069

Goff KE, Ramonell KM (2007) The role and regulation of receptor-like kinases in plant defense. Gene Regul Syst Biol 1:167-175. doi: 10.1016/j.bbamem.2015.02.010.Cationic

González AJ, Trapiello E (2014) Clavibacter michiganensis subsp. phaseoli subsp. nov., pathogenic in bean. Int J Syst Evol Microbiol 64:1752-1755. doi: 10.1099/ijs.0.058099-0

Grandillo S, Chetelat R, Knapp S, Spooner D, Peralta
I, Cammareri M, Perez O, Termolino P, Tripodi $P$, Chiusano ML, Ercolano MR, Frusciante L, Monti L, Pignone $D$, Ithnin $M$, Singh $R$, Din AK (2011) Solanum sect. Lycopersicon. In: Kole C (ed) Wild crop relatives: genomic and breeding resources. Springer Berlin Heidelberg, Berlin, Heidelberg

Grimault V, Prior P (1994) Grafting tomato cultivars resistant or susceptible to bacterial wilt: analysis of resistance mechanisms. J Phytopathol 141:330-334. doi: 10.1111/ j.1439-0434.1994.tb01477.x

Grund E, Knorr C, Eichenlaub R (1990) Catabolism of benzoate and monohydroxylated benzoates by Amycolatopsis and Streptomyces spp. Appl Environ Microbiol 1990 56:1459-1464

GSPP Standard (2017) GSPP Standard for tomato seed and young plant production sites

Gu J-T, Fan S-X, Zhang X-C (2008) Effects of rootstocks on the development, disease resistance and quality of Cucumis sativus $\mathrm{L}$. Acta Hortic 771:161-166

Haggard JE, Johnson EB, St. Clair D a. (2015) Multiple QTL for horticultural traits and quantitative resistance to Phytophthora infestans linked on Solanum habrochaites Chromosome 11. G3 Genes, Genomes, Genet 5:219-233. doi: 10.1534/g3.114.014654

Haley SD, Miklas PN, Stavely JR, Byrum J, Kelly JD (1993) Identification of RAPD markers linked to a major rust resistance gene block in common bean. Theor Appl Genet 86:505512. doi: 10.1007/BF00838567

Hanus-Fajerska E, Wiszniewska A, Riseman A (2014) Elaboration of in vitro root culture protocols to efficiently limit Daphne sudden death syndrome. Acta Sci Pol - Hortorum Cultus 13:117-127

Hassan AA, Strider DL, Konsler TL (1968) Application of cotyledonory symptoms in screening for resistance of tomato to bacterial canker and host range studied. Phytopathology 58:233239

Hausbeck MK (2017) Bacterial canker: strategies to limit losses in Michigan, USA. Acta Hortic 131138. doi: 10.17660/ActaHortic.2017.1159.20

Hausbeck MK, Bell J, Medina-Mora C, Podolsky R, Fulbright DW (2000) Effect of bactericides on population sizes and spread of Clavibacter michiganensis subsp. michiganensis on 
tomatoes in the greenhouse and on disease development and crop yield in the field. Phytopathology 90:38-44. doi: 10.1094/ PHYTO.2000.90.1.38

Henrissat B, Callebaut I (1995) Conserved catalytic machinery and the prediction of a common fold for several families of glycosyl hydrolases. In: Proceedings of the National Academy of Sciences. pp 7090-7094

Hernandez-Blanco C, Feng DX, Hu J, Sanchez-Vallet A, Deslandes L, Llorente F, Berrocal-Lobo M, Keller H, Barlet X, Sanchez-Rodriguez C, Anderson LK, Somerville S, Marco Y, Molina A (2007) Impairment of cellulose synthases required for Arabidopsis secondary cell wall formation enhances disease resistance. Plant Cell Online 19:890-903. doi: 10.1105/ tpc. 106.048058

Higgs HN, Peterson KJ (2005) The PEN1 syntaxin defines a novel cellular compartment upon fungal attack and is required for the timely assembly of papillae. Mol Biol Cell 16:1-13. doi: 10.1091/mbc.E04

Hittalmani S, Parco A, Mew T V, Zeigler RS, Huang N (2000) Fine mapping and DNA markerassisted pyramiding of the three major genes for blast resistance in rice. Theor Appl Genet 100:1121-1128. doi: 10.1007/s001220051395

Houston NL, Fan C, Xiang JQ-Y, Schulze J-M, Jung R, Boston RS, Carolina N, H NCNL (2005) Phylogenetic analyses identify 10 classes of the protein disulfide isomerase family in plants, including single-domain protein disulfide isomerase-related proteins. Plant Physiol 137:762-778. doi: 10.1104/ pp.104.056507.genes

Huang N, Angeles ER, Domingo J, Magpantay G, Singh S, Zhang G, Kumaravadivel N, Bennett J, Khush GS (1997) Pyramiding of bacterial blight resistance genes in rice: markerassisted selection using RFLP and PCR. Theor Appl Genet 95:313-320. doi: 10.1007/ s001220050565

Huitrón M V., Camacho F, Ricárdez MG (2011) Influence of grafted watermelon plant density on yield and quality in soil infested with Melon Necrotic Spot Virus. Acta Hortic 917:265-268

Huot B, Yao J, Montgomery BL, He SY (2014) Growth-defense tradeoffs in plants: A balancing act to optimize fitness. Mol Plant 7:1267-1287. doi: 10.1093/mp/ssu049

Hutson RA, Smith IM (1980) Phytoalexins and tyloses in tomato cultivars infected with Fusarium oxysporum f.sp. lycopersici or Verticillium albo-atrum. Physiol Plant Pathol 17:245-257. doi: 10.1016/S00484059(80)80018-X

Jahr H, Bahro R, Burger A, Ahlemeyer J, Eichenlaub R (1999) Interactions between Clavibacter michiganensis and its host plants. Environ Microbiol 1:113-118. doi: 10.1046/j.14622920.1999.00011.x

Jahr $H$, Dreier J, Meletzus D (2000) The endo- $\beta-1$, 4-glucanase CelA of Clavibacter michiganensis subsp. michiganensis is a pathogenicity determinant required for induction of bacterial wilt of tomato. Mol plant-microbe Interact 13:703-714

Jaquinod $M$, Villiers $F$, Kieffer-Jaquinod $S$, Hugouvieux V, Bruley C, Garin J, Bourguignon J (2007) A proteomics dissection of Arabidopsis thaliana vacuoles isolated from cell culture. Mol Cell Proteomics 6:394-412 . doi: 10.1074/mcp.M600250-MCP200

Jarvis WR (1992) Managing diseases in greenhouse crops. American Phytopathological Society, St. Paul, USA

Jensen MK, Rung JH, Gregersen PL, Gjetting T, Fuglsang AT, Hansen $M$, Joehnk N, Lyngkjaer MF, Collinge DB (2007) The HvNAC6 transcription factor: a positive regulator of penetration resistance in barley and Arabidopsis. Plant Mol Biol 65:137-150. doi: 10.1007/s11103-007-9204-5

Jiang N, Lv QY, Xu X, Cao YS, Walcott RR, Li JQ, Luo LX (2015) Induction of the viable but nonculturable state in Clavibacter michiganensis subsp. michiganensis and in planta resuscitation of the cells on tomato seedlings. Plant Pathol 826-836. doi: 10.1111/ppa. 12454

Jones JDG, Dangl JL (2006) The plant immune system. Nature 444:323-329. doi: 10.1038/ nature 05286

Jong JD, Honma S (1976) Inheritance of resistance to Corynebacterium michiganense in tomato. J or Hered 79-84

Jørgensen IH (1992) Discovery, characterization and exploitation of Mlo powdery mildew 
resistance in barley. Euphytica 63:141-152 . doi: 10.1007/BF00023919

Jung WJ, Mabood F, Souleimanov A, Whyte LG, Niederberger TD, Smith DL (2014) Antibacterial activity of antagonistic bacterium Bacillus subtilis DJM-51 against phytopathogenic Clavibacter michiganensis subsp . michiganensis ATCC 7429 in vitro. Microb Pathog 77:13-16. doi: 10.1016/j. micpath.2014.10.008

Kabelka E, Franchino B, Francis DM (2002) Two loci from Lycopersicon hirsutum LA407 confer resistance to strains of Clavibacter michiganensis subsp. michiganensis. Phytopathology 92:504-510. doi: 10.1094/ PHYTO.2002.92.5.504

Kasselaki AM, Goumas D, Tamm L, Fuchs J, Cooper J, Leifert C (2011) Effect of alternative strategies for the disinfection of tomato seed infected with bacterial canker (Clavibacter michiganensis subsp. michiganensis). NJAS - Wageningen J Life Sci 58:145-147. doi: 10.1016/j.njas.2011.07.001

Kaul K, Shaner G (1989) Effect of temperature on adult-plant resistance to leaf rust in wheat. Phytopathology 79:391-394

Kaup O, Grafen I, Zellermann EM, Eichenlaub R, Gartemann KH (2005) Identification of a tomatinase in the tomato-pathogenic actinomycete Clavibacter michiganensis subsp. michiganensis NCPPB382. Mol PlantMicrobe Interact 2005 18:1090-1098

Kawaguchi A, Tanina K, Inoue K (2010) Molecular typing and spread of Clavibacter michiganensis subsp. michiganensis in greenhouses in Japan. Plant Pathol 59:76-83 . doi: 10.1111/j.1365-3059.2009.02207.x

Kawchuk LM, Hachey J, Lynch DR, Kulcsar F, van Rooijen G, Waterer DR, Robertson A, Kokko E, Byers R, Howard RJ, Fischer R, Prufer D (2001) Tomato Ve disease resistance genes encode cell surface-like receptors. Proc Natl Acad Sci 98:6511-6515 . doi: 10.1073/pnas.091114198

Kim J, Shiu SH, Thoma S, Li WH, Patterson SE (2006) Patterns of expansion and expression divergence in the plant polygalacturonase gene family. Genome Biol 7. doi: 10.1186/gb2006-7-9-r87

Kondo $K$, Yamamoto $M$, Matton DP, Sato T, Hirai
M, Norioka S, Hattori T, Kowyama Y (2002) Cultivated tomato has defects in both S-RNase and $H T$ genes required for stylar function of self-incompatibility. Plant J 29:627-636. doi: 10.1046/j.0960-7412.2001.01245.x

Kotan R, Cakir A, Ozer H, Kordali S, Cakmakci R, Dadasoglu F, Dikbas N, Aydin T, Kazaz C (2014) Antibacterial effects of Origanum onites against phytopathogenic bacteria: Possible use of the extracts from protection of disease caused by some phytopathogenic bacteria. Sci Hortic (Amsterdam) 172:210220. doi: 10.1016/j.scienta.2014.03.016

Kraemer R, Schlegel H, Opel M (1988) Reaktion von zellsuspensionskulturen der tomate auf das toxin von Clavibacter michiganensis subsp. michiganensis (Smith) Davis. Arch fuer Phytopathol und Pflanzenschutz 24:325-334

Kritzman G (2014) A package for plant antimicrobial treatment. WO2014170894

Kudoyarova GR, Vysotskaya LB, Arkhipova TN, Kuzmina LY, Galimsyanova NF, Sidorova L V., Gabbasova IM, Melentiev Al, Veselov SY (2017) Effect of auxin producing and phosphate solubilizing bacteria on mobility of soil phosphorus, growth rate, and $\mathrm{P}$ acquisition by wheat plants. Acta Physiol Plant 39:1-8. doi: 10.1007/s11738-017-25569

Kuriyama T, Kuniyasu K (1974) Studies on the breeding of resistant tomato by interspecific hybridization. III. on the breeding of a new tomato line resistant to bacterial canker caused by Corynebacterium michiganense. Bull Veg Ornam Crop. Res Stn Jpn A 1:93-107

Lamichhane JR, Balestra GM, Varvaro L (2011) Severe outbreak of bacterial canker caused by Clavibacter michiganensis subsp. michiganensis on tomato in central Italy. Plant Dis 95:221. doi: 10.1094/PDIS-09-100635

Lanteigne C, Gadkar VJ, Wallon T, Novinscak A, Filion M (2012) Production of DAPG and HCN by Pseudomonas sp. LBUM300 contributes to the biological control of bacterial canker of tomato. Phytopathology 102:967-73. doi: 10.1094/PHYTO-11-11-0312

Lara-Ávila JP, Isordia-Jasso MI, Castillo-Collazo R, Simpson J, Alpuche-Solís ÁG (2011) 
Gene expression analysis during interaction of tomato and related wild species with Clavibacter michiganensis subsp. michiganensis. Plant Mol Biol Report 30:498511. doi: 10.1007/s11105-011-0348-8

Lazzeri L, Baruzzi G, Malaguti L, Antoniacci L (2003) Replacing methyl bromide in annual strawberry production with glucosinolatecontaining green manure crops. Pest Manag Sci 59:983-990. doi: 10.1002/ps.726

Lelis FMV, Czajkowski R, Souza RM, Ribeiro DH, Wolf JM (2014) Studies on the colonization of axenically grown tomato plants by a GFPtagged strain of Clavibacter michiganensis subsp. michiganensis. Eur J Plant Pathol 139:53-66. doi: 10.1007/s10658-013-0362-9

Lemmon $M$ a, Schlessinger J (2011) Cell signaling by receptor-tyrosine kinases. Biochemistry 141:1117-1134. doi: 10.1016/j. cell.2010.06.011.Cell

León L., Siverio F, López MM, Rodríguez A (2011) Clavibacter michiganensis subsp. michiganensis, a seedborne tomato pathogen: healthy seeds are still the goal. Plant Dis 95:1328-1339

Li C (2002) Resistance of cultivated tomato to cell content-feeding herbivores is regulated by the octadecanoid-signaling pathway. Plant Physiol 130:494-503. doi: 10.1104/pp.005314

Li W, Xu Y-P, Zhang Z-X, Cao W-Y, Li F, Zhou X, Chen G-Y, Cai X-Z (2012) Identification of genes required for nonhost resistance to Xanthomonas oryzae pv. oryzae reveals novel signaling components. PLoS One 7:e42796. doi: 10.1371/journal.pone.0042796

Li X, Tambong J, Yuan KX, Chen W, Xu H, André Lévesque C, De Boer SH (2018) Reclassification of Clavibacter michiganensis subspecies on the basis of whole-genome and multi-locus sequence analyses. Int J Syst Evol Microbiol 68:234-240. doi: 10.1099/ ijsem.0.002492

Lin C-H, Hsu S-T, Tzeng K-C, Wang J-F (2008) Application of a preliminary screen to select locally adapted resistant rootstock and soil amendment for integrated management of tomato bacterial wilt in Taiwan. Plant Dis 92:909-91 . doi: 10.1094/PDIS-92-6-0909

Lindhout P, Purimahua C (1987) Resistance against Corynebacterium michiganense found in Lycopersicon peruvianum. In: J C (ed)
Synopsis of the 10th EUCARPIA meeting of the Tomato Working Group. Pontecagnano, Italy, pp 162-165

Liu J, Liu D, Tao W, Li W, Wang S, Chen P, Cheng S, Gao D (1999) Molecular marker-facilitated pyramiding of different genes for powdery mildew resistance in wheat. Plant Biol 10-13

Liu N, Zhou B, Zhao X, Lu B, Li Y, Hao J (2009) Grafting eggplant onto tomato rootstock to suppress verticillium dahliae infection: The effect of root exudates. HortScience 44:2058-2062

Liu Y, Schiff M, Dinesh-Kumar SP (2002) Virusinduced gene silencing in tomato. Plant $J$ 31:777-786

López-Gresa MP, Lisón P, Yenush L, Conejero V, Rodrigo I, Bellés JM (2016) Salicylic acid is involved in the basal resistance of tomato plants to citrus exocortis viroid and tomato spotted wilt virus. PLoS One 11:1-25. doi: 10.1371/journal.pone.0166938

López-Solanilla E, González-Zorn B, Novella $\mathrm{S}$, Vázquez-Boland JA, RodríguezPalenzuela P (2003) Susceptibility of Listeria monocytogenes to antimicrobial peptides. FEMS Microbiol Lett 226:101-105. doi: 10.1016/S0378-1097(03)00579-2

Loreti S, Bosco A, Gallelli A, Damiano C, Tonelli M, Caboni E (2008) Factors affecting in vitro evaluation of resistance to Erwinia amylovora in pear genotypes. Acta Hortic 800 PART 2:885-890. doi: 10.17660/ ActaHortic.2008.800.120

Louws FJ, Rivard CL, Kubota C (2010) Grafting fruiting vegetables to manage soilborne pathogens, foliar pathogens, arthropods and weeds. Sci Hortic (Amsterdam) 127:127-146. doi: 10.1016/j.scienta.2010.09.023

Lu R, Martin-Hernandez AM, Peart JR, Malcuit I, Baulcombe DC (2003) Virus-induced gene silencing in plants. Methods 30:296-303. doi: 10.1016/S1046-2023(03)00037-9

Mangal M, Sharma DR (2002) In vitro mutagenesis and cell selection for the induction of black rot resistance in cauliflower. J Hortic Sci Biotechnol 77:268-272. doi: 10.1080/14620316.2002.11511491

Manzer F, Genereux H (1981) Ring rot. In: Hobson WJ (ed) Compendium of potato disease. American Phytopathological Society Press, St Paul, MN, USA, pp 31-32 
Manzo D, Ferriello F, Puopolo G, Zoina A, D'Esposito D, Tardella L, Ferrarini A, Ercolano MR (2016) Fusarium oxysporum f.sp. radicislycopersici induces distinct transcriptome reprogramming in resistant and susceptible isogenic tomato lines. BMC Plant Biol 16:1-14. doi: 10.1186/s12870-0160740-5

Mazier M, German-Retana S, Flamain F, Dubois V, Botton E, Sarnette V, Le Gall O, Candresse T, Maisonneuve B (2004) A simple and efficient method for testing Lettuce mosaic virus resistance in in vitro cultivated lettuce. J Virol Methods 116:123-131. doi: 10.1016/j. jviromet.2003.11.011

McCulloch L (1925) Aplanobacter insidiosum n. sp., the cause of an alfalfa disease. Phytopathology 15:496-497

Medina-Mora CM, Hausbeck MK, Fulbright DW (2001) Bird's eye lesions of tomato fruit produced by aerosol and direct application of Clavibacter michiganensis subsp. michiganensis. Plant Dis 85:88-91. doi: 10.1094/PDIS.2001.85.1.88

Meletzus D, Bermphol A, Dreier J, Eichenlaub R (1993) Evidence for plasmid-encoded virulence factors in the phytopathogenic bacterium Clavibacter michiganensis subsp. michiganensis NCPPB382. J Bacteriol 175:2131-2136

Meletzus D, Eichenlaub R (1991) Transformation of the phytopathogenic bacterium Clavibacter michiganense subsp. michiganense by electroporation and development of a cloning vector. J Bacteriol 1991 173:184-190

Memon AR (2004) The role of ADP-ribosylation factor and SAR1 in vesicular trafficking in plants. Biochim Biophys Acta Biomembr 1664:9-30. doi: 10.1016/j. bbamem.2004.04.005

Miazzi MM, Hajjeh HR, Faretra F (2010) An in vitro method to evaluate grapevine cultivars for Erysiphe necator susceptibility. Vitr Cell Dev Biol - Plant 46:363-367. doi: 10.1007/s11627010-9289-4

Miedes E, Vanholme R, Boerjan W, Molina A (2014) The role of the secondary cell wall in plant resistance to pathogens. Front Plant Sci 5:113. doi: $10.3389 /$ fpls. 2014.00358

Miguel A (2004) Use of grafted plants and IPM methods for the production of tomatoes in the mediterranean region. Proc Int Conf Altern to Methyl Bromide Port 141-145

Miklas PN, Stavely JR, Kelly JD (1993) Identification and potential use of a molecular marker for rust resistance in common bean. Theor Appl Genet 85:745-749. doi: 10.1007/BF00225014

Mora I, Cabrefiga J, Montesinos E (2015) Cyclic lipopeptide biosynthetic genes and products, and inhibitory activity of plant-associated Bacillus against phytopathogenic bacteria. PLoS One 10:1-21. doi: 10.1371/journal. pone. 0127738

Mrabet M, Djebali N, Elkahoui S, Miloud Y, Saïdi S, Tarhouni B, Mhamdi R (2013) Efficacy of selected Pseudomonas strains for biocontrol of Rhizoctonia solani in potato. Phytopathol Mediterr 52:449-456

Munkvold GP (2009) Seed pathology progress in academia and industry. Annu Rev Phytopathol 47:285-311. doi: 10.1146/ annurev-phyto-080508-081916

Nandi M, MacDonald J, Liu P, Weselowski B, Yuan Z-C (2018) Clavibacter michiganensis subsp. michiganensis: Bacterial canker of tomato, molecular interactions and disease management. Mol Plant Pathol 1-15. doi: 10.1111/mpp.12678

Nguyen HT, Yu NH, Park AR, Park HW, Kim IS, Kim JC (2017) Antibacterial activity of pharbitin, isolated from the seeds of Pharbitis nil, against various plant pathogenic bacteria. J Microbiol Biotechnol 27:1763-1772. doi: 10.4014/jmb. 1706.06008

Niks RE, Marcel TC (2009) Nonhost and basal resistance: How to explain specificity? New Phytol 182:817-828. doi: 10.1111/j.14698137.2009.02849.x

Novinscak A, Gadkar VJ, Joly DL, Filion M (2016) Complete genome sequence of Pseudomonas brassicacearum LBUM300, a disease-suppressive bacterium with antagonistic activity toward fungal, oomycete, and bacterial plant pathogens. Genome Announc 4:e01623-15. doi: 10.1128/ genomeA.01623-15

Nyange NE, Williamson B, Lyon GD, McNicol RJ, Connolly T (1997) Responses of cells and protoplasts of Coffea arabica genotypes to partially purified culture filtrates produced 
by Colletotrichum kahawae. Plant Cell Rep 16:763-769. doi: 10.1007/s002990050316

O'Donnell PJ, Truesdale MR, Calvert CM, Dorans A, Roberts MR, Bowles DJ (1998) A novel tomato gene that rapidly responds to wound- and pathogen-related signals. Plant J 14:137-142. doi: 10.1046/j.1365-313X.1998.00110.x

O'Herlihy EA, Doyle Prestwich BM, Wall G (2012) An in vitro study to examine the potential of mutation breeding to create resistance to bacterial wilt (Ralstonia solanacearum) in tomato. Acta Hortic 935:101-106

Oh EJ, Bae C, Lee HB, Hwang IS, Lee HI, Yea MC, Yim KO, Lee S, Heu S, Cha JS, Oh CS (2016) Clavibacter michiganensis subsp. capsici subsp. nov., causing bacterial canker disease in pepper. Int J Syst Evol Microbiol 66:40654070. doi: 10.1099/ijsem.0.001311

Orzaez D, Medina A, Torre S, Fernandez-Moreno JP, Rambla JL, Fernandez-Del-Carmen A, Butelli E, Martin C, Granell A (2009) A visual reporter system for virus-induced gene silencing in tomato fruit based on anthocyanin accumulation. Plant Physiol 150:1122-1134. doi: 10.1104/pp.109.139006

Pagan I, Garcia-Arenal F (2018) Tolerance to plant pathogens: theory and experimental evidence. Int J Mol Sci 19:810. doi: 10.3390/ ijms19030810

Paplomatas EJ, Elena K, Tsagkarakou A, Perdikaris A (2002) Control of Verticillium wilt of tomato and cucurbits through grafting of commercial varieties on resistant rootstocks. Acta Hortic 579:445-449

Park C-S, Paulitz TC, Baker R (1988) Biocontrol of Fusarium wilt of cucumber resulting from interactions between Pseudomonas putida and nonpathogenic isolates of Fusarium oxysporum. Phytopathology 78:190

Paulin MM, Novinscak A, Lanteigne C, Gadkar VJ, Filion M (2017) Interaction between 2,4-diacetylphloroglucinol- and hydrogen cyanide-producing Pseudomonas brassicacearum LBUM300 and Clavibacter michiganensis subsp. michiganensis in the tomato rhizosphere. Appl Environ Microbiol 83:1-13

Paulin MM, Novinscak A, St-Arnaud M, Goyer C, Decoste NJ, Privé JP, Owen J, Filion M (2009) Transcriptional activity of antifungal metabolite-encoding genes phlD and hcnBC in Pseudomonas spp. using qRTPCR. FEMS Microbiol Ecol 68:212-222. doi: 10.1111/j.1574-6941.2009.00669.x

Pavan S, Jacobsen E, Visser RGF, Bai Y (2009) Loss of susceptibility as a novel breeding strategy for durable and broad-spectrum resistance. Mol Breed 25:1-12. doi: 10.1007/s11032009-9323-6

Peng $X$, Wang $H$, Jang $J C$, Xiao $T$, He $H$, Jiang D, Tang $X$ (2016) OsWRKY80-OsWRKY4 module as a positive regulatory circuit in rice resistance against Rhizoctonia solani. Rice 9. doi: 10.1186/s12284-016-0137-y

Peregrine WTH, Ahmad KB (1982) Grafting-A simple technique for overcoming bacterial wilt in tomato. Trop Pest Manag 28:71-76. doi: 10.1080/09670878209370676

Pessina S, Lenzi L, Perazzolli M, Campa M, Dalla Costa L, Urso S, Valè G, Salamini F, Velasco R, Malnoy M (2016) Knockdown of MLO genes reduces susceptibility to powdery mildew in grapevine. Hortic Res 3. doi: 10.1038/ hortres.2016.16

Pessina S, Pavan S, Catalano D, Gallotta A, Visser RGF, Bai Y, Malnoy M, Schouten HJ (2014) Characterization of the $M L O$ gene family in Rosaceae and gene expression analysis in Malus domestica. BMC Genomics 15:618. doi: 10.1186/1471-2164-15-618

Pham DQ, Ba DT, Dao NT, Choi GJ, Vu TT, Kim JC, Giang TPL, Vu HD, Le Dang Q (2017) Antimicrobial efficacy of extracts and constituents fractionated from Rheum tanguticum Maxim. ex Balf. rhizomes against phytopathogenic fungi and bacteria. Ind Crops Prod 108:442-450. doi: 10.1016/j. indcrop.2017.06.067

Pieterse CMJ, Van der Does D, Zamioudis C, LeonReyes A, Van Wees SCM (2012) Hormonal modulation of plant immunity. Annu Rev Cell Dev Biol 28:489-521. doi: 10.1146/annurevcellbio-092910-154055

Pieterse CMJ, Zamioudis C, Berendsen RL, Weller DM, Van Wees SCM, Bakker PAHM (2014) Induced systemic resistance by beneficial microbes. Annu Rev Phytopathol 52:347-375. doi: 10.1146/annurev-phyto-082712-102340

Pombo MA, Zheng Y, Fei Z, Martin GB, Rosli HG (2017) Use of RNA-seq data to identify 
and validate RT-qPCR reference genes for studying the tomato-Pseudomonas pathosystem. Sci Rep 7:1-11. doi: 10.1038/ srep44905

Pombo MA, Zheng Y, Fernandez-Pozo N, Dunham DM, Fei Z, Martin GB (2014) Transcriptomic analysis reveals tomato genes whose expression is induced specifically during effector-triggered immunity and identifies the Epk1 protein kinase which is required for the host response to three bacterial effector proteins. Genome Biol 15:492. doi: 10.1186/ s13059-014-0492-1

Pratelli R, Voll LM, Horst RJ, Frommer WB, Pilot G (2010) Stimulation of nonselective amino acid export by glutamine dumper proteins. Plant Physiol 152:762-773. doi: 10.1104/ pp.109.151746

Prelich G (2012) Gene overexpression: uses, mechanisms, and interpretation. Genetics 190:841-854. doi: 10.1534/genetics.111.136911

Prior P (1993) Bacterial wilt resistance in tomato associated with tolerance of vascular tissues to Pseudomonas solanacearum. 589-594

Qiu Y, Xi J, Du L, Poovaiah BW (2012) The function of calreticulin in plant immunity: new discoveries for an old protein. Plant Signal Behav 7:907-910. doi: 10.4161/psb.

Rai P, Strobel G (1969) Phytotoxic glycopeptides produced by Corynebacterium michiganense. II. Biological properties. Phytopathology 59:53

Ramette A, Frapolli M, Saux MF Le, Gruffaz C, Meyer JM, Défago G, Sutra L, MoënneLoccoz Y (2011) Pseudomonas protegens sp. nov., widespread plant-protecting bacteria producing the biocontrol compounds 2,4-diacetylphloroglucinol and pyoluteorin. Syst Appl Microbiol 34:180-188. doi: 10.1016/j.syapm.2010.10.005

Ramírez V, López A, Mauch-Mani B, Gil MJ, Vera P (2013) An extracellular subtilase switch for immune priming in Arabidopsis. PLoS Pathog 9: . doi: 10.1371/journal.ppat.1003445

Ranocha $P$, Denancé N, Vanholme R, Freydier A, Martinez Y, Hoffmann L, Köhler L, Pouzet C, Renou JP, Sundberg B, Boerjan W, Goffner D (2010) Walls are thin 1 (WAT1), an Arabidopsis homolog of Medicago truncatula NODULIN21, is a tonoplast- localized protein required for secondary wall formation in fibers. Plant J 63:469-483. doi: 10.1111/j.1365-313X.2010.04256.x

Ranocha P, Dima O, Nagy R, Felten J, CorratgéFaillie C, Novák O, Morreel K, Lacombe $B$, Martinez $Y$, Pfrunder $S$, Jin $X$, Renou J-P, Thibaud J-B, Ljung K, Fischer U, Martinoia E, Boerjan W, Goffner D (2013) Arabidopsis WAT1 is a vacuolar auxin transport facilitator required for auxin homoeostasis. Nat Commun 4:1-9. doi: 10.1038/ncomms3625

Rezzonico F, Rupp O, Fahrentrapp J (2017) Pathogen recognition in compatible plantmicrobe interactions. Sci Rep 7:6383. doi: 10.1038/s41598-017-04792-5

Riechmann JL, Heard J, Martin G, Reuber L, Jiang C-Z, Keddie J, Adam L, Pineda O, Ratcliffe OJ, Samaha RR, Creelman R, Pilgrim M, Broun $P$, Zhang JZ, Ghandehari D, Sherman BK, Yu G-L (2000) Arabidopsis transcription factor genome wide comparative analysis among eukaryotes. Science (80- ) 290:2105-2109. doi: 10.1126/science.290.5499.2105

Roderick HW, Thorogood D, Adomako B (2000) Temperature-dependent resistance to crown rust infection in perennial ryegrass, Lolium perenne. Plant Breed 119:93-95. doi: 10.1046/j.1439-0523.2000.00441.x

Rodríguez-Moreno L, Barceló-Muñoz A, Ramos C (2008) In vitro analysis of the interaction of Pseudomonas savastanoi pvs. savastanoi and nerii with micropropagated olive plants. Phytopathology 98:815-822. doi: 10.1094/ PHYTO-98-7-0815

Romero a. M, Vega D, Correa OS (2014) Azospirillum brasilense mitigates water stress imposed by a vascular disease by increasing xylem vessel area and stem hydraulic conductivity in tomato. Appl Soil Ecol 82:38-43. doi: 10.1016/j.apsoil.2014.05.010

Russo P, Slack S a (1998) Tissue culture methods for the screening and analysis of putative virus-resistant transgenic potato plants. Phytopathology 88:437-41. doi: 10.1094/ PHYTO.1998.88.5.437

Sakata Y, Ohara T, Sugiyama M (2007) The history and present state of the grafting of Cucurbitaceous vegetables in Japan. Acta Hortic 159-170

Sakata Y, Sugiyama M, Ohara T, Morishita M (2006) 
Influence of rootstocks on the resistance of grafted cucumber (Cucumis sativus L.) scions to powdery mildew (Podosphaera xanthii $\mathrm{U}$. Braun \& N. Shishkoff). J Japanese Soc Hortic Sci 75:135-140. doi: 10.2503/jjshs.75.135

Sandbrink J, van Ooijen J, Purimahua C, Vrielink M, Verkerk R, Zabel P, Lindhout P (1995) Localization of genes for bacterial canker resistance in Lycopersicon peruvianum using RFLPs. Theor Appl Genet 90:444-450

Savidor A, Chalupowicz L, Teper D, Gartemann $\mathrm{KH}$, Eichenlaub R, Manulis-Sasson S, Barash I, Sessa G (2014) Clavibacter michiganensis subsp. michiganensis Vatr1 and Vatr2 transcriptional regulators are required for virulence in tomato. Mol Plant-Microbe Interact 2014 27:1035-1047

Savidor A, Teper D, Gartemann K-H, Eichenlaub R, Chalupowicz L, Manulis-Sasson S, Barash I, Tews H, Mayer K, Giannone RJ, Hettich RL, Sessa G (2012) The Clavibacter michiganensis subsp. michiganensis-tomato interactome reveals the perception of pathogen by the host and suggests mechanisms of infection. J Proteome Res 11:736-50. doi: 10.1021/ pr200646a

Schauer N, Zamir D, Fernie AR (2005) Metabolic profiling of leaves and fruit of wild species tomato: a survey of the Solanum lycopersicum complex. J Exp Bot 56:297-307 . doi: 10.1093/jxb/eri057

Schindelman G, Morikami A, Jung J, Baskin TI, Carpita NC, Derbyshire P, McCann MC, Benfey PN (2001) COBRA encodes a putative GPIanchored protein, which is polarly localized and necessary for oriented cell expansion in Arabidopsis. Genes Dev 15:1115-1127. doi: 10.1101/gad.879101

Schleifer KH, Kandler O (1972) Peptidoglycan types of bacterial cell walls and their taxonomic implications. Bacteriol Rev 36:407-77

Schuster M, Hoff B, Compton W (1975) Variation, maintenance, loss, and failure to recover virulence in Corynebacterium nebraskense. Plant Dis Report 59:101-105

Sedlák J, Paprštein F, Korba J, Šilerová J (2016) Development of a system for testing apple resistance to Erwinia amylovora using in vitro techniques. Plant Prot Sci 51:1-5. doi: 10.17221/94/2013-PPS
Sen Y (2014) Bacterial canker resistance in tomato. Wageningen University and Research

Sen $Y$, Aysan $Y$, Mirik M, Ozdemir D, MeijerDekens $F$, van der Wolf JM, Visser RGF, van Heusden S (2018) Genetic characterization of Clavibacter michiganensis subsp. michiganensis population in Turkey. Plant Dis 102:300-308. doi: 10.1094/PDIS-02-170276-RE

Sen $Y$, Feng $Z$, Vandenbroucke $H$, Wolf J, Visser RGF, Heusden a. W, Zhu F (2013) Screening for new sources of resistance to Clavibacter michiganensis subsp. michiganensis $(\mathrm{Cmm})$ in tomato. Euphytica 190:309-317. doi: 10.1007/s10681-012-0827-5

Sen Y, Wolf J van der, Visser RG. F., Heusden S van (2015) Bacterial canker of tomato: current knowledge of detection, management, resistance, and interactions. Plant Dis 99:4-13

Senthil-Kumar M, Mysore KS (2013) Nonhost resistance against bacterial pathogens: retrospectives and prospects. Annu Rev Phytopathol 51:407-427. doi: 10.1146/ annurev-phyto-082712-102319

Shahzad Z, Canut M, Tournaire-Roux C, Martinière A, Boursiac Y, Loudet O, Maurel C (2016) A potassium-dependent oxygen sensing pathway regulates plant root hydraulics. Cell 167:87-98.e14. doi: 10.1016/j.cell.2016.08.068

Sharabani G, Manulis-Sasson S, Borenstein M, Shulhani R, Lofthouse $M$, Chalupowicz L, Shtienberg D (2013a) The significance of guttation in the secondary spread of Clavibacter michiganensis subsp. michiganensis in tomato greenhouses. Plant Pathol 62:578-586. doi: 10.1111/j.13653059.2012.02673.x

Sharabani G, Manulis-Sasson S, Chalupowicz L, Borenstein M, Shulhani R, Lofthouse M, Sofer M, Frenkel O, Dror O, Shtienberg D (2014) Temperature at the early stages of Clavibacter michiganensis subsp. michiganensis infection affects bacterial canker development and virulence gene expression. Plant Pathol 1119-1129. doi: 10.1111/ppa.12199

Sharabani G, Shtienberg D, Borenstein M, Shulhani $R$, Lofthouse $M$, Sofer $M$, Chalupowicz L, Barel V, Manulis-Sasson S (2013b) Effects of plant age on disease development and virulence of Clavibacter michiganensis subsp. 
michiganensis on tomato. Plant Pathol 62:1114-1122 . doi: 10.1111/ppa.12013

Shinde BA, Dholakia BB, Hussain K, Panda S, Meir S, Rogachev I, Aharoni A, Giri AP, Kamble AC (2017) Dynamic metabolic reprogramming of steroidal glycol-alkaloid and phenylpropanoid biosynthesis may impart early blight resistance in wild tomato (Solanum arcanum Peralta). Plant Mol Biol 95:411-423. doi: 10.1007/s11103-017-06602

Ślusarski C (2009) Attemps at biological control of Clavibacter michiganensis subsp. michiganensis on rockwool-grown greenhouse tomatoes. Veg Crop Res Bull 69:125-134. doi: 10.2478/v10032-0080027-y

Snedden WA, Blumwald E (2000) Alternative splicing of a novel diacylglycerol kinase in tomato leads to a calmodulinbinding isoform. Plant J 24:317-326. doi: 10.1046/j.1365-313X.2000.00877.x

Sotirova V, Bogatsevska N, Stamova L (1994) Sources of resistance to bacterial diseases in tomato wild species. Acta Hortic. 376:353359

Sotirova V, Shtereva L, Zagorska N, Dimitrov B, Bogatsevska N (1999) Resistance responses of plants regenerated from tomato anther and somatic tissue cultures to Clavibacter michiganensis subsp. michiganensis. Isr J Plant Sci 47:237-243. doi: 10.1080/07929978.1999.10676779

Stapleton JJ (2000) Soil solarization in various agricultural production systems. Crop Prot 19:837-841. doi: https://doi.org/10.1016/ S0261-2194(00)00111-3

Stegemann S, Bock R (2009) Exchange of genetic material between cells in plant tissue grafts. Science (80- ) 649:649-651. doi: 10.1126/ science. 1170397

Stork I, Gartemann KH, Burger A, Eichenlaub R (2008) A family of serine proteases of Clavibacter michiganensis subsp. michiganensis: chpC plays a role in colonization of the host plant tomato. Mol Plant Pathol 2008 9:599-608. doi: 10.1111/j.1364-3703.2008.00484.x

Strider D (1969) Bacterial canker of tomato caused by Corynebacterium michiganense; a literature review and bibliography. NC Agr
Exp Sta Tech Bull

Strider D (1967) Survival studies with the tomato bacterial canker organism. Phytopathology 57:1067-71

Strider DL (1970) Tomato seedling inoculations with Cornybacterium michiganense. Plant Dis Reptr 54:36-39

Stüwe B, Tiedemann A Von (2013) Bacterial canker of tomatoes - histological characterization of cultivar resistance and seed transmission. J plant Dis Prot 120:194-200

Sun D, Zhuo T, Hu X, Fan X, Zou H (2017) Identification of a Pseudomonas putida as biocontrol agent for tomato bacterial wilt disease. Biol Control 114:45-50. doi: 10.1016/j.biocontrol.2017.07.015

Sun $K$, Wolters A-MA, Loonen AEHM, Huibers $R P$, van der Vlugt $R$, Goverse A, Jacobsen $E$, Visser RGF, Bai Y (2016a) Down-regulation of Arabidopsis DND1 orthologs in potato and tomato leads to broad-spectrum resistance to late blight and powdery mildew. Transgenic Res 25:123-138. doi: 10.1007/ s11248-015-9921-5

Sun $\mathrm{K}$, Wolters A-MA, Vossen $\mathrm{JH}$, Rouwet ME, Loonen AEHM, Jacobsen E, Visser RGF, Bai $Y$ (2016b) Silencing of six susceptibility genes results in potato late blight resistance. Transgenic Res 25:731-742. doi: 10.1007/ s11248-016-9964-2

Sun K, Zheng Z, Jacobsen E, Visser RGF, Bai Y (2014) Breeding for disease resistance by editing plant susceptibility genes. 1-5. doi: 10.1079/ PAVSNNR20149031

Svabova L, Lebeda A, Švábová L, Lebeda A (2005) In vitro selection for improved plant resistance to toxin-producing pathogens. J Phytopathol 153:52-64. doi: 10.1111/j.14390434.2004.00928.x

Tambong JT (2017) Comparative genomics of Clavibacter michiganensis subspecies, pathogens of important agricultural crops. PLoS One 12:1-16. doi: 10.1371/journal. pone. 0172295

Tancos M a, Chalupowicz L, Barash I, Manulis-Sasson S, Smart CD (2013) Tomato fruit and seed colonization by Clavibacter michiganensis subsp. michiganensis through external and internal routes. Appl Environ Microbiol 79:6948-57. doi: 10.1128/AEM.02495-13 
Thapa SP, Pattathil S, Hahn M, Jacques M-A, Gilbertson B, Coaker G (2017) Genomic analysis of Clavibacter michiganensis reveals insight into virulence strategies and genetic diversity of a Gram-positive bacterial pathogen. Mol Plant-Microbe Interact 30:MPMI-06-17-0146-R. doi: 10.1094/MPMI06-17-0146-R

Thyr . D. (1972) Virulence of Corynebacterium michiganense isolates on Lycopersicon accessions. Phytopathology 62:1982-1084

Thyr B (1968) Resistance to bacterial canker in tomato, and its evaluation. Phytopathology 58:279-281

Thyr BD (1976) Inheritance of resistance to Corynebacterium michiganense in tomato. Phytopathology 66:1116-1119

Thyr BD (1971) Resistance to Corynebacterium michiganense measured in six Lycopersicon accessions. Phytopathology 61:972-974

Tian M, Benedetti B, Kamoun S (2005) A Second Kazal-like protease inhibitor from Phytophthora infestans inhibits and interacts with the apoplastic pathogenesis-related protease P69B of tomato. Plant Physiol 138:1785-93. doi: 10.1104/pp.105.061226

Tian M, Win J, Song J, van der Hoorn R, van der Knaap E, Kamoun S (2006) A Phytophthora infestans Cystatin-Like protein targets a novel tomato papain-like apoplastic protease. Plant Physiol 143:364-377. doi: 10.1104/ pp.106.090050

Ton J, Van Pelt JA, Van Loon LC, Pieterse CMJ (2002) Differential effectiveness of salicylatedependent and jasmonate/ethylenedependent induced resistance in Arabidopsis. Mol Plant Microbe Interact 15:27-34. doi: 10.1094/MPMI.2002.15.1.27

Torre MMP, Núñez-palenius HG, Gómez-lim MA (2016) Tomato transformation with genes involved in plant immunity to confer broad resistance against bacteria. Rev Fitotec Mex 39:349-358

Tripathi L, Atkinson H, Roderick H, Kubiriba J, Tripathi JN (2017) Genetically engineered bananas resistant to Xanthomonas wilt disease and nematodes. Food Energy Secur 6:37-47. doi: 10.1002/fes3.101

Tripathi L, Mwaka H, Tripathi JN, Tushemereirwe WK (2010) Expression of sweet pepper Hrap gene in banana enhances resistance to Xanthomonas campestris pv. musacearum. Mol Plant Pathol 11:721-731. doi: 10.1111/j.1364-3703.2010.00639.x

Tunc-Ozdemir M, Jones AM (2017) Ligand-induced dynamics of heterotrimeric $G$ proteincoupled receptor-like kinase complexes. PLoS One 12:1-16. doi: 10.1371/journal. pone. 0171854

Utkhede R, Koch C (2004) Biological treatments to control bacterial canker of greenhouse tomatoes. BioControl 305-313

van Damme M, Andel A, Huibers RP, Panstruga R, Weisbeek PJ, van den Ackerveken G (2005) Identification of Arabidopsis loci required for susceptibility to the downy mildew pathogen Hyaloperonospora parasitica. Mol Plant Microbe Interact 18:583-592. doi: 10.1094/ MPMI-18-0583.

van Damme $M$, Huibers RP, Elberse J, van Den Ackerveken G (2008) Arabidopsis DMR6 encodes a putative 2OG-Fe(II) oxygenase that is defense-associated but required for susceptibility to downy mildew. Plant J 54:785-793. doi: 10.1111/j.1365313X.2008.03427.x

van den Bulk RW, Jansen J, Lindhout WH, Loffler HJM (1991) Screening of tomato somaclones for resistance to bacterial canker (Clavibacter michiganensis subsp. michiganensis). Plant Breed 107:190-196. doi: 10.1111/j.14390523.1991.tb01206.x

van Heusden A, Koornneef $M$, Voorrips $R$, Brüggemann W, Pet G, Vrielink-van Ginkel R, Chen X, Lindhout P (1999) Three QTLs from Lycopersicon peruvianum confer a high level of resistance to Clavibacter michiganensis ssp . michiganensis. TAG Theor Appl Genet 99:1068-1074 . doi: 10.1007/s001220051416

van Loon LC, Rep M, Pieterse CMJ (2006) Significance of inducible defense-related proteins in infected plants. Annu Rev Phytopathol 44:135-62. doi: 10.1146/ annurev.phyto.44.070505.143425

van Schie CCN, Takken FLW (2014) Susceptibility Genes 101: How to Be a Good Host. Annu Rev Phytopathol 1-31. doi: 10.1146/annurevphyto-102313-045854

van Steekelenburg NAM (1985) Resistance to Corynebacterium michiganense in tomato 
genotypes. Euphytica 34:245-250. doi: 10.1007/BF00022916

van Vuuren RJ, Woodward B (2001) The response of cassava cultivars to root-knot nematode infestation: An in vitro method. Euphytica 120:109-113. doi: 10.1023/A:1017524210671

van Wees SC, van der Ent S, Pieterse CM (2008) Plant immune responses triggered by beneficial microbes. Curr Opin Plant Biol 11:443-448. doi: 10.1016/j.pbi.2008.05.005

Vega D, Romero a. M (2016) Survival of Clavibacter michiganensis subsp. michiganensis in tomato debris under greenhouse conditions. Plant Pathol n/a-n/a. doi: 10.1111/ppa.12444

Víquez-Zamora $M$, Vosman $B$, van de Geest $H$, Bovy A, Visser RGF, Finkers $R$, van Heusden AW (2013) Tomato breeding in the genomics era: insights from a SNP array. BMC Genomics 14:354. doi: 10.1186/1471-2164-14-354

Vogel JP, Raab TK, Schiff C, Somerville SC (2002) $P M R 6$, a pectate lyase-like gene required for powdery mildew susceptibility in Arabidopsis. Plant Cell 14:2095-106. doi: 10.1105/ tpc.003509.sis

Vos IA, Pieterse CMJ, van Wees SCM (2013) Costs and benefits of hormone-regulated plant defences. Plant Pathol 62:43-55. doi: 10.1111/ppa. 12105

Vulkova Z V, Sotirova VG (1993) Study of the threegenome hybrid Lycopersicon esculentum Mill . - L. chilense Dun . - L. peruvianum var "humifusum" Mill . and its use as a source for resistance. Theor Appl Genet 337-342

Warschefsky EJ, Klein LL, Frank MH, Chitwood DH, Londo JP, von Wettberg EJB, Miller AJ (2016) Rootstocks: diversity, domestication, and impacts on shoot phenotypes. Trends Plant Sci 21:418-437. doi: 10.1016/j. tplants.2015.11.008

Werner NA, Assistant FG, Fulbright DW, Pathology P, Lansing E, Podolsky R (2002) Limiting populations and spread of Clavibacter michiganensis subsp . michiganensis on seedling tomatoes in the greenhouse. Plant Dis 86:535-542

Winterhagen P, Brendel G, Krczal G, Reustle GM (2007) Development of an in vitro dual culture system for grapevine and Xiphinema index as a tool for virus transmission. South African J Enol Vitic 28:1-5
Wittmann J, Brancato C, Berendzen KW, Dreiseikelmann B (2015) Development of a tomato plant resistant to Clavibacter michiganensis using the endolysin gene of bacteriophage CMP1 as a transgene. Plant Pathol 65:496-502. doi: 10.1111/ppa.12417

Wolters AMA, Caro M, Dong S, Finkers R, Gao J, Visser RGF, Wang X, Du Y, Bai Y (2015) Detection of an inversion in the Ty-2 region between S. lycopersicum and S. habrochaites by a combination of de novo genome assembly and BAC cloning. Theor Appl Genet 128:1987-1997. doi: 10.1007/s00122-0152561-6

Xu CL, Jiao CW, Yu L, Xie H, Wang DW, Li Y, Cheng $X$ (2015) Establishment of new monoxenic culture systems for root-knot nematodes, Meloidogyne spp., on axenic water spinach roots. Nematology 17:725-732. doi: 10.1163/15685411-00002905

Yadeta KA, Thomma BPHJ (2013) The xylem as battleground for plant hosts and vascular wilt pathogens. Front Plant Sci 4:1-12. doi: 10.3389/fpls.2013.00097

Yang D-L, Yao J, Mei C-S, Tong X-H, Zeng L-J, Li Q, Xiao L-T, Sun T, Li J, Deng X-W, Lee CM, Thomashow MF, Yang Y, He Z, He SY (2012) Plant hormone jasmonate prioritizes defense over growth by interfering with gibberellin signaling cascade. Proc Natl Acad Sci 109:E1192 LP-E1200

Yang H, Postel S, Kemmerling B, Ludewig U (2014a) Altered growth and improved resistance of Arabidopsis against Pseudomonas syringae by overexpression of the basic amino acid transporter AtCAT1. Plant, Cell Environ 37:1404-1414. doi: 10.1111/pce.12244

Yang P, Lüpken $T$, Habekuss A, Hensel $G$, Steuernagel B, Kilian B, Ariyadasa R, Himmelbach A, Kumlehn J, Scholz U, Ordon F, Stein N (2014b) PROTEIN DISULFIDE ISOMERASE LIKE 5-1 is a susceptibility factor to plant viruses. Proc Natl Acad Sci 111:21042109. doi: $10.1073 /$ pnas. 1320362111

Yang $X$, Caro M, Hutton SF, Scott JW, Guo Y, Wang $X$, Rashid MH, Szinay D, de Jong $H$, Visser RGF, Bai Y, Du Y (2014c) Fine mapping of the tomato yellow leaf curl virus resistance gene $T y-2$ on chromosome 11 of tomato. Mol Breed 34:749760. doi: 10.1007/s11032-014-0072-9 
Yasuhara-Bell J, Alvarez a. M (2014) Seed-associated subspecies of the genus Clavibacter are clearly distinguishable from Clavibacter michiganensis subsp. michiganensis. Int J Syst Evol Microbiol 65:811-826. doi: 10.1099/ ijs. 0.000022

Yasuhara-Bell J, Alvarez AM (2015) Differentiation of Clavibacter michiganensis subsp. michiganensis from other Clavibacter species found in seed and plant tissues. Acta Hortic 1069:87-94

Yasuhara-Bell J, Baysal-Gurel F, Miller S a., Alvarez AM (2015) Utility of a loop-mediated amplification assay for detection of Clavibacter michiganensis subsp. michiganensis in seeds and plant tissues. Can J Plant Pathol 37:1-7. doi: 10.1080/07060661.2015.1053988

Yasuhara-Bell J, Kubota R, Jenkins DM, Alvarez AM (2013) Loop-Mediated amplification of the Clavibacter michiganensis subsp. michiganensis micA gene is highly specific. phy 103:1220-6. doi: 10.1094/PHYTO-03-130078-R

Yogev A, Raviv M, Kritzman G, Hadar Y, Cohen R, Kirshner B, Katan J (2009) Suppression of bacterial canker of tomato by composts. Crop Prot 28:97-103. doi: 10.1016/j. cropro.2008.09.003

Yoon M-Y, Choi GJ, Choi YH, Jang KS, Cha B, Kim J-C (2011) Antifungal activity of polyacetylenes isolated from Cirsium japonicum roots against various phytopathogenic fungi. Ind Crops Prod 34:882-887. doi: 10.1016/j. indcrop.2011.02.013

Zagorska N a., Shtereva L a., Kruleva MM, Sotirova VG, Baralieva DL, Dimitrov BD (2004) Induced androgenesis in tomato (Lycopersicon esculentum Mill.). III. Characterization of the regenerants. Plant Cell Rep 22:449-456. doi: 10.1007/s00299-003-0720-8

Zamir D (2001) Improving plant breeding with exotic genetic libraries. Nat Rev Genet 2:983989. doi: $10.1038 / 35103589$

Zanón MJ, Jordá C (2008) Eradication of Clavibacter michiganensis subsp. michiganensis by incorporating fresh crop debris into soil: Preliminary evaluations under controlled conditions. Crop Prot 27:1511-1518. doi: 10.1016/j.cropro.2008.07.014

Zeilmaker T, Ludwig NR, Elberse J, Seidl MF, Berke
L, Van Doorn A, Schuurink RC, Snel B, Van Den Ackerveken G (2015) Downy mildew resistant 6 and DMR6-like oxygenase 1 are partially redundant but distinct suppressors of immunity in Arabidopsis. Plant J 81:210222. doi: $10.1111 /$ tpj.12719

Zeng Y, Chung KP, Li B, Lai CM, Lam SK, Wang X, Cui Y, Gao C, Luo M, Wong K-B, Schekman R, Jiang $L$ (2015) Unique COPII component AtSar1a/ AtSec23a pair is required for the distinct function of protein ER export in Arabidopsis thaliana. Proc Natl Acad Sci 112:1436014365. doi: 10.1073/pnas.1519333112

Zheng Z, Gao S, Zhou M, Yan G, Liu C (2017) Enhancing Fusarium crown rot resistance by pyramiding large-effect QTL in common wheat (Triticum aestivum L.). Mol Breed 37:107. doi: 10.1007/s11032-017-0708-7

Zheng $Z$, Nonomura T, Appiano M, Pavan S, Matsuda Y, Toyoda H, Wolters A-MA, Visser RGF, Bai $Y$ (2013) Loss of function in Mlo orthologs reduces susceptibility of pepper and tomato to powdery mildew disease caused by Leveillula taurica. PLoS One 8:e70723. doi: 10.1371/journal.pone.0070723 



\section{Summary}

Clavibacter michiganensis subsp. michiganensis $(\mathrm{Cmm})$ is one of the most important bacterial pathogens affecting tomatoes. It is a quarantine organism in Europe and other countries. The pathogen can infect tomatoes through multiple ways and can be transmitted via seeds. The quarantine status and the devastating disease symptoms caused by $\mathrm{Cmm}$ are problematic for many parties. Even though resistance/tolerance breeding is one of the most important and successful ways to manage diseases, other paths can also be walked to manage disease symptoms. A combination of several methods might successfully limit the disease symptoms even more. Our goal is to get symptomless tomato plants with minimal bacterial density. In the present thesis, we developed a new and an efficient way to screen big tomato populations in vitro. Furthermore, we also studied different approaches to get symptomless tomato plants after infection with $\mathrm{Cmm}$.

Chapter 1 presents an introduction about the pathogen, the pathogen-host interaction and the different techniques that can be used to manage $\mathrm{Cmm}$. In Chapter 2, we look at the development of a new disease screening method on in vitro tomato seedlings. This system is efficient and cost effective to screen big populations in one experiment. Two different inoculation methods were tested in combination with two different plant ages. Based on the inoculation procedure that gave uniform wilting symptoms, we proceeded to test this protocol on several wild relatives of tomato. The disease scoring of the tomato wild relatives was compared to the scoring on the same accessions in the greenhouse. The majority produced similar symptom scores. This new protocol speeds up the disease screening process of large populations using minimal space. In Chapter $\mathbf{3}$ we used the in vitro disease screening protocol to fine map the QTL on chromosome 7. The marker analyses were done with Single Nucleotide Polymorphisms (SNPs) and the KASP platform (KBiosciences, UK). To predict the gene variants in the fine mapped region of the highly tolerant wild source Solanum arcanum LA2157, we used an in-house prediction tool, the HaploSmasher. The QTL region has been fine mapped to $211 \mathrm{~Kb}$ which resulted in 15 annotated genes. The results are the first step to understand a tolerance mechanism against $\mathrm{Cmm}$. In Chapter 4 several susceptibility $(S)$ genes were used to test effectiveness against $\mathrm{Cmm}$. Susceptibility genes are plant genes, whose impairment leads to durable, broad-spectrum resistance. No resistance $(R)$ genes have been found against $\mathrm{Cmm}$, thus exploiting the $S$-genes could be an alternative approach to fight the pathogen. Four candidate S-genes, CESA3, CESA4, PMR6 and WAT1, were tested using the virusinduced gene silencing (VIGS) assay to see the effects on the infection of $\mathrm{Cmm}$. From the VIGS assay, we found WAT1 confers higher tolerance than the control plants. This finding could be a starting point of applying $S$-genes in tolerance breeding 
against $\mathrm{Cmm}$. In Chapter $\mathbf{5}$ alternative approaches were applied to reduce $\mathrm{Cmm}$ disease symptoms by applying grafting and utilizing biocontrol agents. Reciprocal and self-grafting were used with a highly tolerant genotype (S. arcanum LA2157) and a susceptible genotype (cv. Moneymaker). For the biocontrol agent experiment, Pseudomonas spp. consortia were applied to enhance the tolerance mechanism in different tomato genotypes. Different $\mathrm{Cmm}$ inoculation methods were tested to see the effectiveness of grafting and biocontrol agent against the pathogen from different entries. From these two methods, we found reduced wilting symptoms only when the pathogen enters from the roots. Finally, Chapter 6 presents the general discussion of the thesis. In conclusion, we developed a new protocol that could ease disease screening using minimal space and time, fine mapped the QTL on chromosome 7 to a smaller region, found a potential new tolerance against $\mathrm{Cmm}$ by manipulating the WAT1 gene and tested two alternative approaches to minimize wilting symptom. 


\section{Acknowledgements}

To have reached this point is like a dream come true. I could not have achieved all this without the help of amazing people who have been supporting me. Writing the acknowledgements is not as easy as it seems, so here it goes.

To my two awesome Doktorväter. I like the German word for supervisors because the two of you are a father figure to me.

Dr. Adriaan W. van Heusden a.k.a Sjaak. There are so many things that I want to write about you, and I could write a chapter to acknowledge you. I am glad to know you way before I did my PhD. You have made my PhD journey full of joy, laughter and happiness. You were always optimistic whenever I was pessimistic about my work. If things did not go the way I wanted it, you always positively looked at them. You taught me to learn from my mistakes, and I did (and still do) learn a lot from them. You gave me so much freedom and let me do whatever I wanted. You never imposed your ideas too strong on me or dictated how I should do things. For all this, I thank you.

Dr. Jan van der Wolf, I'm glad that you are on my committee. Your presence complements Sjaak ;) I always have this butterfly feeling after our talk. Discussing with you about Clavibacter is never dull. You gave me so many inputs and ideas that motivated me to set-up my experiments. You helped me deal with the bureaucratic procedures regarding our beloved $\mathrm{Cmm}$. I was able to use many labs/ equipment etc. because of you.

To my promotor Prof. Richard Visser. You may not have been actively involved with my projects and discussion, but you tried to attend my presentations whenever you were available. I was happy whenever I saw your face amongst the audiences. During the last stretch of my PhD, you were more involved with my thesis, and I appreciate that.

Prof. Yuling Bai and Dr. Henk Schouten thanks for opening my eyes to the S-gene world. Henk, I'm grateful for the S-gene map that you made and being patient while you explained the $S$-gene concept to me. Yuling, thanks for letting me be a part of your S-gene group, I felt more secure and supported to work on this topic.

Dr. Frank Millenaar, I always enjoyed our annual consortia meeting. You always asked interesting (and challenging) questions and gave valuable inputs. I am more prepared for my defence because of your critical questions and feedback.

Fien, you helped me to be more familiar with molecular lab and greenhouse work. I learned new techniques and faster (and proper) ways to do lab work. Thanks for letting me use your things occasionally ;) 
Patricia and Flavia thanks for guiding me in the Biointeraction lab. You made me more aware and cautious of working with $\mathrm{Cmm}$ in the lab. Working with $\mathrm{Cmm}$ is challenging for sure! Flavia, you are not only my supervisor but also my friend. I am happy that we are and will remain in touch.

Bertus and Michel, thanks for taking care of compartment 2.5. It is not an easy compartment (thanks to $\mathrm{Cmm}$ ), and I'm glad that you handled my tomato babies with care.

Wim and Joyce, thanks for providing biocontrol agents and clear instructions on how to work with them.

The PBR secretary ladies Nicole, Letty, Daniëlle and Janneke. Thanks for helping with bureaucratic things related/non-related to my PhD. You made my life (and other people's) a lot easier. Nicole, thanks for suggesting me to move to a PhD room in the beginning of my PhD journey. I made new friends (and became more social) because of you :D

Many thanks to the technicians and scientists in PBR and Bioteraction groups. Especially to Isolde, Iris, Bernadette, Marjan, Marian, Jos, Annelies, Danny, Doret, Irma, Gerard, Marga, Trudy, Pieter and Theo. Thanks for your help in the labs and teaching me lab works and using the instruments.

To my paranymphs Michela and Eleni. Miki! You have no clue how much you play an essential part in my PhD and life! You are my officemate, supervisor and friend. You are my sweet angel and my sunshine. You are my emotional support; you lent me your shoulders and ears when I need them. You are my sports motivator (or dictator? haha :P); I don't think I would know how to swim if you hadn't forced me. I am so grateful to know you. Eleni/ELENA! You are my student-cum-friend. I'm happy that you continue working on $\mathrm{Cmm}$. I thought that the $\mathrm{Cmm}$ project (on the plant part) would die after me. I always loved our discussions, especially when you had one of those epiphanies. Thanks for showing me around your hometown, experiencing the "big Greek family" and feeding me with delicious Greek goodies.

To my E1.215 officemates Dalia, Myluska, Peter Bourke, Charlie, Ehsan, Miguel, Katharina and Daniel (and of course Miki and Eleni), you brought joy to my PhD life. Dalia, because of you I got to have lunch with other PhD candidates. Thanks for making me feel less lonely at the beginning of my PhD year. Mylu! You are warm and made me feel welcome. You are perceptive and noticed when something went wrong with me. Peter, I'm glad that we went volunteering together. I don't think I would volunteer at Rumah Kita if you did not suggest it. Charlie, thanks for feeding me with delicious Taiwanese sweets and giving me your plants. I enjoy talking with you about Taiwan and Malaysia. Ehsan, you didn't speak much in the office, but 
when you did, you can talk a lot. I hope we can collaborate in the future, I will need a good bioinformatician for sure! Miguel, you are funny in your own way. You are like a brother I've never had. Your sarcastic jokes made me laugh (sometimes :P). Katharina, thanks for the German teas, bread and cookies. I appreciate your detailed notes, protocols and sweet surprises. Daniel, we have not been an officemate, but I knew you from Eleni before you started joining E1.215. Thanks to you, I got interesting lecture notes.

Anne, you are my first and closest Dutch friend. You are sweet and (very) direct. I'm glad that I knew you from my first year and that we are still in touch. Thanks for having me as your paranymph, I was honoured :) Christos, you are brilliant and have a unique sense of humour. I'm glad that you asked me as your paranymph. Charlotte you are not my third choice, you just arrived a bit later. I'm so happy to know you a lot better after our work trip to Valencia. You are my squash partner, my positive energy and my good friend. Atiyeh, you are my first officemate, and also the last one. You are a brilliant, strong and positive person. I wish for your success! Cynara, you are such a sweet person. The simple thank you E-Mail that you sent me made me so welcome in PBR.

Arwa, Xuan Xu and Valentina, you are my gorgeous, sexy, sweet, funny, confident, strong and athletic sisters. I've become more active when I hang-out with you. Your positive vibes always cheer me up.

Ira, I'm glad you stalked my blog. I wouldn't know that there is an awesome Malaysian living nearby if you hadn't done so. I enjoy our day out, makan-makan and trip together.

Behzad, Vivi, Marine, Andres, Narges, I will not forget my first (and hopefully last) Reggaeton experience and long-distance walking Paris trip. It was such a nice and fun experience!

My students, Afrida, Bihani, Eleni, Sudeep, Juan Carlos and Afroz. Thanks for working with me. I enjoyed our talks and discussions, and I also learned lots of things from you. All of you played a significant role in this thesis.

Pauline, Jarst and Jasper, I will miss our boardgame sessions and funny jokes (or bad jokes) during lunch break. You guys are so positive (and somewhat funny :P) that I will miss having your company.

My PBR friends, I've got to know many culture (and stereotypes) because of you. I enjoy the exchange of talks and laughs during coffee break/lunch etc. Sara, Jordi, Kaile, Tim, Carolina, Mathilde, Jeroen, Manos, Yan Zhe, Xue Xue, Xiao Lin, Peter Dinh, Marcela, Rafael, Meng Jin, Yiqian, Kim, Aurelie, Sri, Lorena, Gurnoor, and Raana. 
Kepada teman senegara dan seperjuangan, Izan, Shikin, Tihah, Fauzana dan Nadia. Disebabkan kamu, aku tak lupa Bahasa Melayu (yang makin lama makin teruk). Aku hargai masa yang kita luangkan bersama semasa di Radix. Syai, terima kasih sebab datang lawat aku di sini. Kaulah kawan aku yang paling lama dan kau teman aku masa aku mahu pergi bercuti sepanjang aku buat PhD.

Keluarga muni tersayang, Mak, Abah, Along, Angah, Abang Yadi dan Adam. Terima kasih sebab sokong Muni dari dulu lagi. Muni tidak mungkin akan sampai tahap ini kalau bukan sebab keluarga Muni.

Moritz, my sayang, you opened my eyes to Europe. I may not have been in Wageningen if I would not have married to you. Thanks for coming with me to Wageningen and share a new experience together. Ich liebe dich. Thanks for your support and listening to my constant complains and worries. You are a good and a loving husband. To mama Jutta, papa Ludwig and Marius. You are my family in Europe. I'm glad and lucky to have a place to call home in Dieburg, Germany. Your kindness and love make me less homesick.

Finally, my acknowledgements go to the Ministry of Higher Education (MOHE) Malaysia and Universiti Putra Malaysia (UPM) for funding my PhD and Nunhems, vegetable seeds of BASF, The Netherlands, to support the PhD project.

Thank you! Bedankt! Danke! Terima kasih!

-Mas- 


\section{About the author}

Mas Muniroh binti Mohd Nadzir (Mas) was born on the $28^{\text {th }}$ of May 1985 in Kuala Lumpur, Malaysia. After finishing her high school, she received a scholarship from the Malaysian government to do a bachelor in Biotechnology at the University of California, Davis (UCD) and graduated in 2004. She continued her MSc in Agrotechnology at the Universiti Putra Malaysia (UPM) in which Dr Adriaan W. van Heusden (Sjaak) was one of her supervisors. The (fun) encounter she had with Sjaak brought her to continue her PhD with him together with the bacteria expert, Dr Jan van der

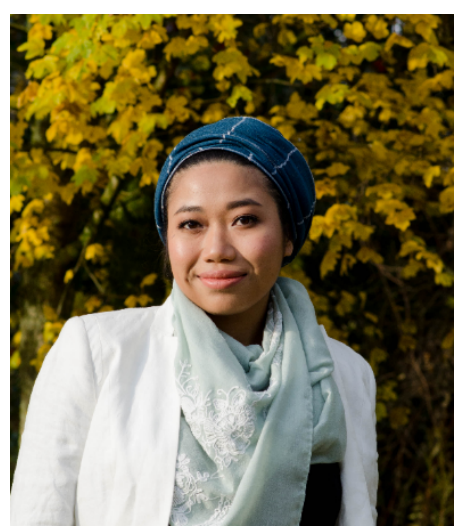
Wolf. She started her PhD program in Plant Breeding (PBR) at Wageningen University and Research in June 2014 where she worked with a "challenging" pathogen $\mathrm{Cmm}$. She enjoyed working on her PhD project while socialising with her PBR colleagues and friends (and baking lots of cakes) ever since. 



\title{
Education Statement of the Graduate School Experimental Plant Sciences
}

\author{
Issued to: Mas Muniroh binti Mohd Nadzir \\ Date: \\ 14 December 2018 \\ Group: \\ Laboratory of Plant Breeding \\ University: \\ Wageningen University \& Research
}

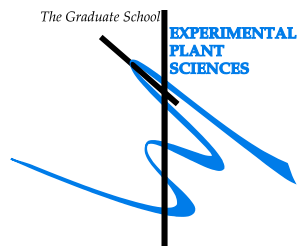

1) Start-Up Phase

$\underline{\text { date }}$

- First presentation of your project

Proposal presentation at Breeding for Resistance Group

17 Feb 2015

- Writing or rewriting a project proposal

Resistance to bacterial canker in tomato

28 Nov 2014

- Writing a review or book chapter

- MSc courses

Advanced Statistics (MAT-20306)

01 Sep - 20 Oct 2014

Genomics (ABG-30306)

27 Oct - 20 Dec 2015

- Laboratory use of isotopes

Subtotal Start-Up Phase

13.5 *

\section{2) Scientific Exposure}

date

\section{- EPS PhD student days}

EPS PhD students days 'Get2Gether', Soest, the Netherlands

29-30 Jan 2015

EPS PhD students days 'Get2Gether', Soest, the Netherlands

09-10 Feb 2017

- EPS theme symposia

EPS Theme 2 Symposium 'Interactions between plants and biotic agents' \& Willie Commelin Scholten Day, Utrecht, the Netherlands

20 Feb 2015

EPS Theme 2 Symposium 'Interactions between plants and biotic agents' \& Willie Commelin Scholten Day, Leiden, the Netherlands

22 Jan 2016

EPS Theme 2 Symposium 'Interactions between plants and biotic agents' \& Willie Commelin Scholten Day, Wageningen, the Netherlands

23 Jan 2017

- National meetings (e.g. Lunteren days) and other National Platforms Annual meeting 'Experimental Plant Sciences', Lunteren, the Netherlands Annual meeting 'Experimental Plant Sciences', Lunteren, the Netherlands

11-12 Apr 2016 Annual meeting 'Experimental Plant Sciences', Lunteren, the Netherlands 10-11 Apr 2017 Solanaceae Symposium 'Solanaceae genetic resources in research and breeding', Nijmegen, the Netherlands

26 Apr 2017

- Seminars (series), workshops and symposia

Symposium: Plant Breeding - Research Day, Wageningen, the Netherlands

24 Sep 2014

Symposium: Omics Advances for Academia and Industry - Towards True Molecular Plant Breeding, Wageningen, the Netherlands

11 Dec 2014 
Symposium: 2nd Wageningen PhD Symposium 'Connecting Ideas, Combining Forces', Wageningen, the Netherlands

06 May 2015

Symposium: Plant Breeding - Research Day, Wageningen, the Netherlands

29 Sep 2015

Symposium: The Wageningen Plant Microbiome Network Kick-off meeting,

Wageningen, the Netherlands

29 Jun 2016

Mini-symposium: Rewriting our genes?, Wageningen, the Netherlands

30 Sep 2016

Seminar: Dr. Hideki Takahashi - 'Intron-mediated enhancement of disease resistance gene expression in Arabidopsis thaliana'

10 Mar 2015

Seminar: Dr. Siobhan Brady - 'Regulation of root morphogenesis in tomato

species in the face of a changing environment'

09 Sep 2015

Seminar: Dr. Jane Parker - 'Plant intracellular immunity: evolutionary and molecular underpinnings'

$21 \operatorname{Jan} 2016$

Seminar: Dr. Asaf Levy - 'Bacteria and the future of agriculture: from sequence to function'

22 Feb 2018

Seminar: Dr. Margaret Frank - 'Grafting-induced vigor in crops: new

approaches to understanding an ancient practice'

19 Jun 2018

Seminar: Dr. Mary C. Wildermuth - 'Salicylic acid and cell cycle control of

plant-microbe interactions'

25 Jun 2018

\section{- Seminar plus}

\section{- International symposia and congresses}

12th Solanaceae Conference, Bordeaux, France

25-29 Oct 2015

5th International Symposium on Tomato Diseases, Málaga, Spain

13-16 Jun 2016

20th Eucarpia General Congress, Zürich, Switzerland

14th Solanaceae and 3rd Cucurbitaceae Joint Conference, Valencia, Spain

29 Aug - 01 Sep 2016

19th Eucarpia Meeting of the Tomato Working Group, Naples, Italy

03-06 Sep 2017

02-04 May 2018

\section{- Presentations}

Poster: 12th Solanaceae Conference, Bordeaux, France

25-29 Oct 2015

Poster: 5th International Symposium on Tomato Diseases, Málaga, Spain

13-16 Jun 2016

Poster: 20th Eucarpia General Congress, Zürich, Switzerland

Poster: 14th Solanaceae and 3rd Cucurbitaceae Joint Conference, Valencia, Spain

29 Aug - 01 Sep 2016

03-06 Sep 2017

Talk: 19th Eucarpia Meeting of the Tomato Working Group, Naples, Italy

02-04 May 2018

\section{- IAB interview}

\section{- Excursions}

Visit to the company Keygene, Wageningen, the Netherlands

12 Oct 2017

Visit to Flower Trials 2018 and to the company Dümmen Orange, De Lier, the Netherlands

15 Jun 2018 


\section{3) In-Depth Studies}

date

\section{- EPS courses or other PhD courses}

Postgraduate course 'Genome Assembly', Wageningen, the Netherlands

Postgraduate course 'Basic Statistics', Wageningen, the Netherlands

20-27 May 2015

Postgraduate course 'Transcription Factors and Transcriptional Regulation',

Wageningen, the Netherlands

12-14 Dec 2016

Postgraduate course 'Introduction to R for Statistical Analysis', Wageningen, the Netherlands

17-18 May 2018

Postgraduate course 'The Power of RNA-Seq', Wageningen, the Netherlands

11-13 Jun 2018

- Journal club

- Individual research training

\section{4) Personal Development}

$\underline{\text { date }}$

\section{- Skill training courses}

EPS Introduction Course, Wageningen, the Netherlands

20 Jan 2015

$\mathrm{PhD}$ Competence Assesment, Wageningen, the Netherlands

$03 \& 18$ Feb 2015

Course 'Project and Time Management', Wageningen, the Netherlands

Mar - May 2015

Course 'Information Literacy PhD including EndNote Introduction',

Wageningen, the Netherlands

15-16 Apr 2015

Wageningen Graduate Schools PhD Workshop Carousel, Wageningen, the Netherlands

17 Apr 2015

Course 'Presenting with Impact', Wageningen, the Netherlands

May - Jun 2015

Wageningen Graduate Schools PhD Workshop Carousel, Wageningen, the Netherlands

18 Apr 2016

Course 'Scientific Writing', Wageningen, the Netherlands

Jan - Mar 2017

Course 'Scientific Artwork - Vector graphics and images', Wageningen, the Netherlands

02-03 Oct 2017

Workshop 'Last Stretch of the PhD Programme', Wageningen, the Netherlands

22 Sep 2017

- Organisation of PhD students day, course or conference

- Membership of Board, Committee or PhD council

Subtotal Personal Development

6.6 *

\section{TOTAL NUMBER OF CREDIT POINTS}

42.3 *

Herewith the Graduate School declares that the PhD candidate has complied with the educational requirements set by the Educational Committee of EPS which comprises of a minimum total of 30 ECTS credits.

${ }^{*}$ A credit represents a normative study load of 28 hours of study. 
This work was supported by Ministry of Higher Education Malaysia and Nunhems, vegetable seeds of BASF. The work was performed at Plant Breeding, Wageningen University \& Research.

Financial support from Wageningen University for printing this thesis is greatly appreciated.

Cover \& layout design: Iliana Boshoven-Gkini | AgileColor.com

Printed by: GVO drukkers \& vormgever, Ede (NL) | gvo.nl 
